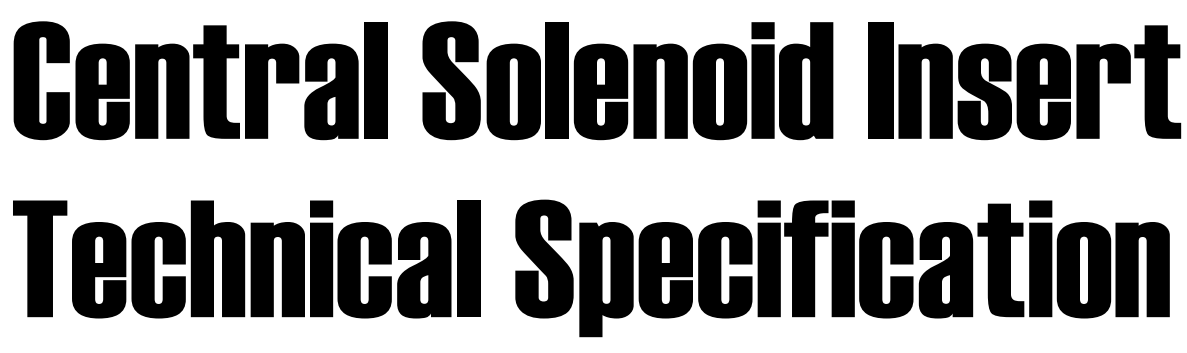


This report was prepared as an account of work sponsored by an agency of the United States Government. Neither the United States Government nor any agency thereof, nor any of their employees, makes any warranty, express or implied, or assumes any legal liability or responsibility for the accuracy, completeness, or usefulness of any information, apparatus, product, or process disclosed, or represents that its use would not infringe privately owned rights. Reference herein to any specific commercial product, process, or service by trade name, trademark, manufacturer, or otherwise, does not necessarily constitute or imply its endorsement, recommendation, or favoring by the United States Government or any agency thereof. The views and opinions of authors expressed herein do not necessarily state or reflect those of the United States Government or any agency thereof. 


\title{
CENTRAL SOLENOID INSERT TECHNICAL SPECIFICATION
}

\author{
Nicolai Martovetsky \\ Alexandre Smirnov
}

Prepared by

OAK RIDGE NATIONAL LABORATORY

Oak Ridge, Tennessee 37831-6283

managed by

UT-BATTELLE, LLC

for the

U.S. DEPARTMENT OF ENERGY

under contract DE-AC05-00OR22725 



\section{CENTRAL SOLENOID INSERT TECHNICAL SPECIFICATION}

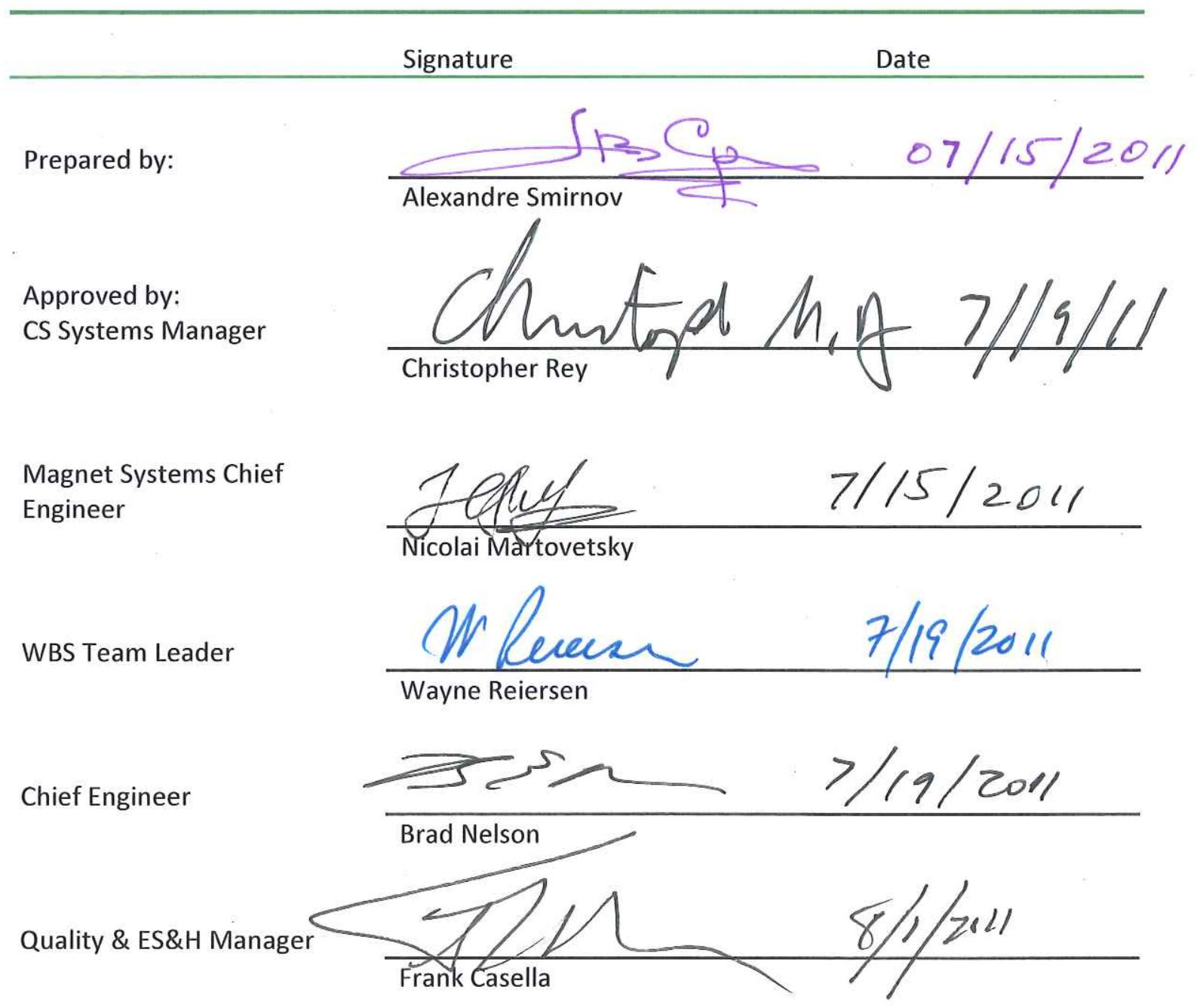





\section{REVISION RECORD}

\section{Technical Specification for ITER Central Solenoid Insert}

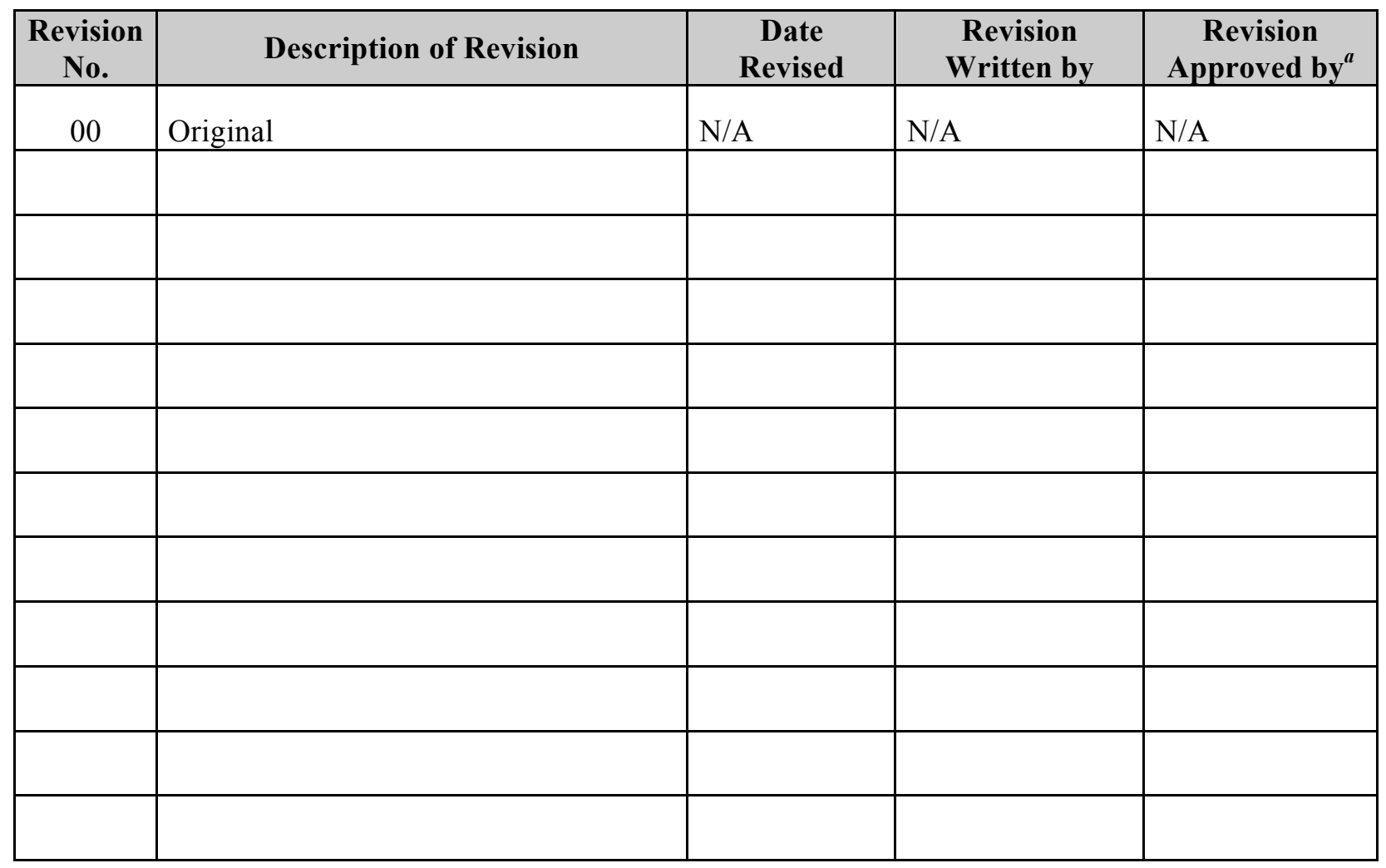

${ }^{a}$ Approval must be at the level of the WBS Manager or above. 



\section{CONTENTS}

Page

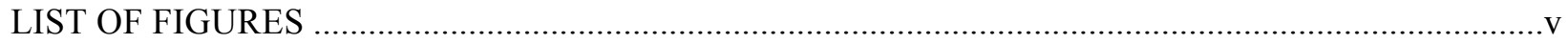

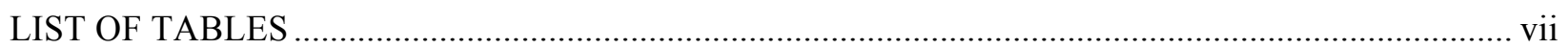

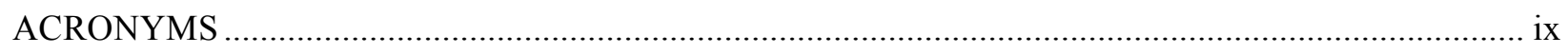

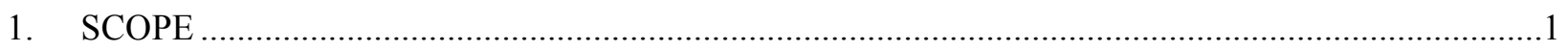

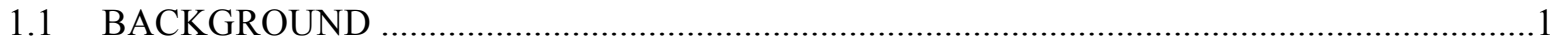

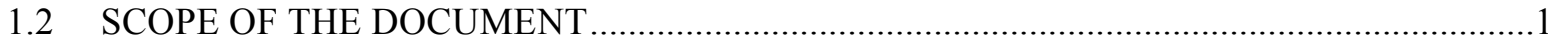

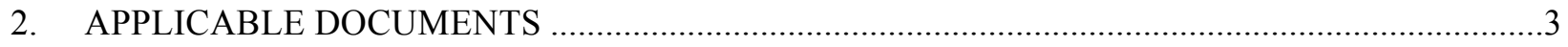

2.1 DRAWINGS FURNISHED TO THE SUPPLIER BY USIPO .............................................

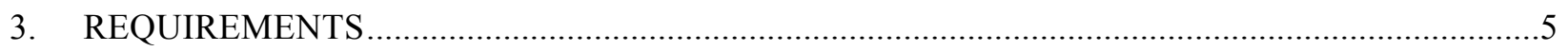

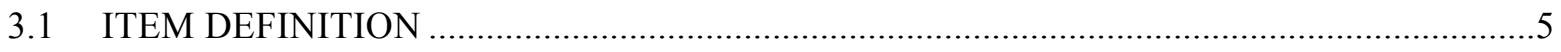

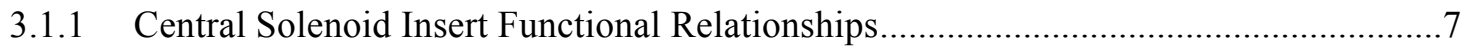

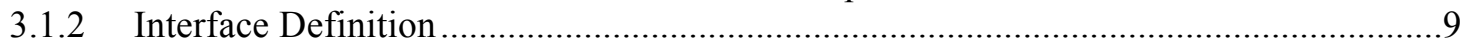

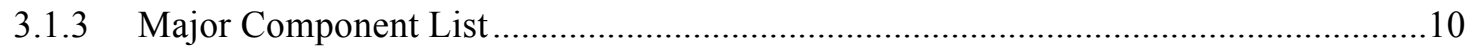

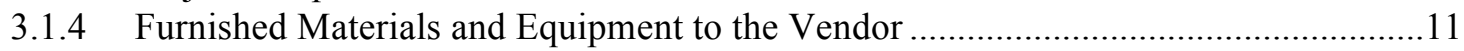

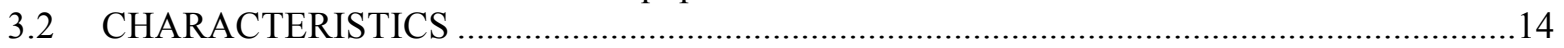

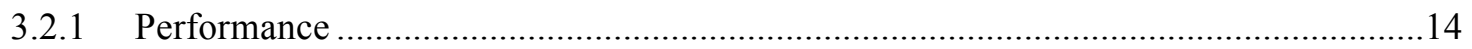

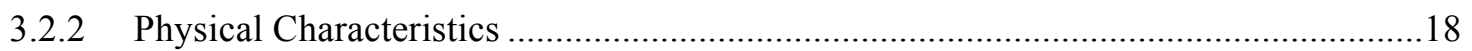

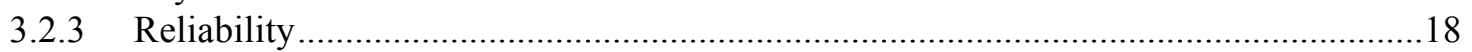

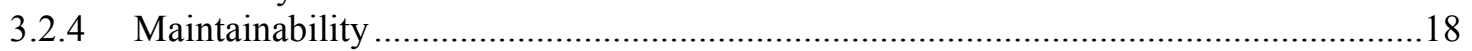

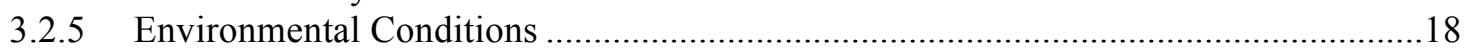

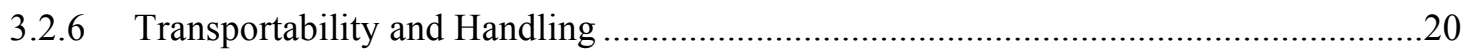

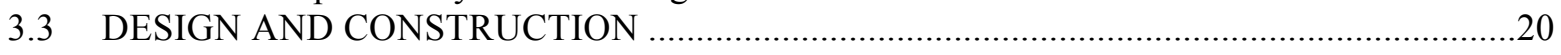

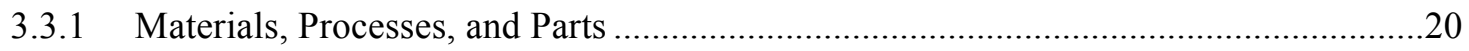

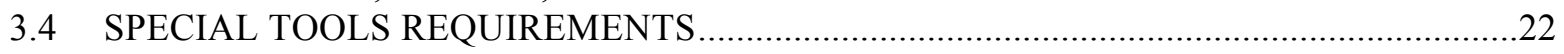

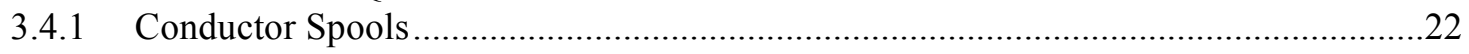

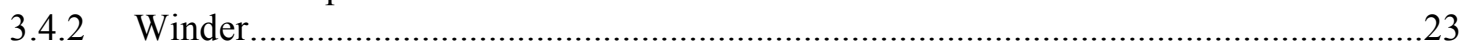

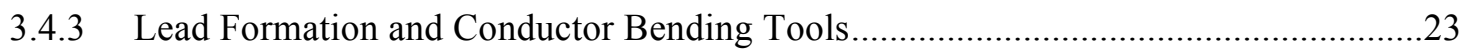

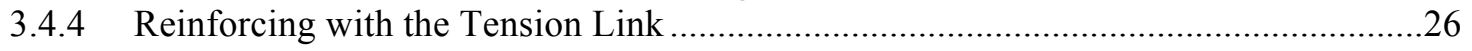

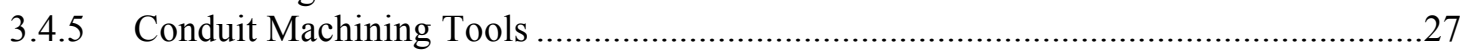

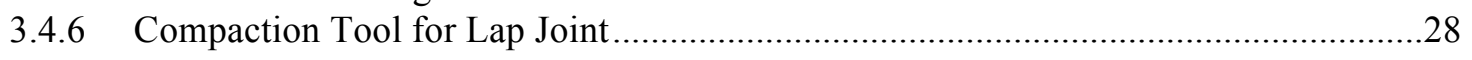

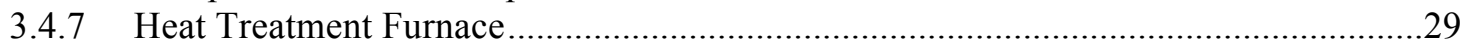

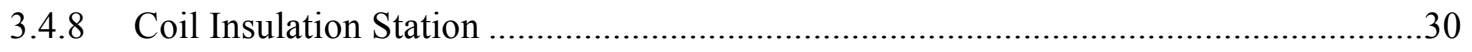

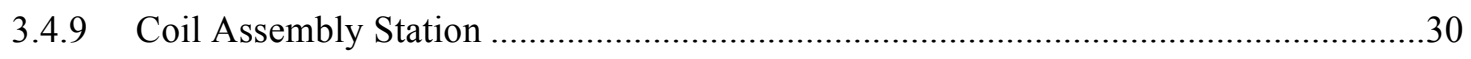

3.4.10 VPI Mold, Vacuum, Heating, and Resin Transfer Equipment ...................................30

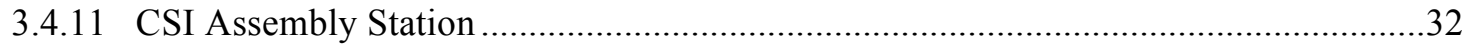

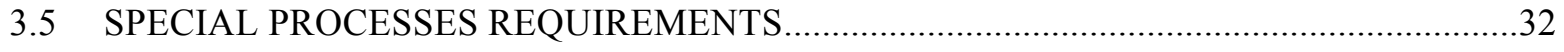

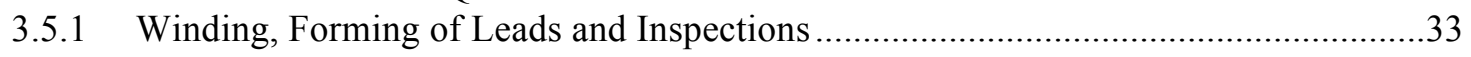

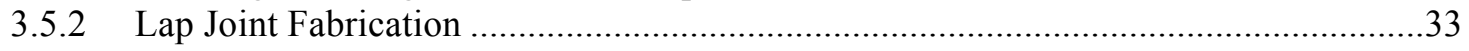

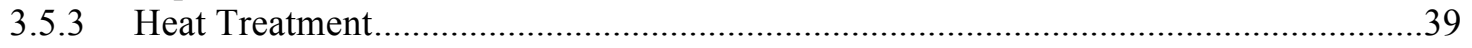

3.5.4 Emergency Actions Requirements for Heat Treatment ..........................................41

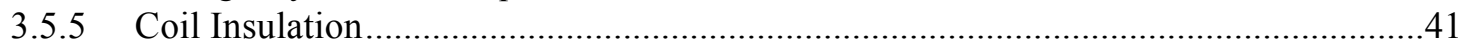

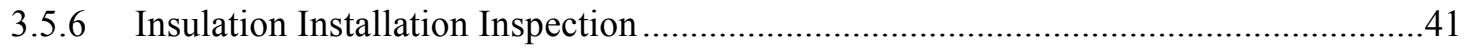

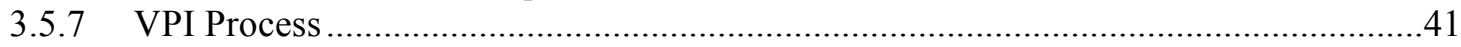




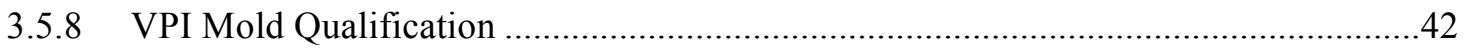

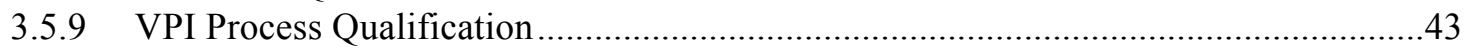

3.5.10 Qualification of Insulation - High Potential and Turn insulation Tests ......................43

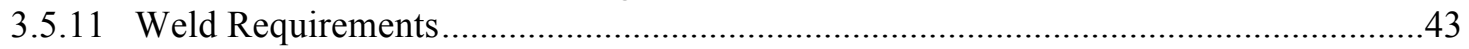

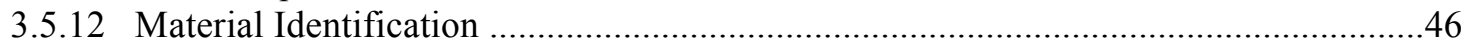

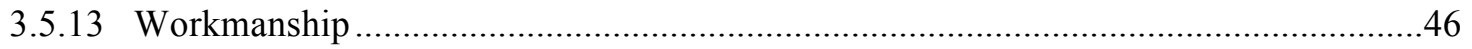

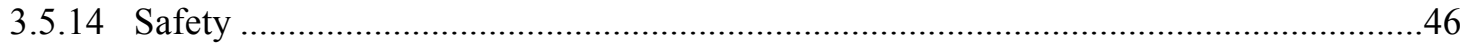

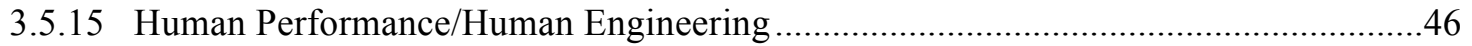

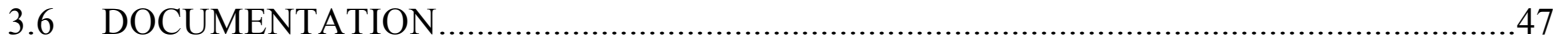

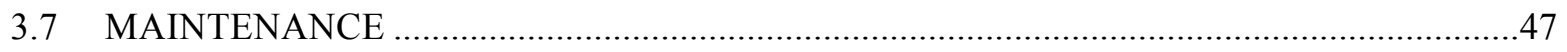

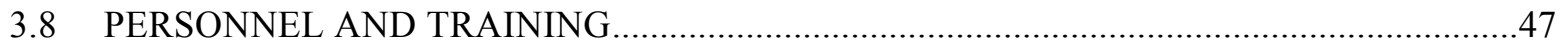

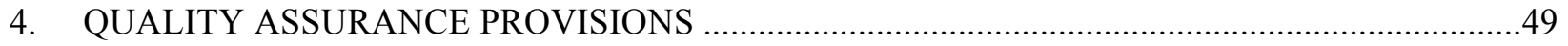

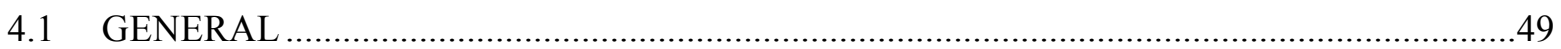

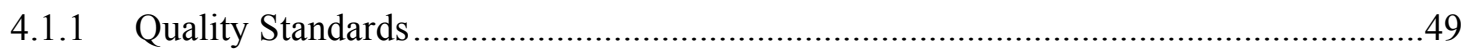

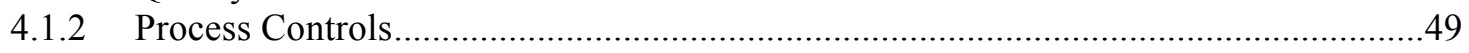

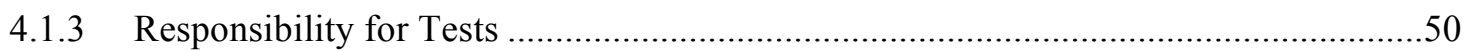

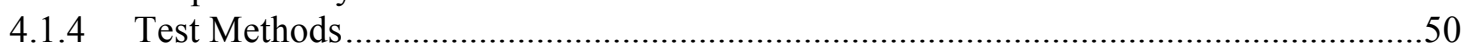

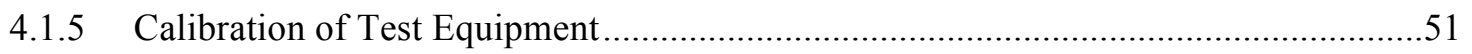

4.2 QUALITY CONFORMANCE INSPECTIONS AND TESTS ............................................51

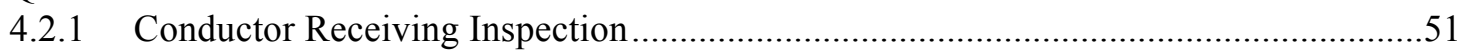

4.2.2 ITER Furnished Auxiliary Components Receiving Inspection .................................51

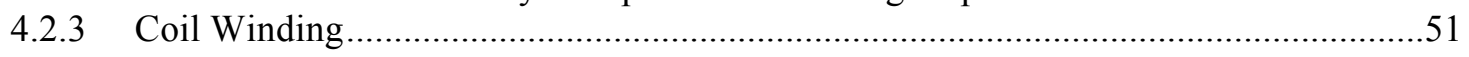

4.2.4 Tests and Inspections during CSI Electric Terminal Fabrication ................................51

4.2.5 Reaction Heat Treatment Tests and Inspections ....................................................51

4.2.6 Turn Insulation Application Tests and Inspections ...............................................51

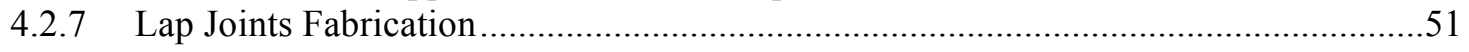

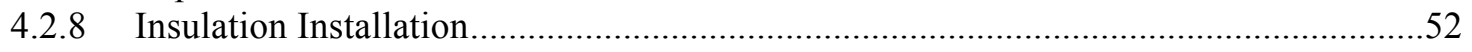

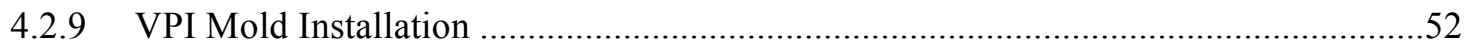

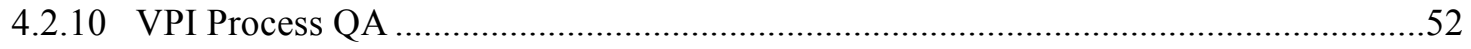

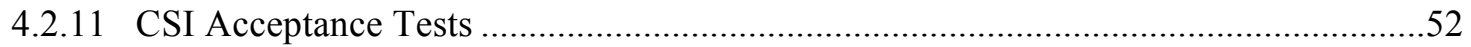

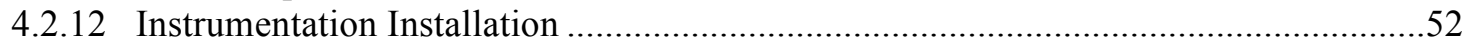

4.2.13 Test During Assembly and Final Acceptance Tests ..............................................52

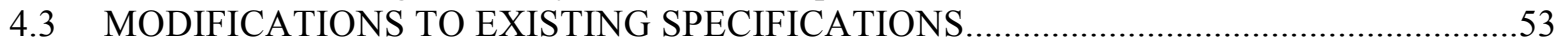

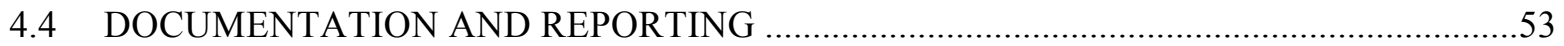

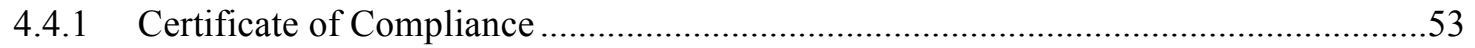

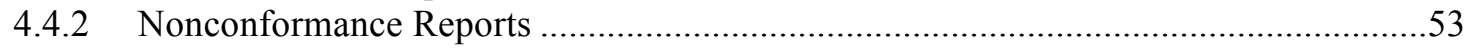

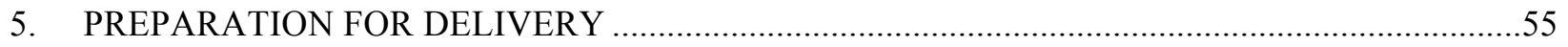

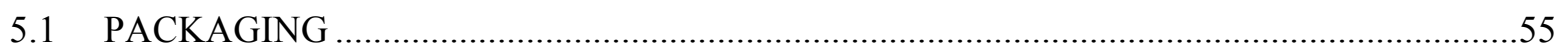

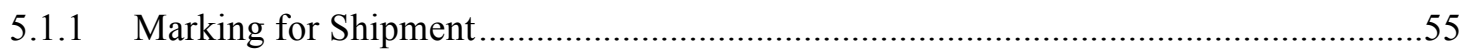

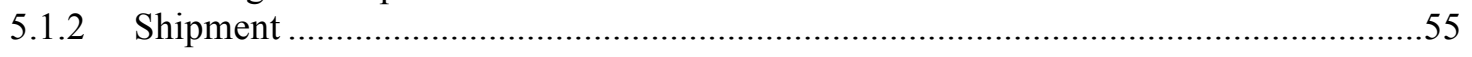

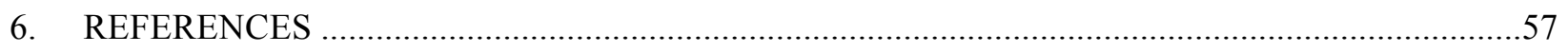

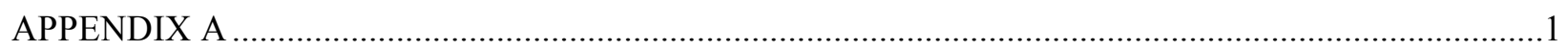




\section{LIST OF FIGURES}

Figure

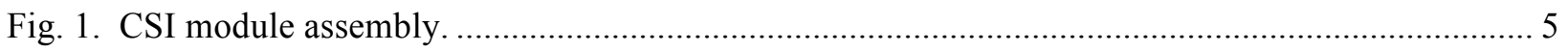

Fig. 2. Computer-generated 3-D model of CSMC with plumbing and electrical interfaces. ..................... 7

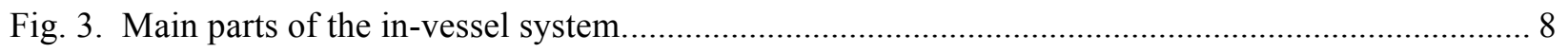

Fig. 4. CSI in the CSMC assembly (CSMC winding pack is not shown). ........................................... 8

Fig. 5. Mounting studs and self-positioning T-bolts mechanism on the bottom flange. .......................... 9

Fig. 6. Detail of the vertical alignment system on the top flange. ...................................................... 10

Fig. 8. Cable and conduit before assembly and after the compaction. ................................................... 12

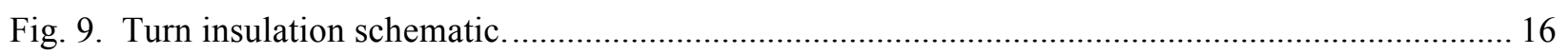

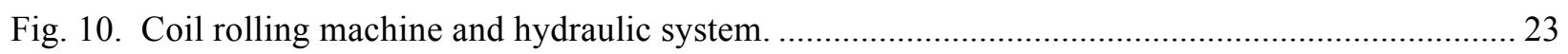

Fig. 11. Three-point bender used to straighten the rolled conductor. ..................................................... 24

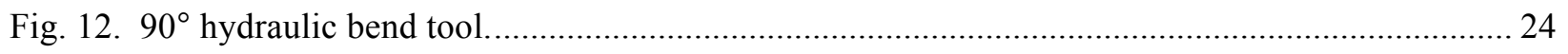

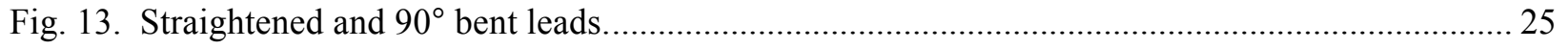

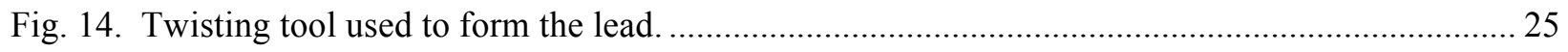

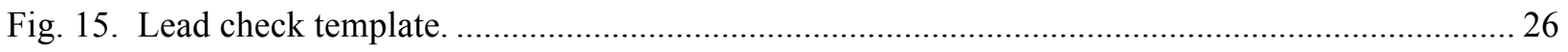

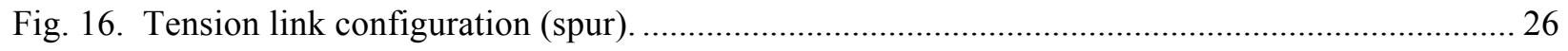

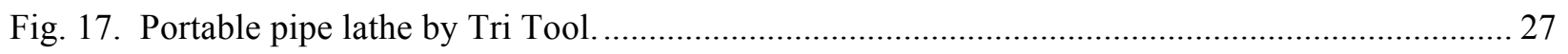

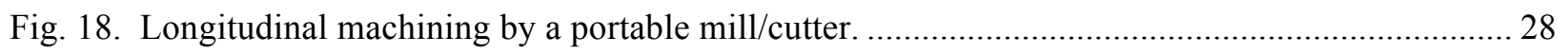

Fig. 19. Custom Crimp CC30-a 155-ton compaction machine ......................................................... 28

Fig. 20. Schematic of the heat treatment furnace and auxiliary equipment ........................................... 29

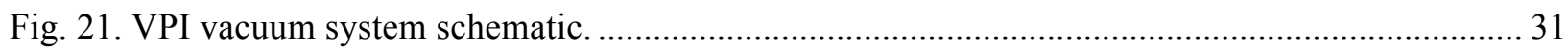

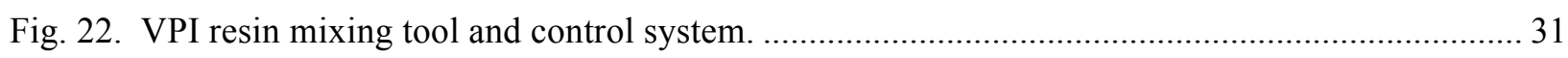

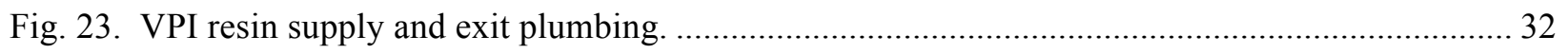

Fig. 24. Copper-stainless steel CSI electric terminal assembly drawing. ............................................ 34

Fig. 25. CSI electric terminals received after brazing....................................................................... 35

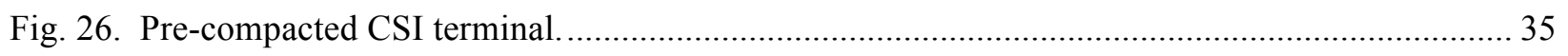

Fig. 27. Compaction test results. Tubes before and after compaction.................................................. 36

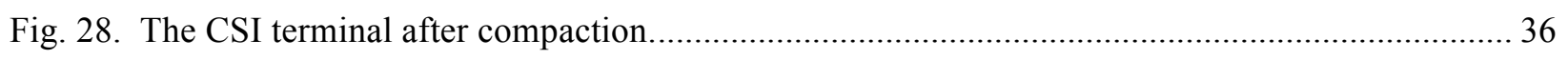

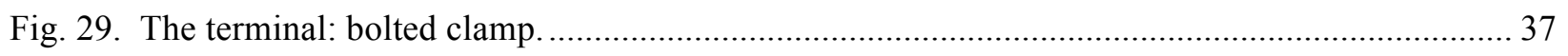

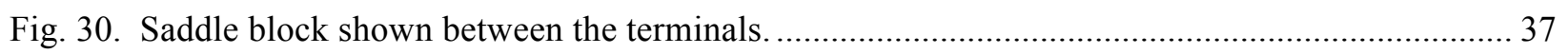

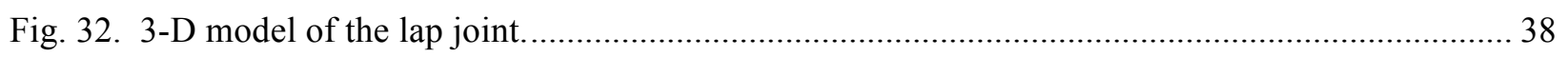

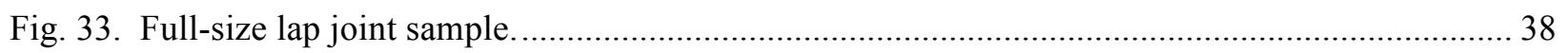




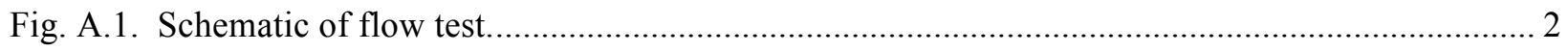

Fig. A.2. Test circuit for helium leak test by vacuum tank method............................................. 3

Fig. A.3. Vacuum bag and tool for helium leak test. Sniffer Tip is moved to the bag with a standard leak for calibration and then to the bagged object for measurements of the leak rate. 


\section{LIST OF TABLES}

Table

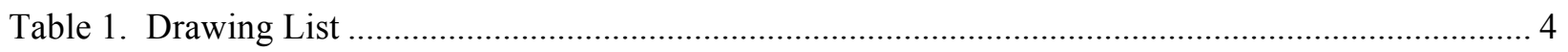

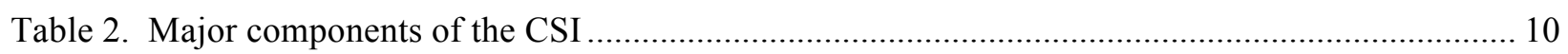

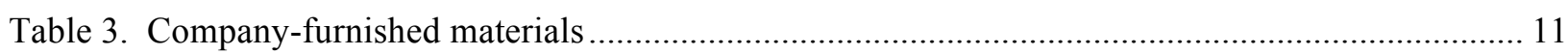

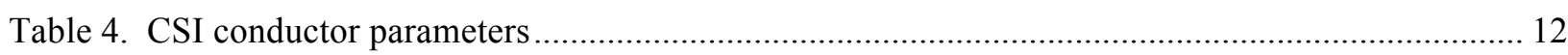

Table 5. Chemical composition of base material for conduit with JK2LB............................................. 13

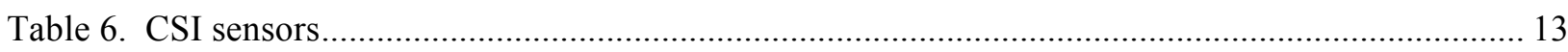

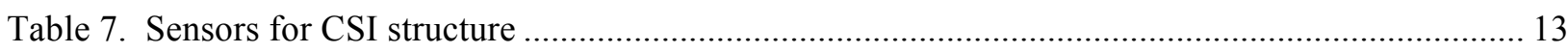

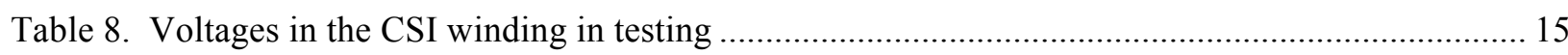

Table 9. Manufacturing size and tolerances for the CSI conductor ...................................................... 21

Table 10. Manufacturing size and tolerances for the CSI coil winding pack ...................................... 21

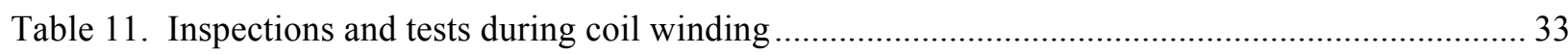

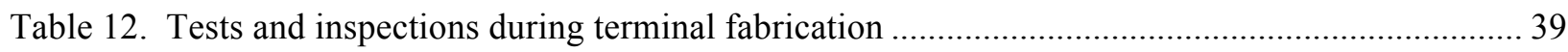

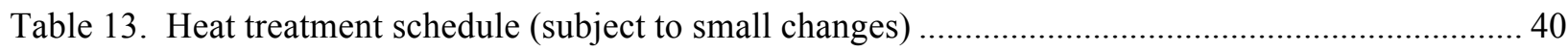

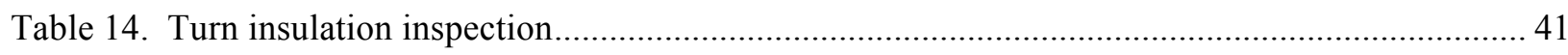

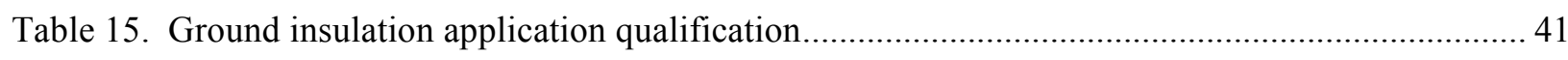

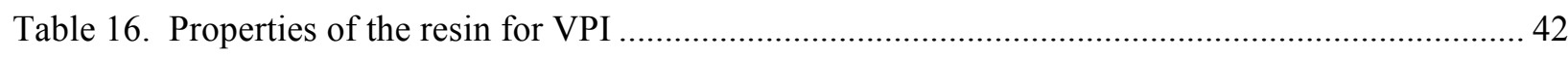

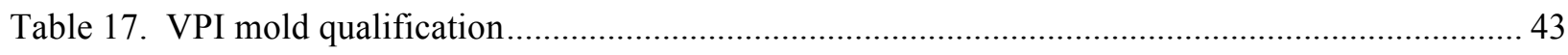

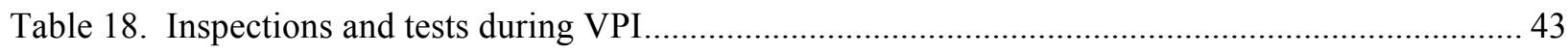

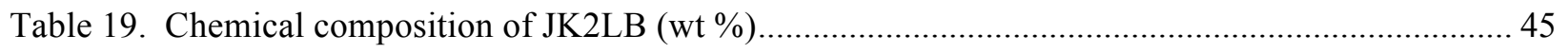

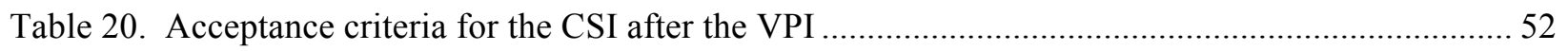

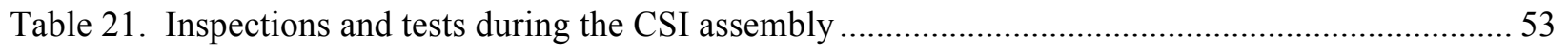

Table A.1. Conditions and records during flow testing .................................................................. 1

Table A.2. Method of helium leak test by vacuum test ..................................................................... 2

Table A.3. Method of helium leak test by sniff test........................................................................ 3

Table A.4. Minimum data requirement for leak test report ................................................................ 4

Table A.5. Conditions of proof pressure test …............................................................................... 5

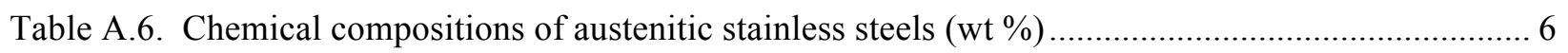

Table A.7. Mechanical requirements at RT in accordance with ASME A240 ........................................ 6 



\section{ACRONYMS}

$\mathrm{AC}$

ASME

ASTM

BPS

BPVC

CICC

$\mathrm{CS}$

CSI

CSMC

DC

DDD

DS

EDA

FDR

GKG

HT

ICD

IDD

I\&C system

JADA

JAEA

JHPGSL

JK2LB

KHK

MTP

NDE

PQR

QA

QC

$\mathrm{SHe}$

SOW

SRD

USIPO

VPI

WPQ

WPS

\author{
Alternating current \\ American Society of Mechanical Engineers \\ American Society for Testing and Materials \\ brazing procedure specifications \\ Boiler and Pressure Vessel Code (of ASME) \\ cable-in-conduit conductor used in the CSI \\ Central Solenoid \\ Central Solenoid Insert \\ Central Solenoid Model Coil \\ Direct current \\ ITER Design Description Document \\ Development specification \\ engineering design activities \\ Final Design Report \\ glass-Kapton-glass \\ heat treatment \\ Interface Control Document \\ Interface Design Document \\ Instrumentation and Controls System \\ Japanese ITER Domestic Agency \\ Japan Atomic Energy Agency \\ Japanese High-Pressure Gas Safety Law \\ Jacket material, product of Kobe Steel, Japan \\ High-Pressure Gas Safety Institute of Japan \\ Master Test Plan \\ Nondestructive Evaluation \\ procedure qualification record \\ Quality assurance \\ Quality control \\ supercritical helium \\ statement of work \\ Systems Requirement Document \\ US ITER Project Office \\ vacuum pressure impregnation process \\ welder performance qualification \\ welding procedure specifications
}





\section{SCOPE}

\subsection{BACKGROUND}

The US ITER Project Office (USIPO) is responsible for the ITER central solenoid (CS) contribution to the ITER project. The Central Solenoid Insert (CSI) project will allow ITER validation the appropriate lengths of the conductors to be used in the full-scale CS coils under relevant conditions. The ITER Program plans to build and test a CSI to verify the performance of the CS conductor. The CSI is a onelayer solenoid with an inner diameter of $1.48 \mathrm{~m}$ and a height of $4.45 \mathrm{~m}$ between electric terminal ends. The coil weight with the terminals is approximately $820 \mathrm{~kg}$ without insulation.

The major goal of the CSI is to measure the temperature margin of the CS under the ITER direct current (DC) operating conditions, including determining sensitivity to load cycles. Performance of the joints, ramp rate sensitivity, and stability against thermal or electromagnetic disturbances, electrical insulation, losses, and instrumentation are addressed separately and therefore are not major goals in this project. However, losses and joint performance will be tested during the CSI testing campaign.

The USIPO will build the CSI that will be tested at the Central Solenoid Model Coil (CSMC) Test Facility at the Japan Atomic Energy Agency (JAEA), Naka, Japan. The industrial vendors (the Suppliers) will report to the USIPO (the Company). All approvals to proceed will be issued by the Company, which in some cases, as specified in this document, will also require the approval of the ITER Organization. Responsibilities and obligations will be covered by respective contracts between the USIPO, called Company interchangeably, and the industrial Prime Contractors, called Suppliers. Different stages of work may be performed by more than one Prime Contractor, as described in this specification. Technical requirements of the contract between the Company and the Prime Contractor will be covered by the Fabrication Specifications developed by the Prime Contractor based on this document and approved by the Company and ITER. The Fabrication Specifications may reflect some national requirements and regulations that are not fully provided here. This document presents the ITER CSI specifications.

\subsection{SCOPE OF THE DOCUMENT}

This document contains technical specifications for the CSI, including the following requirements for the CSI and its major components. These requirements are based on not only on the functional specifications but also on the following considerations:

- interfaces with CSMC systems

- fabrication steps of critical operations

- $\quad$ special tools for critical fabrication steps

The specifications contain quality assurance/quality control (QA/QC) provisions, including qualifications, tests and inspections, procedures and acceptance criteria, equipment, and materials furnished to the industrial Prime Contractors' major deliverables, including hardware and documentation on technical data. 



\section{APPLICABLE DOCUMENTS}

The design information on the CSI is contained in the CSI Development Specification (CSI DS), US ITER 11102-PD0017-R00 ${ }^{1}$ and the corresponding drawings and PRO/E models available in the ITER Document Management System.

The following design criteria are provided in the annexes to CS requirements and guidelines documents in the ITER Document Management System:

- Load Specifications

- Safety Requirements

- Materials Properties Handbook

- Magnet Electrical and Superconducting Design Criteria

- Structural Design Criteria

- Electrical Design Manual

- CAD Handbook

In addition to these documents, the CSI-specific documentation provided includes the following:

- CSI Development Specification

- CSI/Test Facility Interface Control Document

- CSI Fabrication Plan

- CSI Statement of Work (SOW) for Forming

- CSI SOW for Vacuum Pressure Impregnation (VPI)

- CSI SOW for Completion

- CSI SOW for Inspection

- Material Specifications

- Supply and Delivery Schedule

- CSI Conductor Specifications

- CSI PRO/E Models

- CSI 2-D Drawings

- CS and CSI Winding Trials Report

- Results of the full-scale conductor tests with butt-weld and lap joints - research and development (R\&D) performed by the ITER R\&D effort

- Results of the full-scale terminal brazing joint test

These documents are part of this specification to the extent described herein. In the event of a conflict between the referenced documents and the contents of this specification, this specification shall take precedence. Any such conflict shall be brought to the attention of the ITER responsible officer.

Brazing and welding certification, qualifications, inspections, and tests shall be performed in accordance with the American Society of Mechanical Engineers (ASME) Boiler and Pressure Vessel Code (BPVC), Sect. IX. ${ }^{2}$ Acceptance electrical test procedures for these measurements shall follow American Society for Testing and Materials (ASTM) D3755-97 (dc). ${ }^{3}$ 


\subsection{DRAWINGS FURNISHED TO THE SUPPLIER BY USIPO}

The preliminary design of the CSI and interfaces is given in the following drawings, provided to the Supplier in PRO-E format. The design set, listed in Table 1, contains 3-D PRO/E models, 2-D drawings made from these models, and other 2-D drawings.

Table 1. Drawing List

\begin{tabular}{|c|c|c|}
\hline Number & Title & $\begin{array}{c}\text { No } \\
\text { Sheets }\end{array}$ \\
\hline I-M7371-001-01 & CSMC, CSI ASSEMBLY DIMENTIONS (JADA DRAWING) & 1 \\
\hline 1010101-OR-0400-R00 & CSMC (SIMPLF) ASSEMBLY, TERMINAL CROSS SECTION VIEW & 1 \\
\hline 1010101-OR-0401-R00 & $\begin{array}{l}\text { CSMC (SIMPLF) ASSEMBLY, ISOMETRIC VIEW W/ CSMC WINDING } \\
\text { PACK }\end{array}$ & 1 \\
\hline 1010101-OR-0402-R00 & CSI ASSEMBLY GENERAL LAYOUT & 1 \\
\hline 1010101-OR-0403-R00 & CSI WINDING ASSEMBLY, VPI COMPLETE & 1 \\
\hline 1010101-OR-0404-R00 & CSI WINDING PACK WITH TURN INSULATION & 1 \\
\hline 1010101-OR-0405-R00 & CSI ASSEMBLY, SUPPORT STRUCTURE W/ WINDING ASSEMBLY & 1 \\
\hline 1010101-OR-0406-R00 & CSI ASSEMBLY, SUPPORT STRUCTURE W/ COOL LINE & 1 \\
\hline 1010101-OR-0407-R00 & CSI COIL ASSEMBLY, TOP SPACER CYLINDER & 1 \\
\hline 1010101-OR-0408-R00 & CSI COIL ASSEMBLY, BOTTOM SPACER CYLINDER & 1 \\
\hline 1010101-OR-0409-R00 & CSI COIL JACKET, END WELDMENT PREPARATION & 1 \\
\hline 1010101-OR-0410-R00 & CSI COIL, TERMINAL SLEEVE ASSEMBLY & 3 \\
\hline 1010101-OR-0411-R00 & CSI SUPPORT STRUCTURE, TOP FLANGE CASTING & 1 \\
\hline 1010101-OR-0412-R00 & CSI SUPPORT STRUCTURE, TOP FLANGE MACHINED & 1 \\
\hline 1010101-OR-0413-R00 & CSI SUPPORT STRUCTURE, BOTTOM FLANGE CASTIN & 1 \\
\hline 1010101-OR-0414-R00 & CSI SUPPORT STRUCTURE, BOTTOM FLANGE MACHINED & 1 \\
\hline 1010101-OR-0415-R00 & CSI SUPPORT STRUCTURE, MOUNTING STUDS LAYOUT \& PARTS & 2 \\
\hline 1010101-OR-0416-R00 & CSI SUPPORT STRUCTURE, ALIGNING T-BOLTS LAYOUT \& PARTS & 2 \\
\hline 1010101-OR-0417-R00 & CSI SUPPORT STRUCTURE, ALIGNING JACK LAYOUT & 1 \\
\hline 1010101-OR-0418-R00 & $\begin{array}{l}\text { CSI SUPPORT STRUCTURE ALIGNING JACK, SUPPORT WELDMENT } \\
\& \text { DETAILS }\end{array}$ & 2 \\
\hline 1010101-OR-0419-R00 & CSI TERMINAL JOINT, HALF CLAMP ARRANGEMENT & 5 \\
\hline 1010101-OR-0420-R00 & CSI SUPPORT STRUCTURE, COOLING LINE LAYOUT & 1 \\
\hline 1010101-OR-0421-R00 & CSI SUPPORT STRUCTURE, TIE-RODS LAYOUT \& PARTS & 1 \\
\hline 1010101-OR-0422-R00 & RESERVED & \\
\hline 1010101-OR-0423-R00 & RESERVED & \\
\hline 1010101-OR-0424-R00 & RESERVED & \\
\hline 1010101-OR-0425-R00 & RESERVED & \\
\hline
\end{tabular}




\section{REQUIREMENTS}

The set of requirements provided in this section includes the following:

- operational requirements to support the CSI mission

- interface requirements to ensure that the CSI is compatible with the other systems of CSMC Test Facility and can be assembled, installed, and operated as intended

- requirements for special tools

- special processes applicable to the manufacture of the CSI, developed during ITER R\&D efforts

This combination of performance requirements and manufacturing specifications is a cost- and scheduledriven compromise between using ITER's existing investment in magnet development and supporting additional optimization efforts by the Supplier. Critical processes include winding, joint fabrication, heat treatment, insulation, VPI processes, assembly, specified testing methods, and inspection. ITER design criteria also impose certain requirements on testing and procedures, such as material characterization, high-voltage tests, and leak tests.

In general, the Supplier can propose deviations from recommended processes, subject to the ITER review and approval, to obtain a more reliable and/or less expensive product within an acceptable time.

The SOW to be prepared by the Company is provided as part of the Procurement Package. The Supplier is responsible for the materials, facilities, and personnel needed to supply the deliverables listed in the contract.

\subsection{ITEM DEFINITION}

The CSI assembly is shown in drawing 1010101-OR-0402. Details of the design model of the CSI coil are presented in Fig. 1.

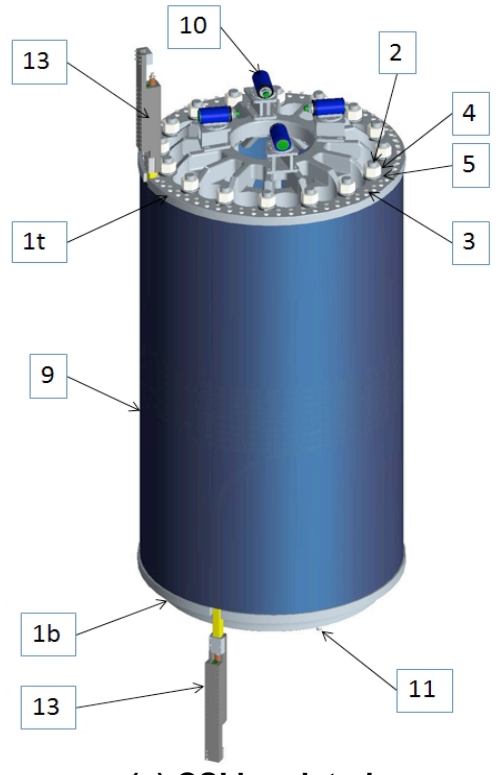

(a) CSI insulated

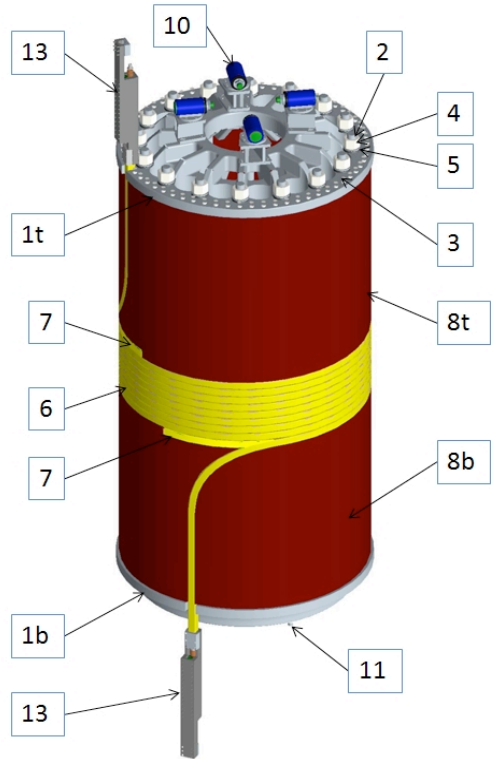

(b) Ground insulation not shown

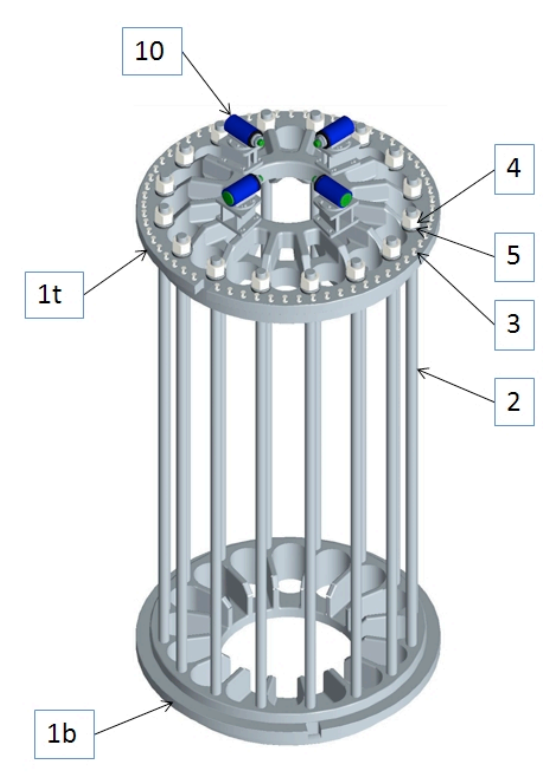

(c) Support structure

Fig. 1. CSI module assembly. 
The main components of the CSI shown in this and other figures are labeled as follows:

1. two stainless steel flanges: Top Flange (1t) and Bottom Flange (1b); material: 316L, casting

2. 16 aluminum tie-rods (material: 7075-T6)

3. 63 pushing bolts

4. 16 tie-rod nuts

5. 16 spherical washers

6. superconducting coil

7. two spurs (material: JK2LB)

8. two stainless steel spacers: Top Spacer (8t) and Bottom Spacer (8b)

9. coil ground insulation

10. four alignment jacks

11. four bottom mounting studs

12. four bottom alignment $\mathrm{T}$-bolts

13. terminal joint

14. two CSI terminals (Fig. 30)

15. saddle (Fig. 30)

16. half clamp (material 316L) (Fig. 30)

The CSI is a single independently operated one-layer circular coil. The assembled CSI also has a structure that provides pre-compression and centering. The CSI coil is wound with a superconducting $\mathrm{Nb}_{3} \mathrm{Sn}$ cablein-conduit conductor (CICC) that is furnished by the ITER Project. The pre-compression provides an axial preload that prevents separation of the CSI turns during testing and minimizes axial deformations during operation. The layer ends above and below the windings extend out to the vertically oriented terminations. Two stainless steel cylinders (spacers) and two spur inserts hold the coil together in place. The conductor is wrapped with $1 \mathrm{~mm}$ thick insulation and with overlapped layers of Polyimide (Kapton) tape and dry glass tape. The entire assembly of the coil and two stainless steel cylindrical spacers are then insulated by a glass tape in vertical and horizontal directions and undergo the VPI process to create a solid structure which will be compressed between the flanges of the support structure. The overall thickness of the ground-insulated section is $59 \mathrm{~mm}$, which gives $4 \mathrm{~mm}$ per side from the insulated coil conductor surface.

The CSI terminal joints provide a uniform current distribution at low DC and alternating current (AC) losses. The CSI joints are designed to generate a low amount of heat $(6 \mathrm{~W}$ or less per joint at peak current) and prevent strong nonuniformity in current distribution, which could reduce the temperature margin. The joints themselves are made in the vertical direction outside the vertical support structure.

The insert and the associated mechanical structure are designed to allow a broad experimental program in which the different parameters of current, field, stress, and temperature can be explored independently of the background field coil.

The CSI coil is cooled with supercritical helium. The helium and electrical power are fed to the CSI by the dedicated plumbing and buses, respectively.

The CSI assembly structure is self-supporting against the coil hoop radial forces. The net radial forces are supported by the alignment jacks at the top and bottom-mounting studs. The vertical forces are supported by the same studs and the interface ring. Details of the supports and preloading are shown in drawings 1010101-OR-0405. 


\subsubsection{Central Solenoid Insert Functional Relationships}

The CSI has physical interfaces and functional relationships with other CSMC sub-systems. The Interface Control Document (ICD) ${ }^{4}$ defines these relationships. Figures 2-6 show the CSMC assembly and its major components. The CSI detailed design shall meet the requirements specified in this document.

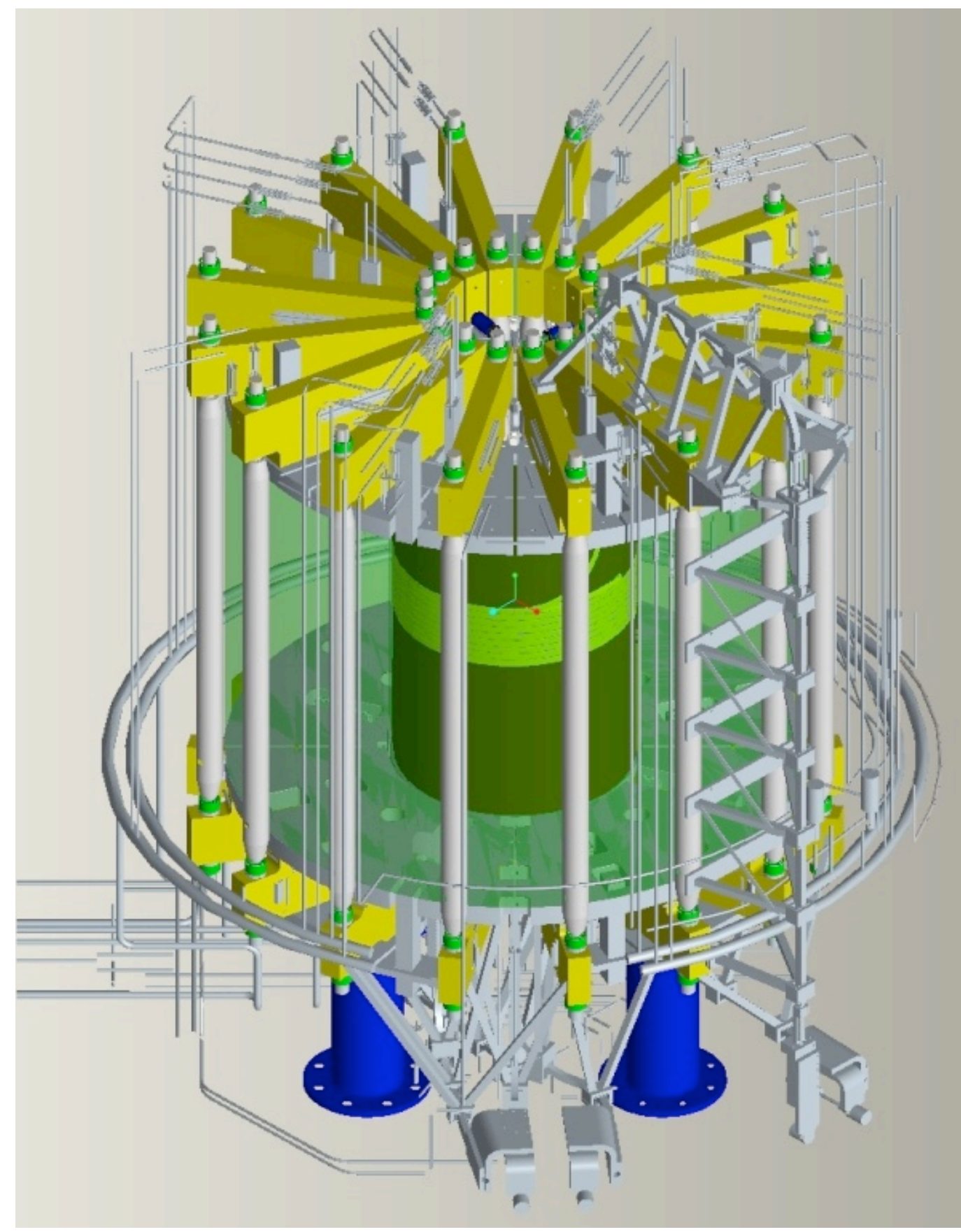

Fig. 2. Computer-generated 3-D model of CSMC with plumbing and electrical interfaces. 


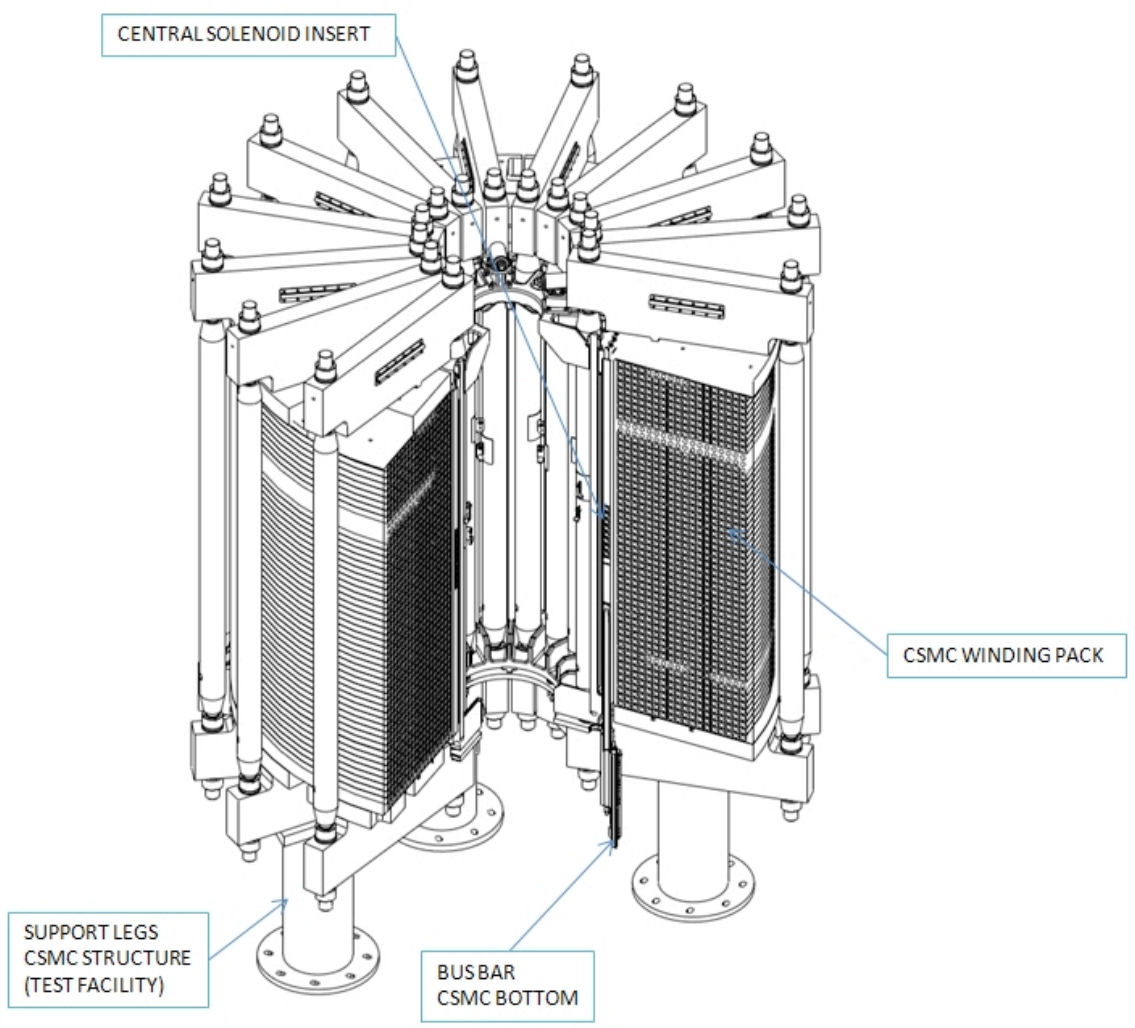

Fig. 3. Main parts of the in-vessel system.

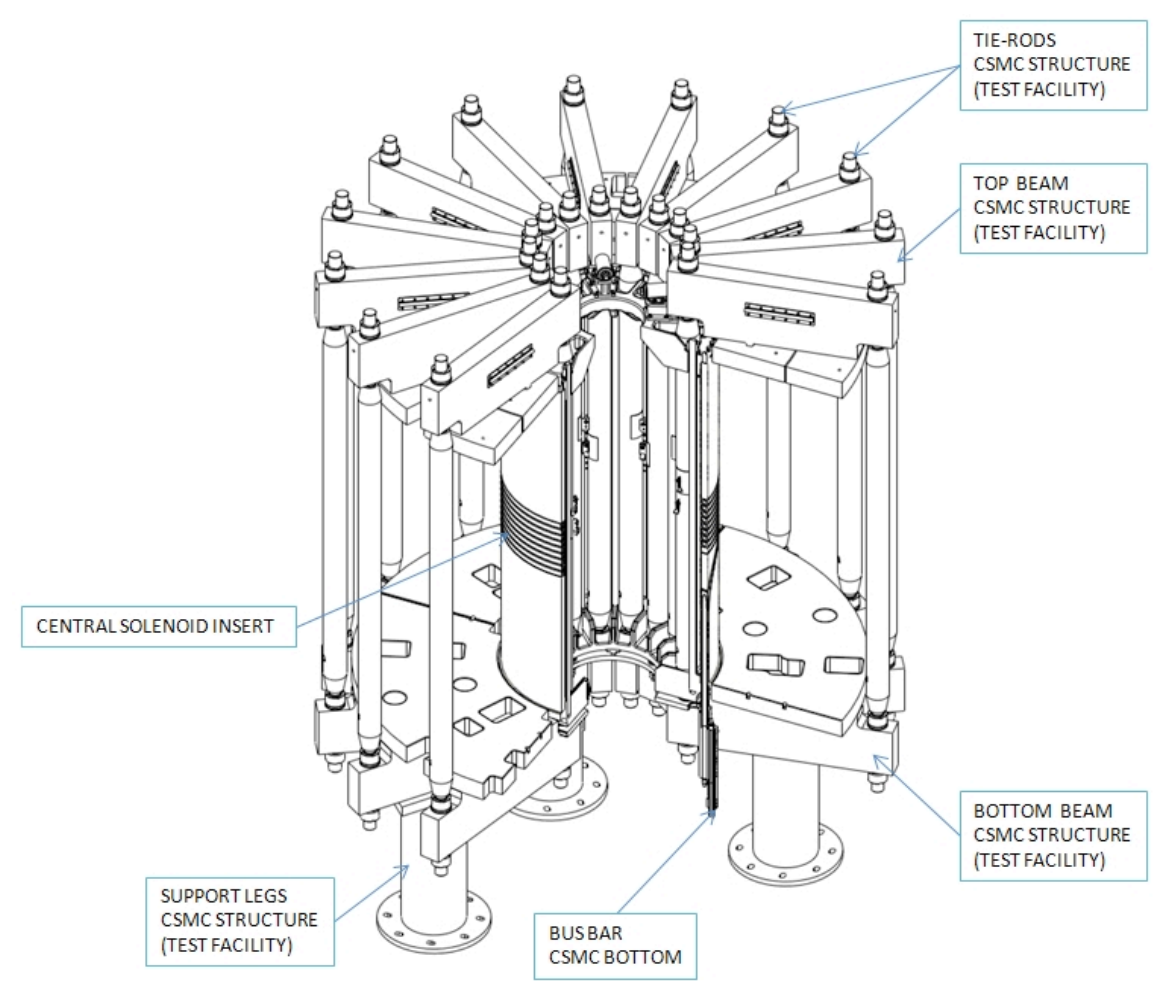

Fig. 4. CSI in the CSMC assembly (CSMC winding pack is not shown). 


\subsubsection{Interface Definition}

\subsubsection{Metric system units}

All measurements shall be in SI units. The Supplier shall use SI units in all engineering drawings, process descriptions, test results, and other internal and external reports and documentation related to this procurement. A secondary unit can be shown in the square bracket.

\subsubsection{Structural interfaces with the CSMC system}

The CSI structure must support gravity forces and accommodate relative motion between the CSMC and CSI systems during all phases of testing. To meet these requirements, the CSI assembly is positioned on the base ring plate with the four $30 \mathrm{~mm}$ studs and four self-positioning T-bolts, providing a sliding and locating mechanism at the bottom, as shown in Fig. 5. Four spring-loaded aligning jacks are mounted on the top support flange to compensate for relatively small radial misalignment between the CSI and the CSMC coils, while maintaining the centering (Fig. 6).

\subsubsection{Interface with the cryogenic system}

The piping arrangement between the CSI and the bus terminals of the CSMC is given in the model (drawing 1010101-OR-0419). Cooling to the preload structure is required. Cooling is not required for the aluminum tie-rods, since they have a small mass compared to the large cold mass of the whole facility. The upper and lower flanges require a cooling system since eddy currents will develop in these continuous rings.

\subsubsection{Interface with the power supply}

In a low-voltage operating mode, two DC power supplies are available to the Test Facility. The power supply system has two DC electrical circuits (DC power supply 1 and 2) and a pulsed electrical circuit that uses a part of the DC circuit in common. Several operating modes will be provided in order to carry out the performance tests. ${ }^{4}$

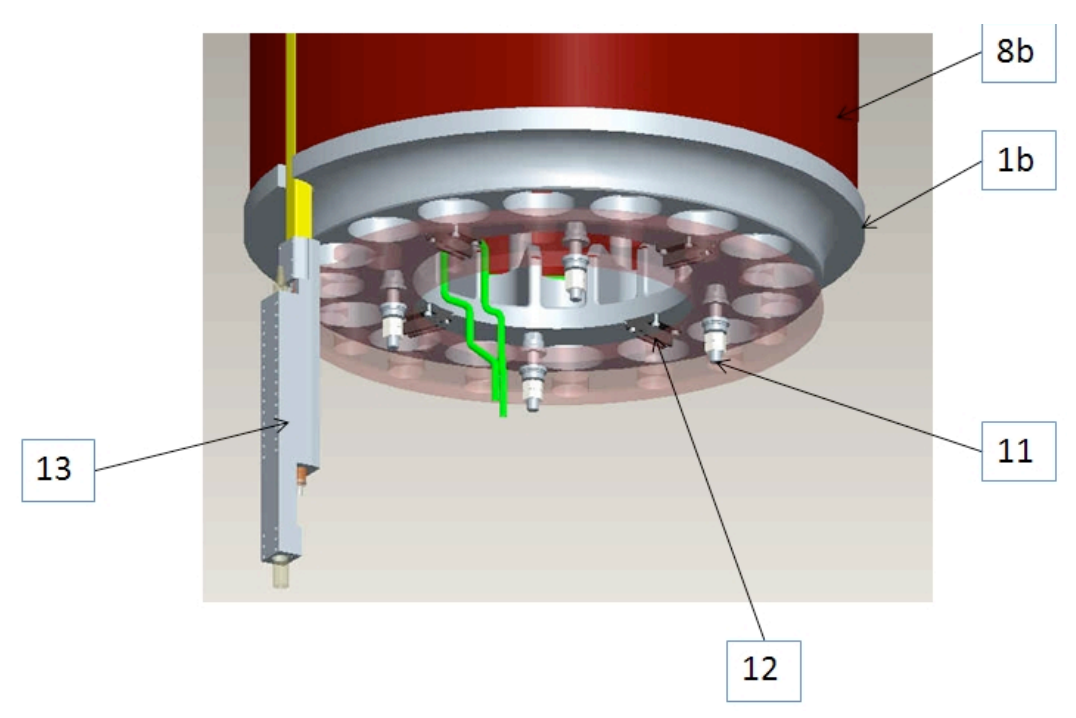

Fig. 5. Mounting studs and self-positioning T-bolts mechanism on the bottom flange. 


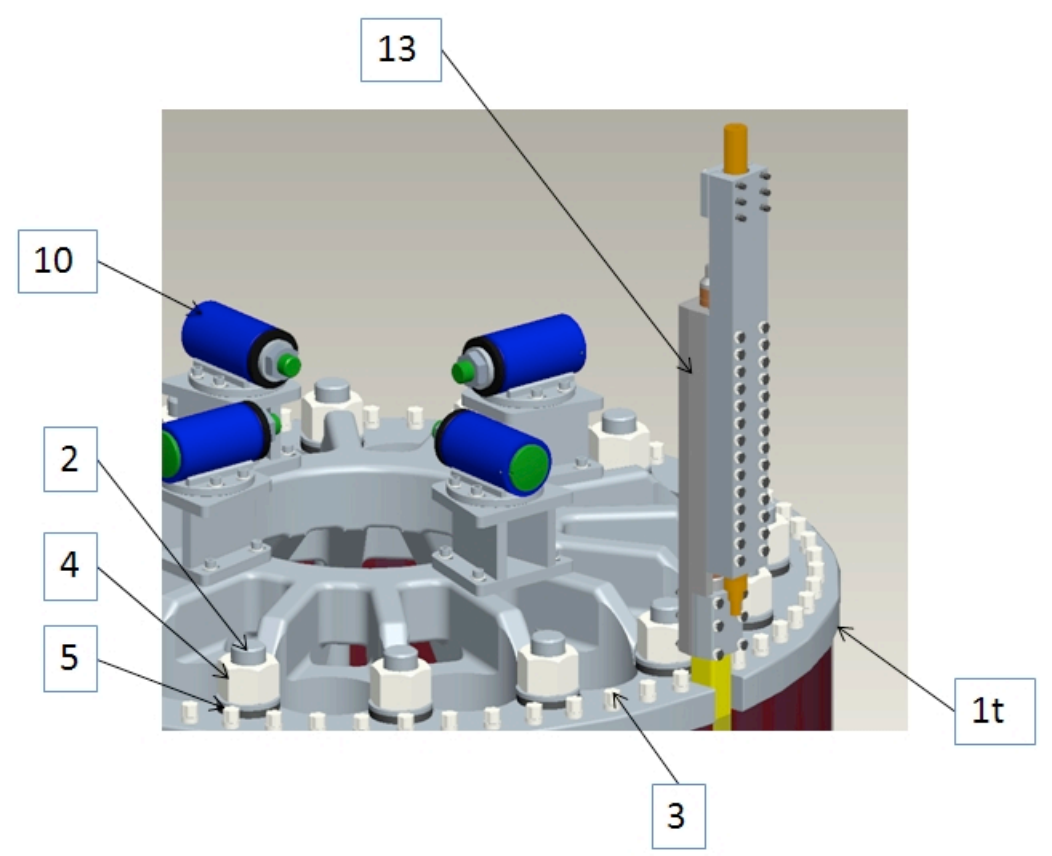

Fig. 6. Detail of the vertical alignment system on the top flange.

\subsubsection{Interface with instrumentation and control system}

A control system is installed in the Test Facility in order to ensure safe and reliable operation of the facility and the coil and to initiate discharge in the event of a coil quench. A series electrical connection of the CSI with the CSMC will never be used during CSI testing; thus, there is no high-voltage requirement on the CSI. Nevertheless the sensors installed on the CSI will use high-voltage (less than $500 \mathrm{~V}$ ) wiring (voltage taps and quench detection leads) and low-voltage (less than $5 \mathrm{~V}$ ) wiring (temperature sensors, strain gauges, and displacement sensors) to communicate the signals to transducers and data converters. The high-voltage wires will be continuous (no intermediate patch panel in the vacuum). Therefore, the Supplier shall provide sufficient lengths of the high-voltage wire to be pulled through the conduits of the feeders. ITER will later determine the length requirements of the high-voltage sensors as the design progresses.

\subsubsection{Major Component List}

Table 2 lists of major components of the CSI.

Table 2. Major components of the CSI

\begin{tabular}{lll}
\hline & \multicolumn{1}{c}{ Item } & Quantities \\
\hline 1 & Module Coil assembly w/support structure & 1 \\
2 & Set of upper support flange & 1 \\
3 & Set of bottom support flange & 1 \\
4 & Set of the electric terminal hardware & 2 \\
5 & Plumbing & 1 set \\
6 & Instrumentation and wiring & $1 \mathrm{set}$ \\
\hline
\end{tabular}




\subsubsection{Furnished Materials and Equipment to the Vendor}

Table 3 lists Company-furnished materials and equipment. The detailed requirements and specifications are given in the following sub-sections of Sect. 3.1.4.

Table 3. Company-furnished materials

\begin{tabular}{clc}
\hline No. & ITER-furnished materials and equipment & Reference \\
\hline 1 & CSI Conductor & 3.1 .4 .1 \\
2 & Empty conduit for the spurs & 3.1 .4 .1 \\
3 & Instrumentation & 3.1 .4 .2 \\
4 & Instrumentation wire & 3.1 .4 .3 \\
5 & Installation manual and procedures & 3.1 .4 .4 \\
\hline
\end{tabular}

\subsubsection{Conductor}

The CSI conductor is an $\mathrm{Nb}_{3} \mathrm{Sn}$ cable in conduit, as shown in Fig. 7. The steel (JK2LB) square jacket is a tube with square cross section and round hole. The jacket is first hot extruded and then cold drawn to achieve the final dimensions. The lengths of the conduit are then butt-welded and a cable is pulled into the conduit. Finally, the CICC is compacted to the desired size. Figure 8 shows the cable and the conduit before assembly and after the compaction. Parameters of the CSI conductor are given in the Table 4. Steel JK2LB chemistry is given in Table 5.

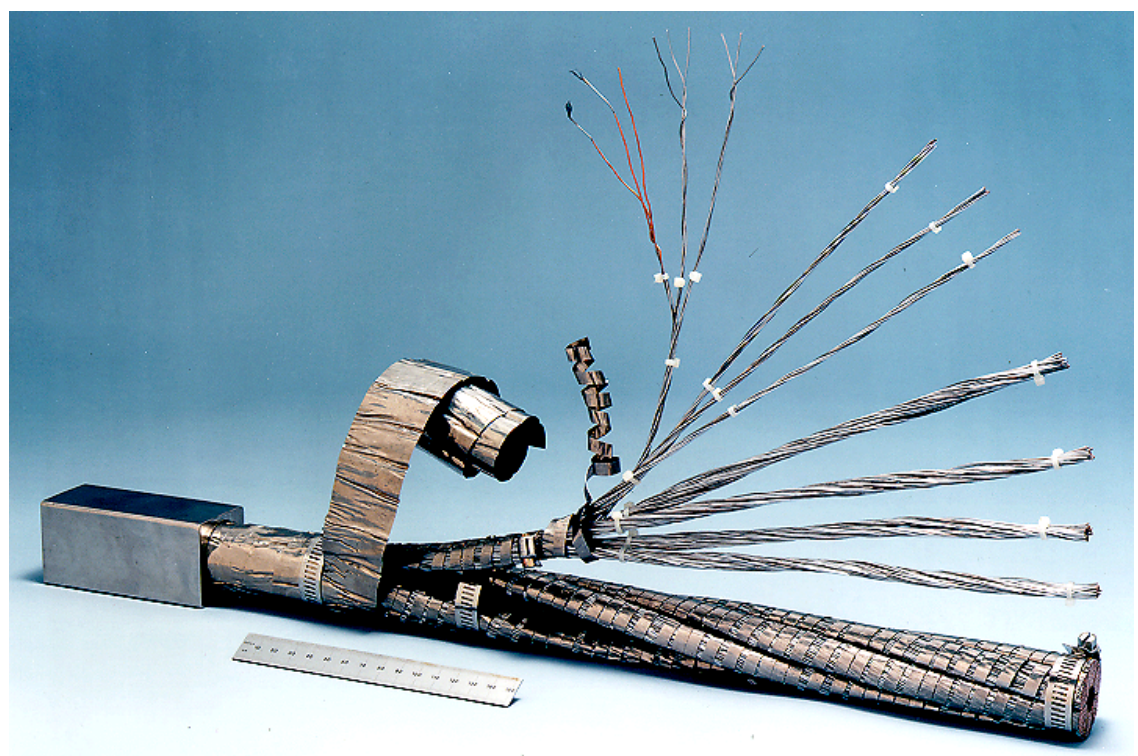

Fig. 7. CS conductor. 


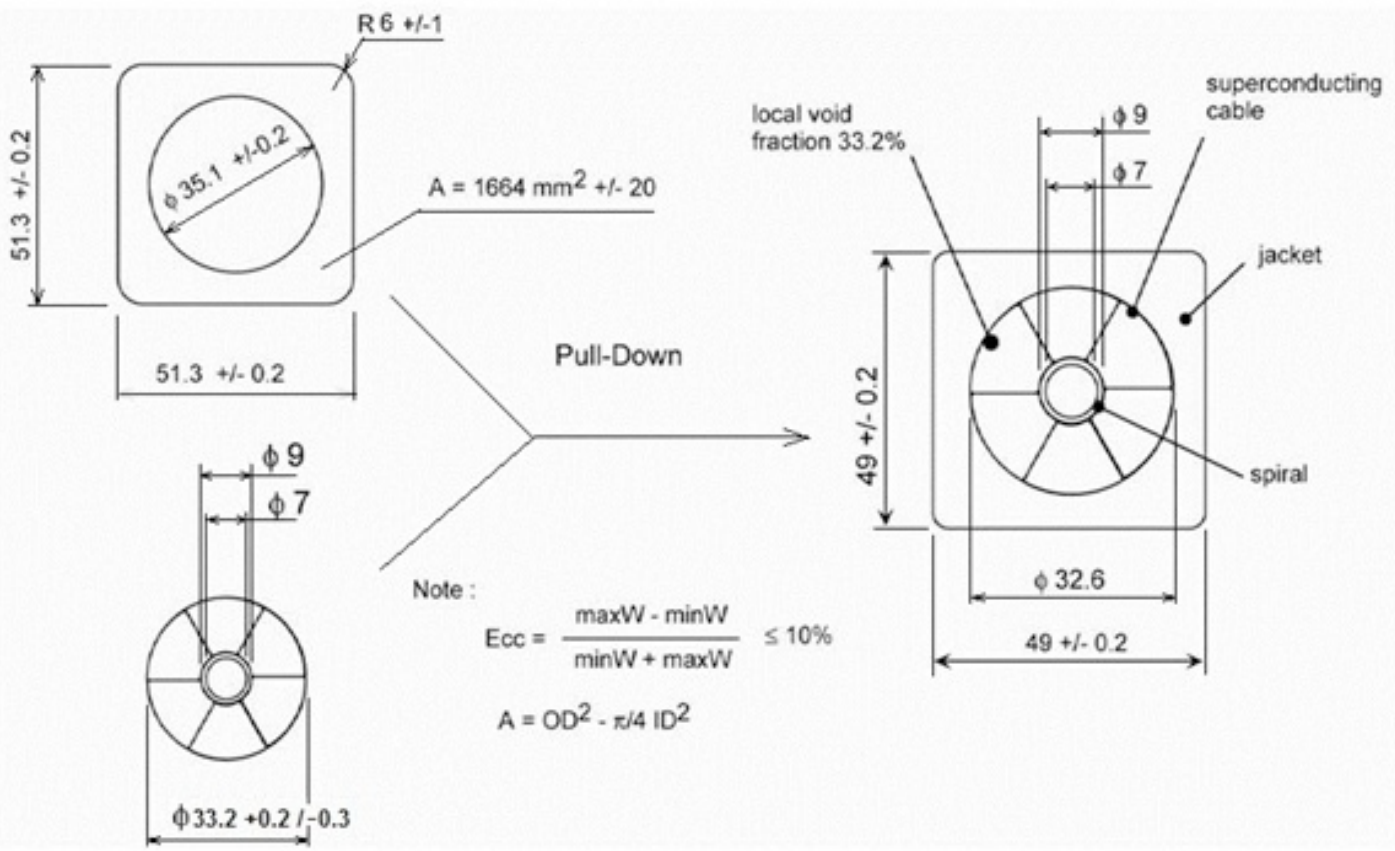

Fig. 8. Cable and conduit before assembly and after the compaction.

Table 4. CSI conductor parameters

\begin{tabular}{|c|c|}
\hline \multicolumn{2}{|c|}{ DB 30-07-2003 } \\
\hline Type of strand & $\mathrm{Nb}_{3} \mathrm{Sn}$ \\
\hline Jacket material & JK2LB \\
\hline Iop $(\mathrm{kA})$ & $40 \mathrm{kA}(\mathrm{SOD}), 45 \mathrm{kA}(\mathrm{EOB})$ \\
\hline $\operatorname{Bmax}-\operatorname{Bmin}(\mathrm{T})$ & 13.0 (SOD)-12.4 (EOB) \\
\hline Top $(\mathrm{K})$ & 4.7 \\
\hline Initial strain $\varepsilon_{\text {init }}=\varepsilon_{\text {th }}+\varepsilon_{\text {extra }}(\%)$ & -0.84 \\
\hline Operating strain $\varepsilon_{\mathrm{op}}(\%)$ & +0.15 \\
\hline Equivalent discharge time constant $\tau_{\mathrm{eq}}(\mathrm{s})$ & 11.5 \\
\hline $\mathrm{Jc}\left(\mathrm{A} / \mathrm{mm}^{2}\right)$ at $12 \mathrm{~T} @ 4.2 \mathrm{~K} @ \varepsilon-0.25 \%$ & 700 \\
\hline $\operatorname{Tcom}(\mathrm{K})$ & 17 \\
\hline $\operatorname{Bc} 20 \mathrm{~m}(\mathrm{~T})$ & 32 \\
\hline SC strand diameter (mm) & 0.83 \\
\hline $\mathrm{Cu}$ :nonCu ratio & 1.0 \\
\hline Copper RRR & 100 \\
\hline Cable pattern & $3 \times 3 \times 4 \times 4 \times 6$ \\
\hline $\mathrm{Cu}$ strand in 1 st triplet & 1 \\
\hline $\mathrm{SC}$ strand $\mathrm{Nr}$ & 576 \\
\hline Local void fraction (\%) & 33.2 \\
\hline Cable diam (mm) & 32.6 \\
\hline Central Chan. od $\times$ id $(\mathrm{mm})$ & $9 \times 7$ \\
\hline Flow Area in annulus $\left(\mathrm{mm}^{2}\right)$ & 252.3 \\
\hline Total Flow Area $\left(\mathrm{mm}^{2}\right)$ & 290.8 \\
\hline Petal wraps (mm) & 0.05 \\
\hline Cable wraps $(\mathrm{mm})$ & $2 \times 0.08=0.16$ \\
\hline External dimensions of jacket (mm) & $49.0 \times 49$ \\
\hline Corner radius of square jacket (mm) & 4 \\
\hline $\mathrm{SC}$ strand cross section in cable $\left(\mathrm{mm}^{2}\right)$ & 311.7 \\
\hline
\end{tabular}


Table 5. Chemical composition of base material for conduit with JK2LB

\begin{tabular}{|c|c|c|c|c|c|c|c|c|c|c|c|}
\hline Wt \% & $\mathrm{C}$ & Si & Mn & $\mathbf{P}$ & $\mathbf{S}$ & $\mathrm{Cr}$ & $\mathbf{N i}$ & Mo & Co & $\mathbf{N}$ & B \\
\hline JK2LB & $\begin{array}{l}\leq 0.030 \\
\quad(\text { target } \\
<0.025)\end{array}$ & $\begin{array}{c}\leq 0.50 \text { (target } \\
<0.28)\end{array}$ & $\begin{array}{r}20.50- \\
22.50\end{array}$ & $\begin{array}{l}\leq 0.015 \\
\quad(\text { target } \\
<0.008)\end{array}$ & $\begin{array}{c}\leq 0.015 \\
(\text { target } \\
<0.008)\end{array}$ & $\begin{array}{r}12.00- \\
14.00\end{array}$ & $\begin{array}{r}8.0- \\
10.0\end{array}$ & $0.5-1.5$ & $\leq 0.1$ & $0.09-0.15$ & $\begin{array}{r}0.0010 \\
0.0040\end{array}$ \\
\hline
\end{tabular}

CSI with CICC cable. For the CSI module to be built, ITER will provide $50 \mathrm{~m}$ of the CSI conductors according to specifications for the CS CICC. The supplied conductor will accommodate the minimum length sufficient for feeding into the winder and for the terminal. Details of the design model of the CSI coil are shown in Figs. 1-3.

Empty Conduit for the spurs. Two short pieces ( $\mathrm{L} \sim 0.70 \mathrm{~m}$ each) of an empty jacket will be used for the spurs.

\subsubsection{Instrumentation}

The following instrumentation will be provided to the Supplier. Instrumentation for the CSI is shown in CS Insert Test Plan ${ }^{5}$. The list of sensors is given in Tables 6 and 7. The designations Facility or "F" mean that these sensors are located in the CSMC facility plumbing and are already installed. ${ }^{2}$

Table 6. CSI sensors

\begin{tabular}{ll}
\hline \multicolumn{1}{c}{ Sensor } & \multicolumn{1}{c}{ Number } \\
\hline Voltage tap & 18 (from 10 locations) \\
Voltage tap for QD & 3 \\
CGR thermometer (Facility) & 2 \\
Cernox thermometer & 4 \\
Pt-Co thermometer (Facility) & 2 \\
Strain gauge & 5 \\
Flow meter (Facility) & 2 \\
Pressure meter (Facility) & 2 \\
Differential pressure meter (F) & 1 \\
Pressure tap (F) & 2 \\
Resistive heater & 2 \\
Inductive heater & 0 \\
Hall probe for current distribution measurement & 0 \\
Compensation coil & 1 \\
\hline
\end{tabular}

Table 7. Sensors for CSI structure

\begin{tabular}{lc}
\hline \multicolumn{1}{c}{ Sensor } & Number \\
\hline Cernox thermometer (F) & 1 \\
Pt-Co thermometer (F) & 8 \\
Flow meter (F) & 1 \\
Pressure tap (F) & 2 \\
Strain gauges on the rods & 4 \\
\hline
\end{tabular}


All sensors, instrumentation wiring, and current-limiting resistors are supplied by ITER according to the instrumentation schematic shown in the CSI Test Plan. ${ }^{5}$

\subsubsection{Instrumentation wire}

The instrumentation wire will be supplied in an amount sufficient to bring the signals to the feeder box interfaces. The Supplier shall design the routing of the instrumentation wiring and determine the amount of the instrumentation wire needed. ITER will supply the required amount of wire to the Supplier in advance to support the schedule.

\subsubsection{Installation manuals and procedures}

Installation manuals and procedures on sensors, wiring, and insulation will be provided to the Supplier. Training on sensor installation will be provided to the Supplier technicians as necessary.

\subsection{CHARACTERISTICS}

\subsubsection{Performance}

The ITER CSI shall support operational scenarios of the CSMC machine as described in Sect. 4 of the CSI Test Plan. ${ }^{5}$

The CSI must be charged to $13 \mathrm{~T}$ at $40 \mathrm{kA}$ and then discharged and charged with an opposite current in accordance with the specified plasma scenarios. In the End of Burn (EOB), the maximum field on the CSI conductor is $12.7 \mathrm{~T}$ at $45 \mathrm{kA}$. The CSI will also be tested at $13 \mathrm{~T}$ with $60 \mathrm{kA}$ without exceeding design parameters of the $\mathrm{I}^{2} \mathrm{t}$ for the CS conductor.

The CSI preliminary design is done in accordance with the ITER design criteria documents for superconductors, structural materials, and insulation. The results of the full-scale CSI conductor tests shall give a high level of confidence that the CS will work in the ITER machine and will support the required ITER scenarios with a sufficient temperature margin if manufactured properly. This section of the document specifies technical requirements for CSI during manufacturing, assembly, and testing of the CSI.

This document indicates the responsibilities of CSI team and Supplier. All of the Supplier development efforts will be aimed at the establishing the most efficient fabrication methods and QA provisions. Feasibility is not expected to be an issue. It is possible that as a result of this effort the current specification may require modification. In this case, the Supplier shall request ITER for a change, according to the established procedure.

During manufacture, the following verifiable performance requirements must be met as acceptance criteria.

\subsubsection{Leak tightness}

Leak tightness of the components containing helium is absolutely essential to the successful operation of the CSI; therefore, every critical operation involving penetrations, welding or plastic deformations of the conductor, terminations, plumbing, instrumentation, etc., requires inspections and tests for leak tightness. Most leak testing will take place at room temperature. Since helium leaks have tendency to increase by 
several orders of magnitude during cooling to cryogenic temperatures, leak checking must be done at the highest practical level. The usual requirement is that there be no detectable leaks at a sensitivity of $10^{-8}$ $\mathrm{Pa}^{*} \mathrm{~m}^{3} / \mathrm{s}$ helium.

\subsubsection{Flow impedance}

Helium to the CSI conductors is supplied into the terminals located at the bottom of the CSI assembly, as shown in Drawing 1010101-OR-0402. The outlets terminal is located at the top. The average mass flow rate through the terminal is $8 \mathrm{to} 10 \mathrm{~g} / \mathrm{s}$, the average hydraulic length is $50 \mathrm{~m}$, and an expected pressure drop through the coil in normal operation is about 0.2 bars. The total volume of void inside the CSI conductor is about $0.03 \mathrm{~m}^{3}$.

The flow impedance of the conductors and joints in hydraulic paths is designed not to exceed $1.0 \mathrm{bar}$ under operating conditions and at a nominal flow rate. A higher-pressure drop will cause a higher pumping loss, which requires more cryogenic power, which is undesirable.

\subsubsection{Structural integrity}

The structural integrity of the CSI and its component is one of the most important requirements. Structural integrity is ensured by an appropriate design and QA/QC program during fabrication. The "Analysis of CS Insert Coil" contains global and local structural analyses of the CSI and its most important elements in operation and shows that the stresses in the CSI and its elements are within allowable limits. The structural integrity requirements specify the sensitivity of the nondestructive evaluation (NDE) for the conductor and major structural elements.

Upon completion of the design and during fabrication of the CSI, the Supplier will be required to satisfy the material certification, process qualification, inspections/tests, acceptance criteria, and documentation requirements as part of the QA/QC plan. It is expected that the Supplier will not change the global design to the extent that the results of the structural analysis performed by ITER analysts become obsolete. However, local structural analysis for particular components designed and developed by the Supplier will be required as a proof that the stresses in the materials are within allowable limits.

If for some reason a design change is desirable, the Supplier will make a proposal and ITER will review, analyze, and assess the proposal as necessary and subsequently accept or reject the proposal in accordance with the configuration management procedure and interface control approved by ITER.

\subsubsection{Electrical strength}

The CSI will develop electrical voltages during testing, as shown in Table 8.

Table 8. Voltages in the CSI winding in testing

\begin{tabular}{lr}
\hline Turn voltage in normal operation (V) & 2 \\
Ground/terminal voltage (V) in normal operation (including fast discharge) & 100 \\
Test voltage (V) ground/terminal & 500 \\
\hline
\end{tabular}

The insulation system for the CSI consists of turn and ground insulation. Each of these insulations consists of a combination of glass and polyimide film, which has good mechanical and insulating 
properties. However, since insulation in the CSI is subject to significant stresses during cooldown and testing operation, the process of insulation application and impregnation had to be qualified for operation at cold temperatures under relevant cyclic load conditions to verify the robustness of the process and materials. The wrap insulation that will be used in the CSI was qualified in a separate project.

All winding operations shall be performed under clean conditions and controlled temperatures, as defined in Sect. 3.2.5.

Turn insulation specification. Before turn insulation is applied, some sensors need to be installed and holders put in place for future sensors. Voltage taps will be attached to the outer surface of the conductor and secured with spot-welded clamps on the surface of the conductor. Also, Teflon pads will be installed at the ID in the spots of the temperature sensors and strain gauges location after VPI, since they cannot survive VPI and they must be installed after VPI. The reacted coil will be spread for installation of the turn insulation. The entire CSI conductor will be insulated by hand.

When the turn insulation is installed on the coil, the radial and vertical dimension buildup must be controlled. Additional allowance for radial space per turn is $0.5 \mathrm{~mm}$, and additional allowance for axial space is $1 \mathrm{~mm}$. The gaps shall be filled with glass tape or cloth to eliminate resin-rich areas.

Turn insulation consists of layers.

- Inner insulation layer: one butt lap of 1581 E-glass tape (thickness $\sim 0.25 \mathrm{~mm}, 51 \mathrm{~mm}$ wide), wound over conduit, with 45\% overlap. Supplier is Caroline Narrow Fabric.

- Second insulation wrap: cowound Kapton and 1581 E-glass tape (thickness $\sim 0.5 \mathrm{~mm}$ ), one pass, $45 \%$ overlap. The Kapton is under the glass, so the outer surface of the wrap insulation is glass. Kapton-suggested supplier is American Durofilm; the tape is type FPC, $0.050 \mathrm{~mm}$ thick and 51 mm wide.

The nominal thickness of the insulation installed is $1 \mathrm{~mm}$. The turn insulation schematic is shown in Fig. 9.

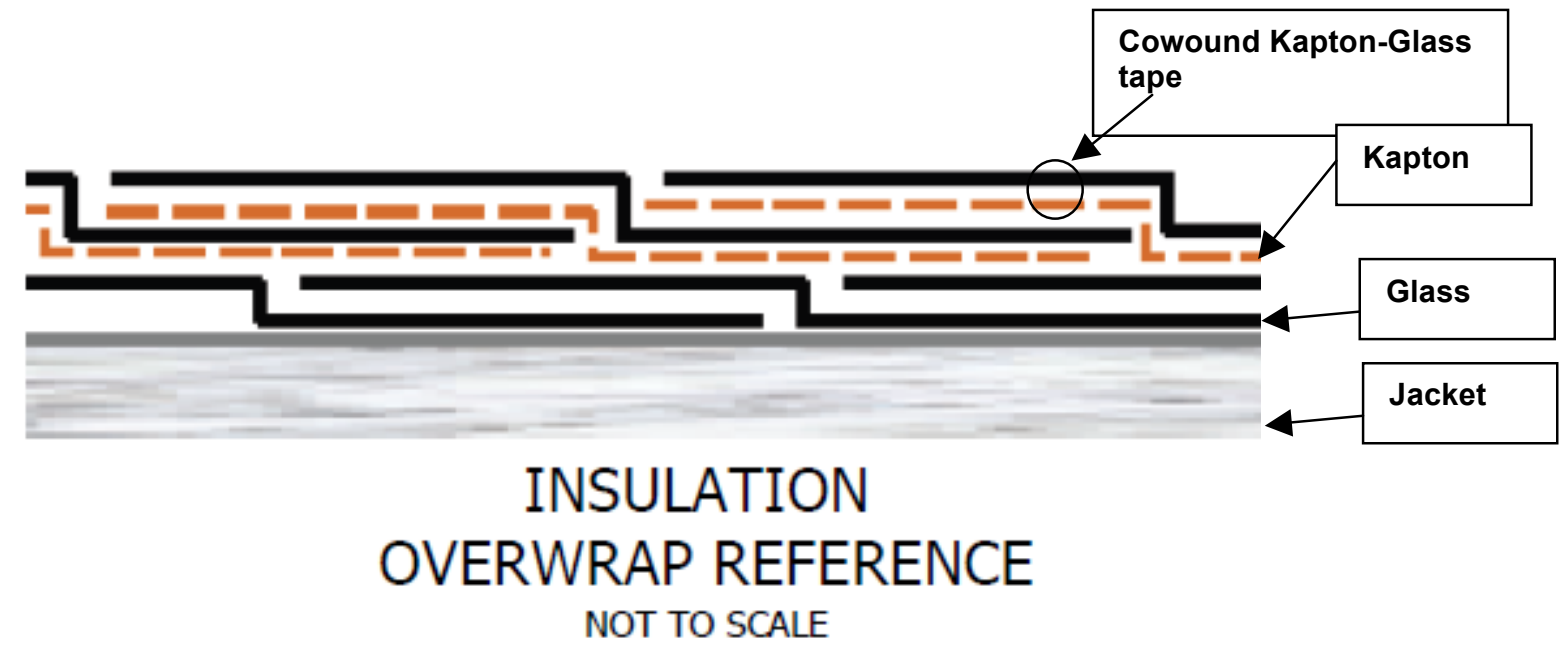

Fig. 9. Turn insulation schematic.

Coil ground insulation. Before application of the ground insulation, which will also serve as a structural member holding the assembly together, the joint terminations will be located in their proper places and 
the turns will be adjusted to uniform diameters. Then, holding the coil in place with temporary clamps, the assembly will receive one layer of insulation wrap around the coil with one layer (49\% overlap) of 1581 E-glass, which will turn into a fiberglass barrier during the impregnation process. Spacers will be brought to the coil and the leads located in the cutouts. After verifying the correct dimensions and locating the terminations, they will be secured in the set of clamps against the coil and prepared for the axial wrap-up. The thickness of the layer insulation will vary and will be chosen to control the height of the winding pack within tolerances as required.

Inner ground insulation and vertical wrap. The inner ground insulation and part of the outer ground insulation will be applied after the coil is assembled with the spacers by wrapping the 1581 E-glass tape around the winding pack and spacers in axial direction with tension that will further compress the assembly. Special attention needs to be paid to the leads in the gap of the spacers; the vertical wrap needs to support the location of the leads in the spacer gap. Details of the insulation will be provided on the drawings, listed in the Sect. 2.1 of this document.

Outer ground insulation. The outer insulation is partially formed during the vertical wrap. Additional insulation is then applied by wrapping the glass tape circumferentially around the coil and the spacers to complete the application of ground insulation, which is more a structural member than is electrical insulation. Details of the insulation will be provided in the drawings listed in Sect. 2.1 of this document.

Insulation of busses, pipes, joints, terminals and other CSI parts. Some of the CSI plumbing joints, inlets, and outlets will require installation of insulation after the VPI process. For these parts, the Supplier shall design the insulation, which would have continuity with the CSI module insulation and would not create any singularities or weak spots at the interfaces. The insulation shall consist of a combination of glass-polyimide tapes. At least one layer of the polyimide layer in the insulation system is required; minimum overall thickness of the insulation is $1 \mathrm{~mm}$. The glass system shall meet the same requirements as described in Sect. 3.2.1.4. Wet layup or prepreg systems are acceptable. Resin systems with roomtemperature curing systems are acceptable and compatible with operation in a cryogenic and radioactive environment.

The Supplier shall present details of the insulation design, methods of application, and how he satisfies QA provisions given in this specification for review and approval by ITER. The Supplier shall be required to pass the acceptance tests on the insulation system as specified in Sect. 4.2.11.

\subsubsection{Quench detection and protection}

The CSI must be protected against excessive heat generation in the normal zone in the winding. Since current density in the conductor is very high, the appearance of the normal zone must be detected quickly. Discharge of the CSI must be accomplished quickly to prevent overheating above the allowable limit. The Design Description Document (DDD) and the ITER Model Coil program proved that the CS conductor can withstand the $2 \mathrm{~s}$ allocated for detection of the normal zone and $7.5 \mathrm{~s}$ for the energy dump onto the dump resistor. Quench detectors to protect the coil are installed in the JAEA Test Facility in Japan and are capable of providing reliable and fast detection of a coil quench. A Control system is installed in the Test Facility to ensure safe and reliable operation and to initiate discharge in case of a coil quench. The functionality of the instrumentation is responsibility of Japanese ITER Domestic Agency (JADA). 


\subsubsection{Physical Characteristics}

\subsubsection{Size}

The height of the CSI assembly with the feeders is about $4.5 \mathrm{~m}$, as shown in drawing 1010101-OR-0402. The height of the CSI module is $2.79 \mathrm{~m}$, the inner radius is $0.71 \mathrm{~m}$, and the outer radius is $0.76 \mathrm{~m}$. The winding pack height is nearly $0.5 \mathrm{~m}$. The support structure and the preload structure are $1.56 \mathrm{~m}$ in diameter.

\subsubsection{Weight}

The CSI assembly installed in the CSMC is estimated to weigh 8.1 ton.

\subsubsection{Reliability}

The CSI shall be designed to serve the test lifetime with $100 \%$ reliability without failures. The CSI shall not quench under any normal operation scenarios, but in some tests we will intentionally impose a normal zone in the CSI that will generate quench. The quench detection and protection system shall safely evacuate the energy from the system. The USIPO is responsible for developing and following a solid QA/QC program, which ensures a defect-free product that should not quench unexpectedly. JAEA will provide quench detection and protection system.

\subsubsection{Maintainability}

The CSI shall be maintenance free during the test. The CSI is designed to be removable from the CSMC. Reliability of the CSI and its component should be high enough to make such a failure extremely unlikely. There is no easy access to the CSI and its components once the cryostat is closed, and any repair will cause a down time. The USIPO is responsible for developing and implementing the QA/QC provisions to reach this goal.

\subsubsection{Environmental Conditions}

The CSI will operate in vacuum and at cryogenic temperatures. The finished CSI module shall not be cooled down or warmed up at a rate faster than $2 \mathrm{~K} /$ hour at any temperatures above $77 \mathrm{~K}$. Below $77 \mathrm{~K}$ the rate of cooling or warm-up is not limited.

During fabrication, the CSI shall withstand the seismic loads specified in document ${ }^{1}$. ITER will run a confirmatory analysis on the model before approval of the final design.

After heat treatment, the CSI modules and its components shall be protected from moisture and other adverse environmental elements.

During fabrication, the CSI shall be protected from foreign objects entering the winding, especially metallic parts (e.g., nails, paper clips, slivers, etc.). After heat treatment any work done on the coil conductor, coil components in their final (ready to assemble) conditions, or on coil insulation materials shall be carried out in a clean condition area.

The term CLEAN CONDITION refers to the working conditions and special measures which shall be applied to avoid contamination by conventional workshop contaminants such as oil, machine or finger grease, swarf, metal chips, dirt, atmospheric dusts, paint, etc. 
A CLEAN AREA is a separate building or annex or a closed room with tight-fitting doors and windows. A suitable area of the normal workshop space may be adapted, provided it is completely isolated from the rest of the workshop.

- Clean condition is defined at the industrial standard ISO 14644-1, JIS B 9920.

- Class $10^{6}$ : Density of floating particles $=10^{6} \times(0.1 / \mathrm{D})^{2.08} \mathrm{n} / \mathrm{m}^{3} \mathrm{D}$ : Diameter of particles in micrometers.

The following requirements shall be met.

(a) Environmental control of particulate contamination, temperature $\left(20^{\circ} \mathrm{C} \pm 10^{\circ} \mathrm{C}\right)$, humidity $(50 \% \pm 30 \%)$, air change, and filtering of the inlet air slightly over pressurized over the ambient pressure is required.

(b) A floor of fine-screened concrete or equivalent, which must be adequately painted or sealed.

(c) Adequate lighting for the type of process being carried out.

(d) Adequate heating, well guarded to reduce the risk of fire. Naked-flame heating is not acceptable.

(e) Specific controls for entrance and exit, clothes, and shoes control. All personnel to enter the clean area shall put on the lab coats and clean disposable overshoes and gloves to avoid foreign particles and substances.

(f) Disposable sticky mats to capture any loose particles are required and changed as required to prevent contamination of the clean area. Metallic components shall be inspected at entrance and removed in order to prevent an alien substance from entering a winding pack. Small metallic pieces such as staples in paper, small pins, small loose parts in components, etc., are not allowed in the clean room. When necessary, these materials shall be recorded and removed from the clean area when the work is done to document and prevent any unaccountable items from entering the winding pack and causing shorts or other damage.

\subsubsection{Workshop conditions}

Initial work on material - for example, storage and preparation for machining, forming, assembly, etc.may be carried out under normal workshop conditions, unless the contract technical specification states otherwise. When initial work is complete, transportable material shall be moved to the CLEAN AREA. Material, which is not easily moved - e.g., during the site insulation-shall have a CLEAN AREA created around it to preserve the established state of cleanliness.

In the CLEAN AREA the following conditions shall apply:

- Environmental

- Smoking and the storage, food and drinks shall not be permitted.

- The use of sulfur-bearing fluids and materials shall be strictly controlled to minimize the risk of corrosion in stainless steel and nickel-based alloys.

- Working Dress

- Normal working dress shall be clean laboratory-type white coat, suitable clean gloves and clean disposable overshoes or working shoes used in the clean area only. The conductor shall not be touched by bare hands.

- Tools and Equipment

- A minimum quantity of degreased and cleaned hand-tools and equipment shall be retained in the CLEAN AREA as part of its permanent equipment. All tools in the area shall be recorded and accounted for. 
- Overhead cranes shall have drip trays to prevent oil drips contaminating material being worked in the CLEAN AREA.

\subsubsection{Transportability and Handling}

The CSI will be transported to the JAEA, Naka, Japan site for final assembly and installation; therefore, all parts shall be designed and fabricated to withstand transport and handling without being damaged. The Supplier must design handling tools to ensure safe rigging of the CSI and its components in the shop, between the fabrication stations and sites, and for long-distance transportation.

Care should be taken to protect the parts from moisture, the environment, and mechanical damage. The terminals are especially vulnerable and must be protected at all times. For transport outside fabrication area facilities, the CSI conductors shall be filled with helium or dry nitrogen to 5 bars gauge pressure and shall have an attached dial indicator and a valve that is secured and protected from transportation loads. For overseas transportation, the CSI modules shall be shipped in a watertight crate with rigging provisions for safe transportation by a commercial shipping company. A shipping frame is required to support sensitive components such as instrumentation, terminations, etc.

\subsection{DESIGN AND CONSTRUCTION}

\subsubsection{Materials, Processes, and Parts}

\subsubsection{Fabrication sequence}

The sequence to be used for the CSI fabrication is the wind-react-transfer and insulate-epoxy impregnateassemble. This sequence was proven least risky for the ultimate performance of the CS magnet. This sequence is developed and verified due to high sensitivity of the $\mathrm{Nb}_{3} \mathrm{Sn}$ to stresses.

\subsubsection{Geometry and tolerances}

Dimensions of the CSI are provided on the CSI drawings and models given to the Supplier, listed in Sect. 2.1 of this document.

The CSI consists of one electrically independent module, arranged in a vertical support system. It is freestanding and supports all the magnetic loads through its structural elements: the conductor jacket, insulation, preload structure, and supports. The main loads are the magnetic hoop force, which creates hoop tension in the structural material, which creates vertical compression. The module is made as one single-layer coil.

Tables 9 and 10 list the tolerances required for the CSI and its components and assemblies.

Table 9 shows the size and tolerance of the CSI conductor, which is furnished to the Supplier, and nominal turn insulation thickness, applied by the Supplier. The radial and axial allowances for insulation are given to simplify fitting the turns into the winding pack envelope and shall be used by the Supplier as necessary to meet the dimensional requirements.

Table 10 shows the maximum acceptable tolerances for the CSI winding pack of the CSI assembly. The tolerances are given for the spatial dimensions of the winding pack and for the location of the centerline. 
These tolerances are governed by two sets of requirements - error field and manufacturing stack-up study. The absolute radial and axial dimensions of the winding pack are constrained by the interfaces with the CSMC system.

Table 9. Manufacturing size and tolerances for the CSI conductor

\begin{tabular}{ll}
\hline & \multicolumn{1}{c}{$(\mathbf{m m})$} \\
\hline Conduit size & $49.0 \pm 0.2$ \\
Cable space diameter & 32.6 \\
Turn insulation thickness & 1.0 \\
Additional insulation allowance $(\mathrm{R})$ & $0.0-0.5$ \\
Additional insulation allowance $(\mathrm{Z})$ & $0.0-1.0$ \\
\hline
\end{tabular}

Table 10. Manufacturing size and tolerances for the CSI coil winding pack

\begin{tabular}{lll}
\hline \multicolumn{1}{c}{ Dimension } & \multicolumn{1}{c}{ Value } & \multicolumn{1}{c}{ Notes } \\
\hline Winding mean radius: Arc & $0.76(\mathrm{~m})$ \\
Winding pack radial thickness: dR & $0.06(\mathrm{~m}) ?$ \\
Winding height: $\mathrm{dZ}$ & $2.80(\mathrm{~m})$ from flange to flange & 4.48 with terminal leads \\
Radial tolerance on the coil envelope & $0,+6.0(\mathrm{~mm})$ \\
Axial tolerance on the coil envelope $_{\text {dRp radial }^{a}}$ & $0,+4.0(\mathrm{~mm})$ \\
dRp axial $^{a}$ & $\pm 2.0(\mathrm{~mm})$ \\
\hline
\end{tabular}

${ }^{a} \mathrm{dRp}$ : Coil centerline location in circular as determined by mean of $\mathrm{dR}$ and $\mathrm{dZ}$ at any section

\subsubsection{Conductor handling}

The conductor required for fabrication of the modules, qualification, and process development and verification will be furnished to the Supplier. The superconductor after heat treatment is brittle intermetallic $\mathrm{Nb}_{3} \mathrm{Sn}$ and needs special care during handling. No impact loads are allowed on the heattreated conduit at any time. Before heat treatment, the conductor needs to be handled with care as well. The minimum-bending radius of conductor shall be $0.5 \mathrm{~m}$.

When stripping the sheath from the cable, all precautions shall be taken to avoid any damage to the strands. Qualification of all fabrication processes with exposed cable is required, and photographs of the cable proving no damage shall be included in the QA records.

During welding of the inlets, outlets, joint parts, and other specified parts, only the established qualified procedure shall be used to avoid overheating the strands above the specified temperature (normally $210^{\circ} \mathrm{C}$ if welding is performed before heat treatment and $500^{\circ} \mathrm{C}$ if the welding is performed after heat treatment).

After winding the conductor into the coils and preparation for the heat treatment, the coils will be heat treated in a vacuum (or inert-gas-filled) furnace to form the $\mathrm{Nb}_{3} \mathrm{Sn}$ superconductor.

After heat treatment, $\mathrm{Nb}_{3} \mathrm{Sn}$ must be handled with great care. No impacts on the heat-treated conductor and no strain more than $\pm 0.2 \%$ on the cable are allowed during the rest of the manufacturing. The turns shall not be split more than $0.25 \mathrm{~m}$ apart to avoid damage. 


\subsubsection{Terminations and joints}

The CSI joints are required to provide a reasonably uniform current distribution at low DC and AC losses. The CSI joints are designed to generate low amount of heat ( $6 \mathrm{~W}$ or less per joint at peak current) and prevent strong nonuniformity in current distribution, which could reduce the temperature margin.

The CSI has one kind of joint: joints between the extension buses and the utility buses at the CSMC Test Facility, or so-called terminal joints. Their locations are shown in drawing 1010101-OR-0419. This is a lap joint design, which was developed and verified by ITER R\&D efforts.

\subsubsection{CSI support and preload structure}

The CSI support structure consists of two centering flanges, bottom-mounting studs, 16 tie-rods, 63 pushing bolts, and four upper supports bumpers. The CSI coil must be pre-compressed to $230 \mathrm{MPa}$ at operating temperature before charging. Design of this components and assembly is given in drawing 1010101-OR-0406. The requirements for performance and testing of the CSI support and preload structure components are given in Sect. A.5.

\subsubsection{Final assembly and installation on site}

The CSI will be assembled at the chosen Supplier facility under USIPO technical supervision in accordance with the CSI assembly plan developed by the Supplier and reviewed and approved by USIPO responsible officer. The assembly procedure shall ensure that the requirements of CSI alignment, preload, leak tightness, structural integrity, and electrical strength are met in accordance with the acceptance criteria given in Sect. 4.2.11. Installation on site of the CSMC Test facility will be done by the separate vendor and is outside of the scope of this specification.

\subsection{SPECIAL TOOLS REQUIREMENTS}

Fabrication of the CSI will require special tools. Most of the tools that were developed and used in the ITER Model Coil programs were saved and have been reconditioned for the use in CSI project. Still, design and fabrication of some tools may be required by the Supplier or its subcontractors. The final reports on the CSMC will be provided to the Supplier. The final report on the toroidal field (TF) Model Coil is available upon request. The following list of the tooling is preliminary. The requirements are also preliminary and will be clarified during the tooling design phase.

\subsubsection{Conductor Spools}

The conductor length of about $50 \mathrm{~m}$ has a mass of about $0.85 \mathrm{t}$. Spools shall support the weight of the conductor during transport and handling. The Supplier shall design and procure the spools that will be used to deliver the conductor from the Conductor supplier site at the appropriate time. There are no firm constraints on the spools, but transporting of spools larger than $4 \mathrm{~m}$ in diameter may be difficult and expensive. Therefore, final design of the spools will be derived from the trade-off studies from the manufacturing plan. 


\subsubsection{Winder}

The winder is one of the key tooling items critical to the success of the project. Winding of the $50 \mathrm{~m}$ coil will be achieved on the six-roller winding machine; Fig. 10 shows the components of the Winding Machine before shipment to Tennessee.

The calibration results should be used to achieve a $1427 \mathrm{~mm}$ ID. The CS and CSI Winding Trials report ${ }^{7}$ will be provided to the Supplier. The "pay off" and "take up" structures, mounted on two forklift machines, will be used for holding the formed coils. The pay-off and take-up mechanisms will be designed and built before winding. Wood crates should be used for formed conductors.

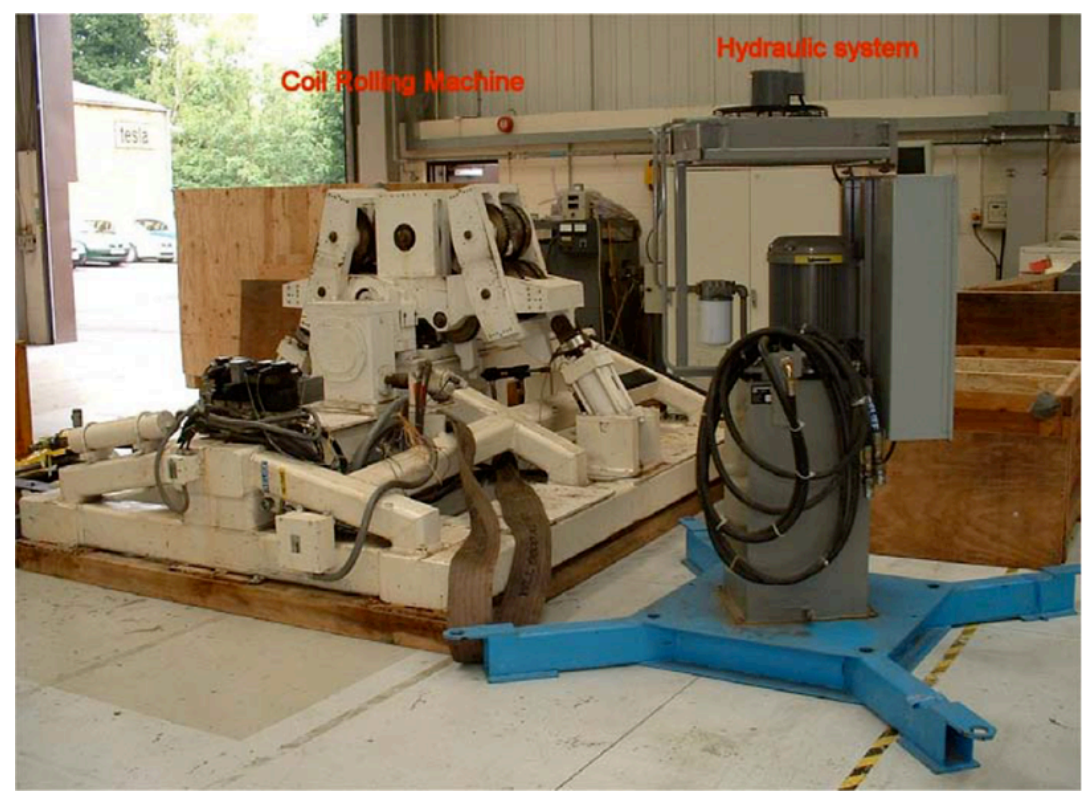

Fig. 10. Coil rolling machine and hydraulic system.

The preliminary fabrication plan includes the following operations, as shown in the CSI Coil Fabrication Plan $^{8}$ :
a. taking the conductor from the "pay-off" spool
b. forming the conductor to the appropriate radius of curvature, corresponding to the required radius of the corresponding turn in the coil
c. laying the formed piece of the conductor onto the "take-up" spool at the required location and securing it

\subsubsection{Lead Formation and Conductor Bending Tools}

The lead forming process will start with straightening both ends of the conductor. The conductor will be straightened by using the three-point hydraulic bending tool shown in Fig. 11. The process will be controlled manually, and the conductor turns will be straightened by trial and error until they meet the process requirements for straightness.

After straightening, a $90^{\circ}$ bend will be formed in each straight section to make a $500 \mathrm{~mm}$ internal transitional radius from the circumferential to the vertical direction using a hydraulic tool, shown in 
Fig. 12, which bends the conductor around a die. This process will also be controlled manually, and the final position will be determined by trial and error by using templates. The bending process will align the end of the conductor approximately parallel to the coil axis (Fig. 13).

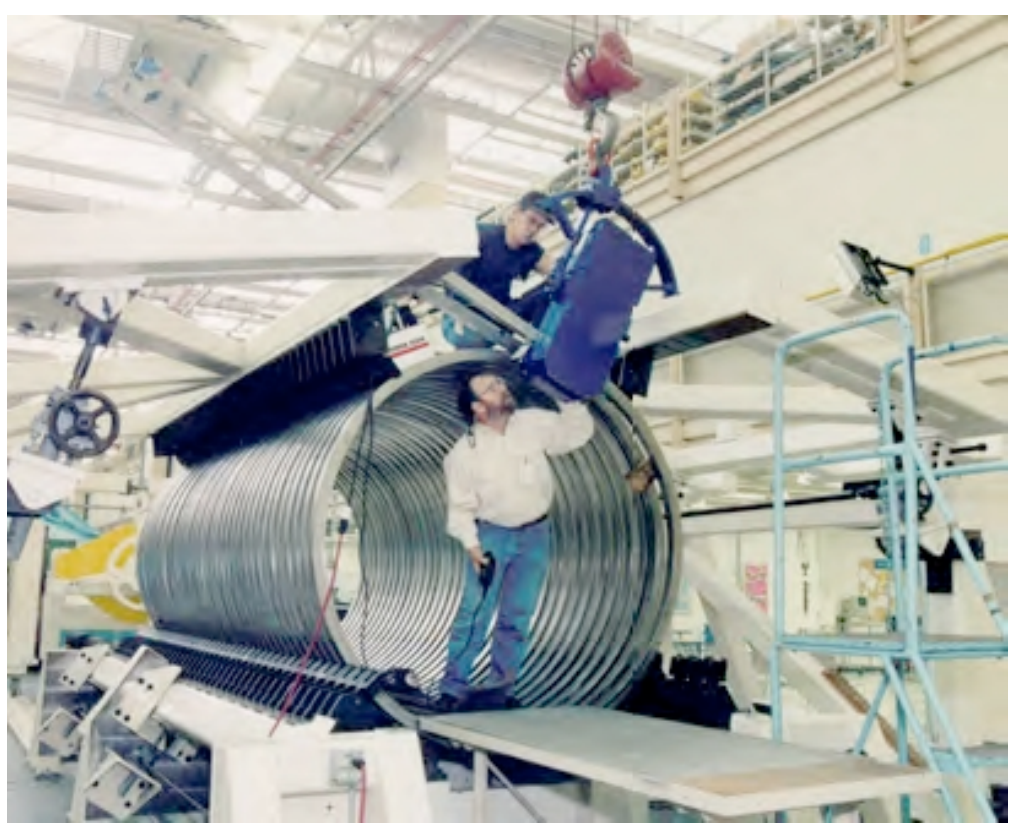

Fig. 11. Three-point bender used to straighten the rolled conductor.

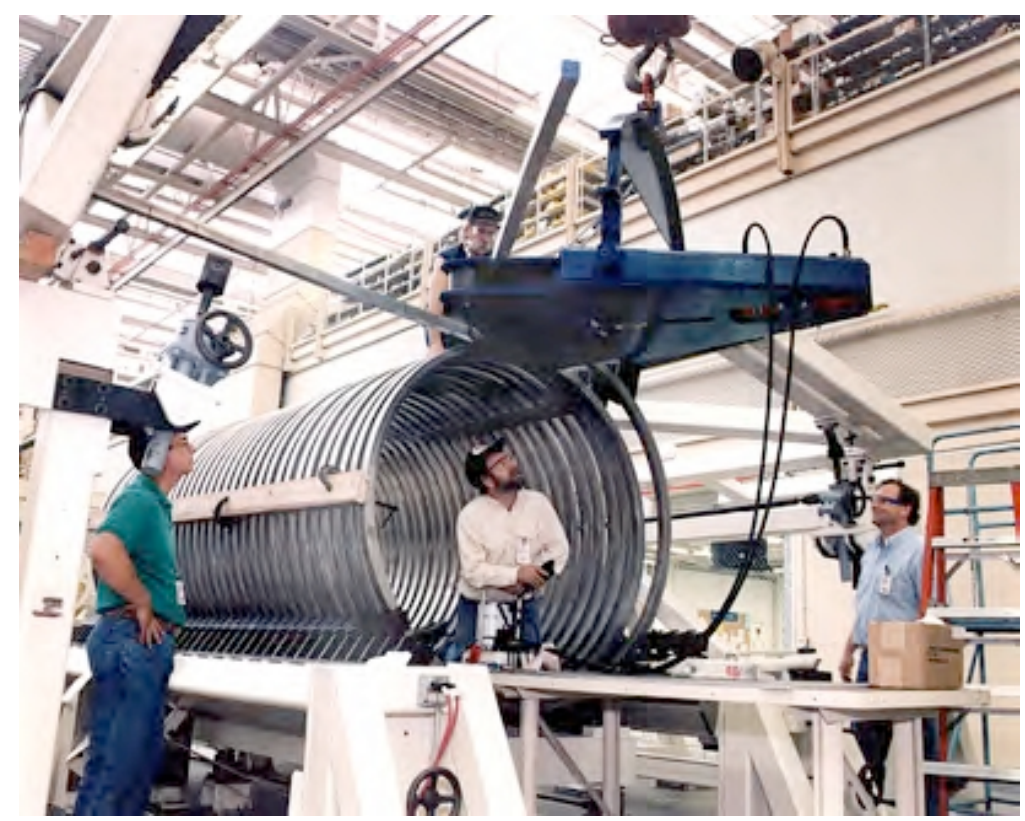

Fig. 12. $90^{\circ}$ hydraulic bend tool. 


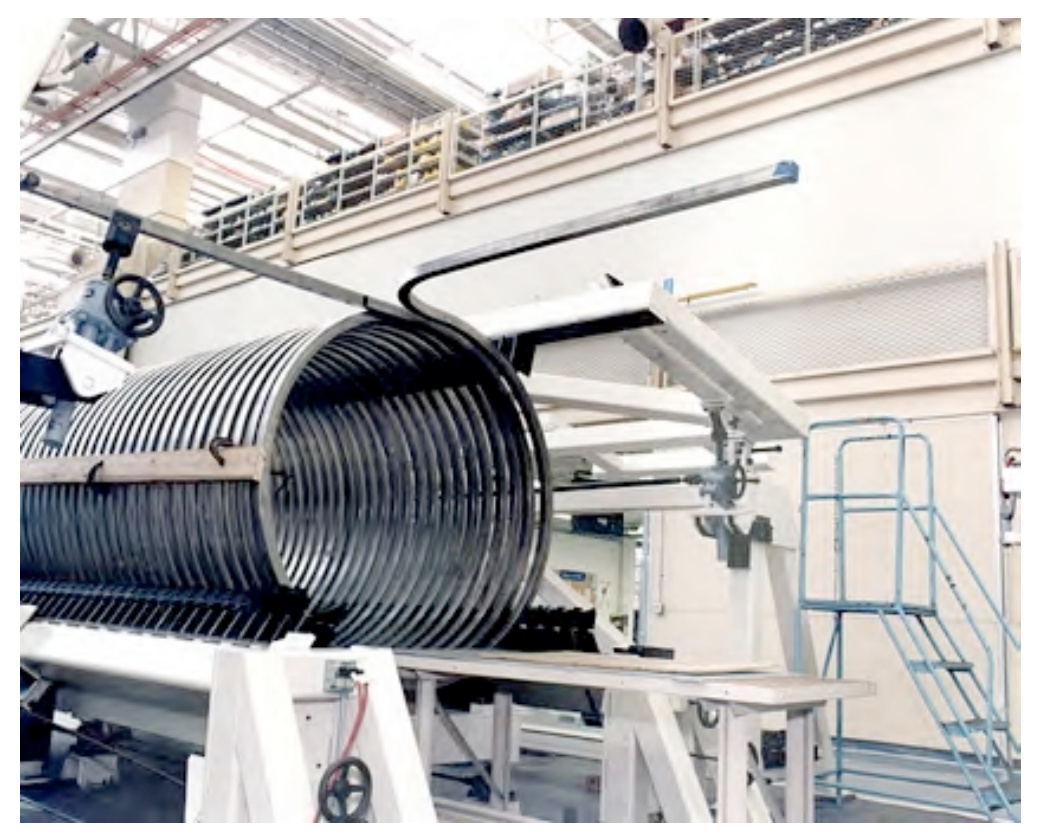

Fig. 13. Straightened and $90^{\circ}$ bent leads.

After the $90^{\circ}$ bending operation, each of the coil ends will be reformed so that the outside surface of the conductor in the lead $90^{\circ}$ bend area is coincident with the cylindrical surface of the coil and tangent to the coil diameter. This will be achieved by using a commercial hydraulic torque wrench and a small reaction frame, as shown in Fig. 14, allowing the twisting of the conductor at any location, and by using the threepoint bender that was used initially to straighten the conductor (Fig. 11).

The formed lead geometry will be inspected using a three-dimensional plywood inspection template, as shown in Fig. 15.

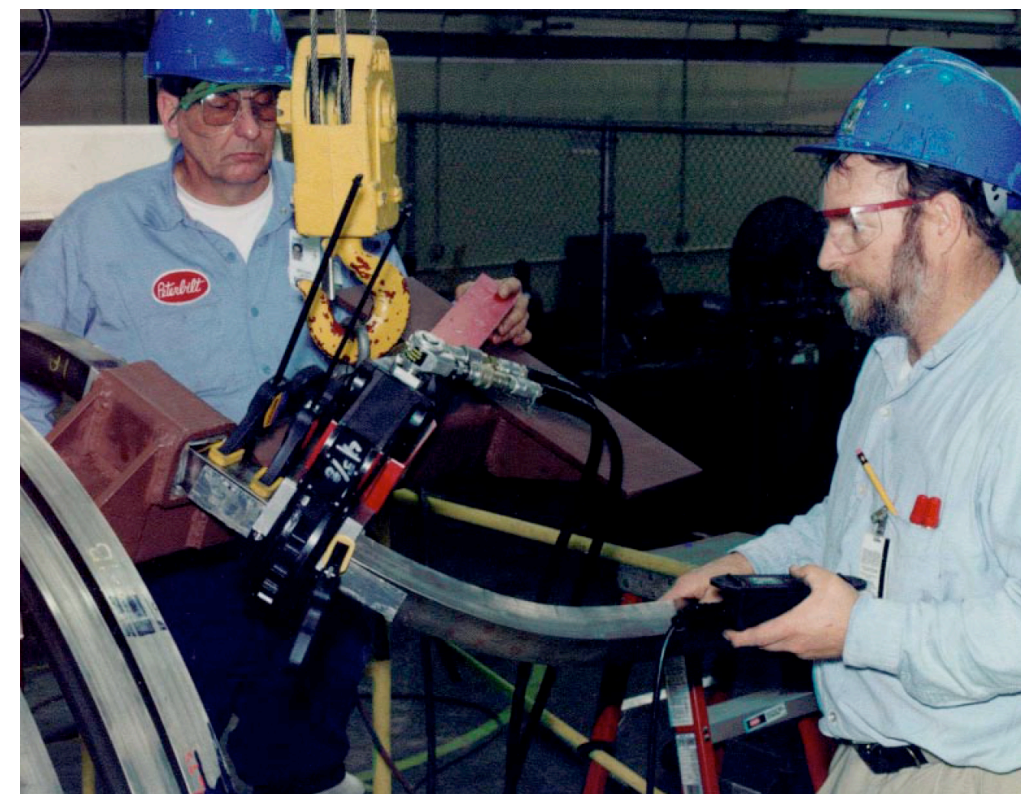

Fig. 14. Twisting tool used to form the lead. 


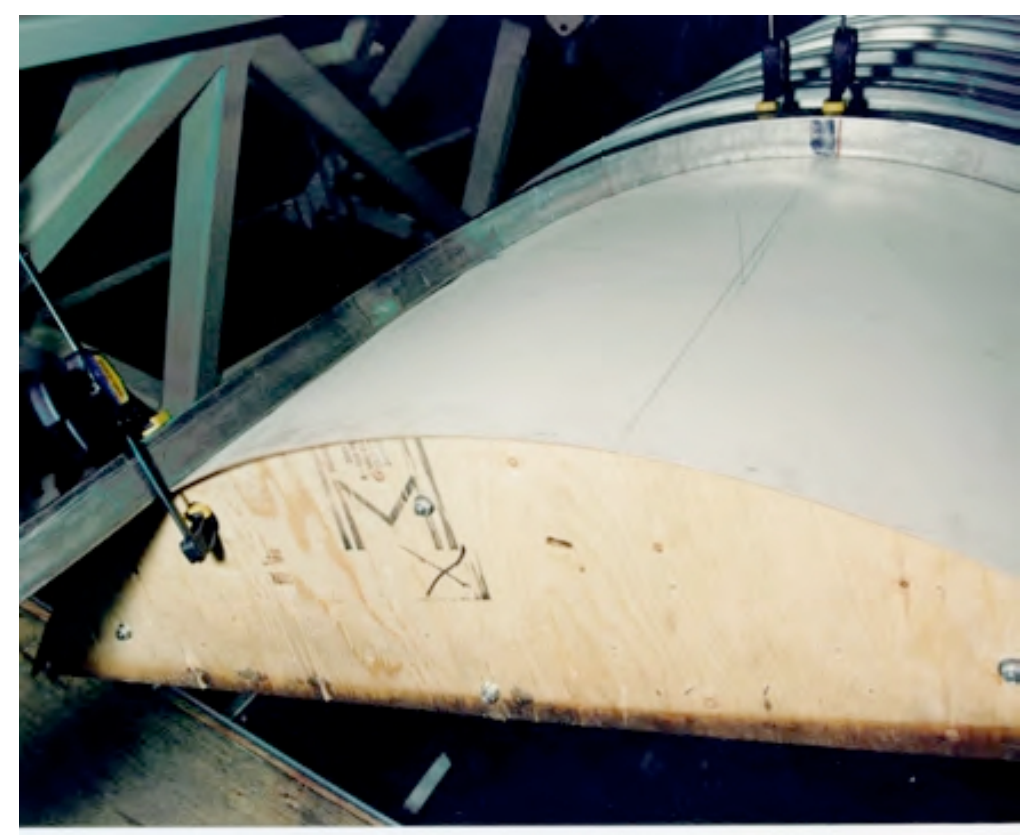

Fig. 15. Lead check template.

\subsubsection{Reinforcing with the Tension Link}

The tension link ("the spur") will be welded to the conductor in the area of the lead bends (Fig. 16). A piece of the jacket will be used for the spurs. A welding qualification process will be conducted in accordance with Sect. IX of the ASME BPVC ${ }^{2}$ to determine the welding parameters and to qualify the welder. Special tooling may be necessary to position and align links relative to the lead bend area of the conductor. The lead geometry will be inspected and corrected for any weld distortion, if necessary. The conductor will be cooled at a rate of $\sim 15 \mathrm{ft}^{3} / \mathrm{min}$, established during CSMC fabrication, which is sufficient to keep the cable at temperatures below $230^{\circ} \mathrm{C}$.

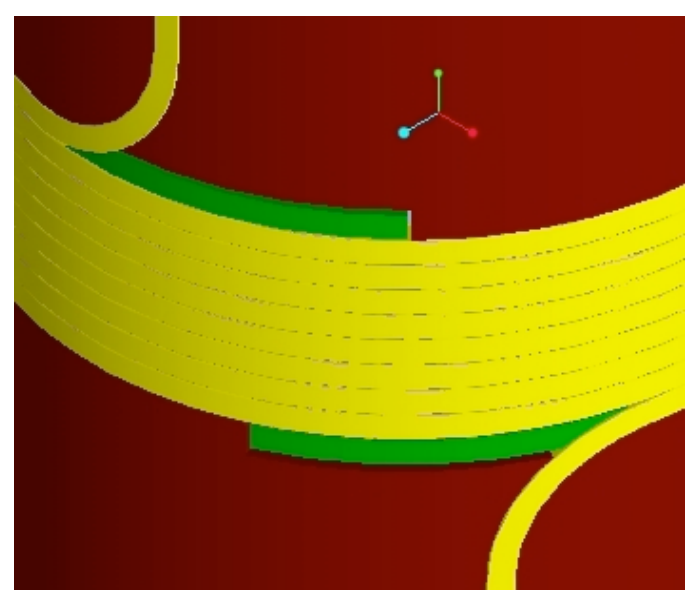

Fig. 16. Tension link configuration (spur). 


\subsubsection{Conduit Machining Tools}

In preparation for the installation and welding of the electrical terminals, the jacket will be removed at both ends. A conduit-machining tool (lathe) is required for stripping the conduit and machining it for welding with the other parts near the terminations. This type of portable tube lathe by Tri Tool, Inc. is mounted on the conduit as a base. A cutter then runs around the axis of the conduit as shown in Fig. 17 to machine to the required cylindrical/conical shape.

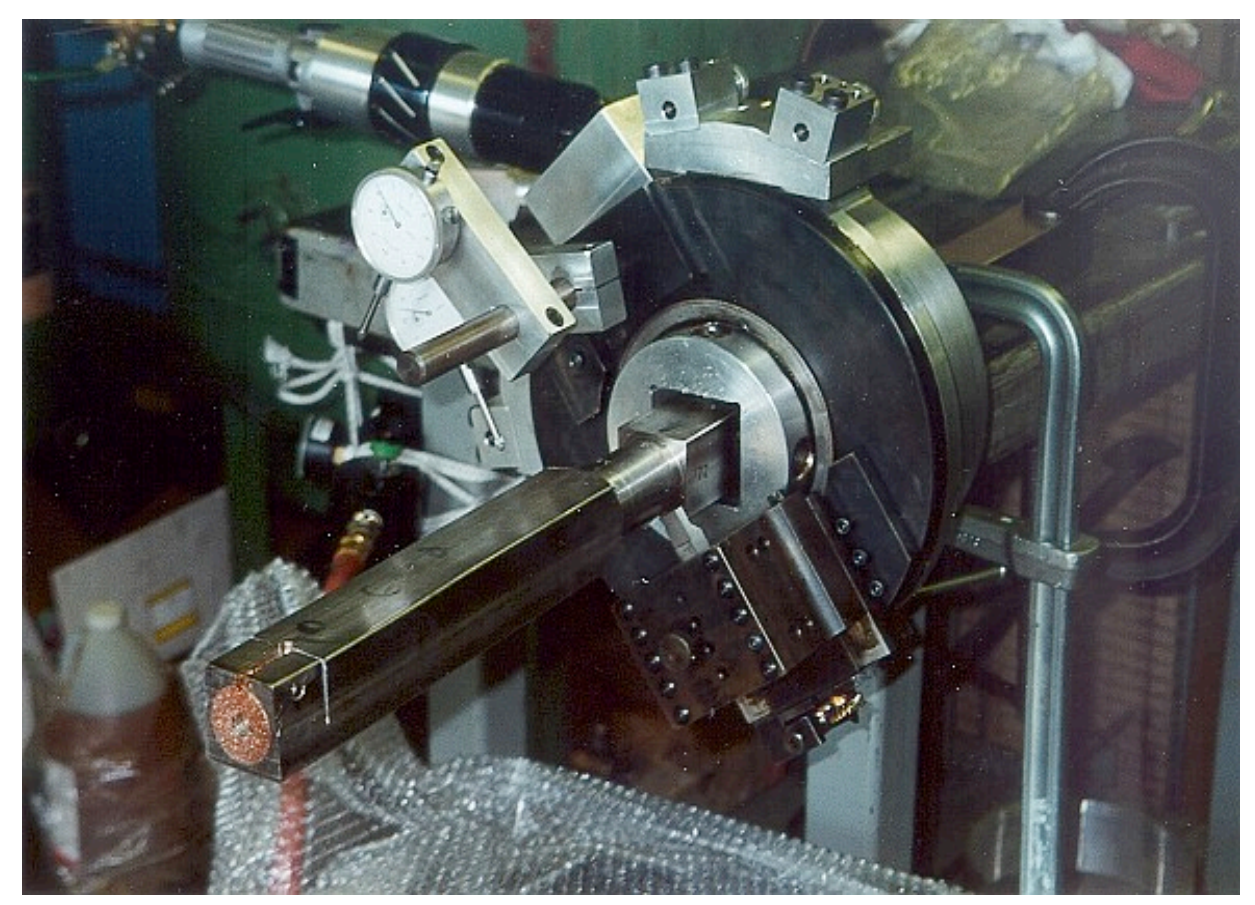

Fig. 17. Portable pipe lathe by Tri Tool.

A longitudinal cutting tool for the conduit splitting is the Climax Portable Machine Tools, Inc., portable mill (Fig. 18), which can cut precise longitudinal grooves in the conduit. The depth of the conduit shall be controlled by an ultrasonic sensor, allowing precise measurement of the remaining depth of the cut. The last break of the metal shall be done by a chisel, which eliminates any risk of cable damage. 


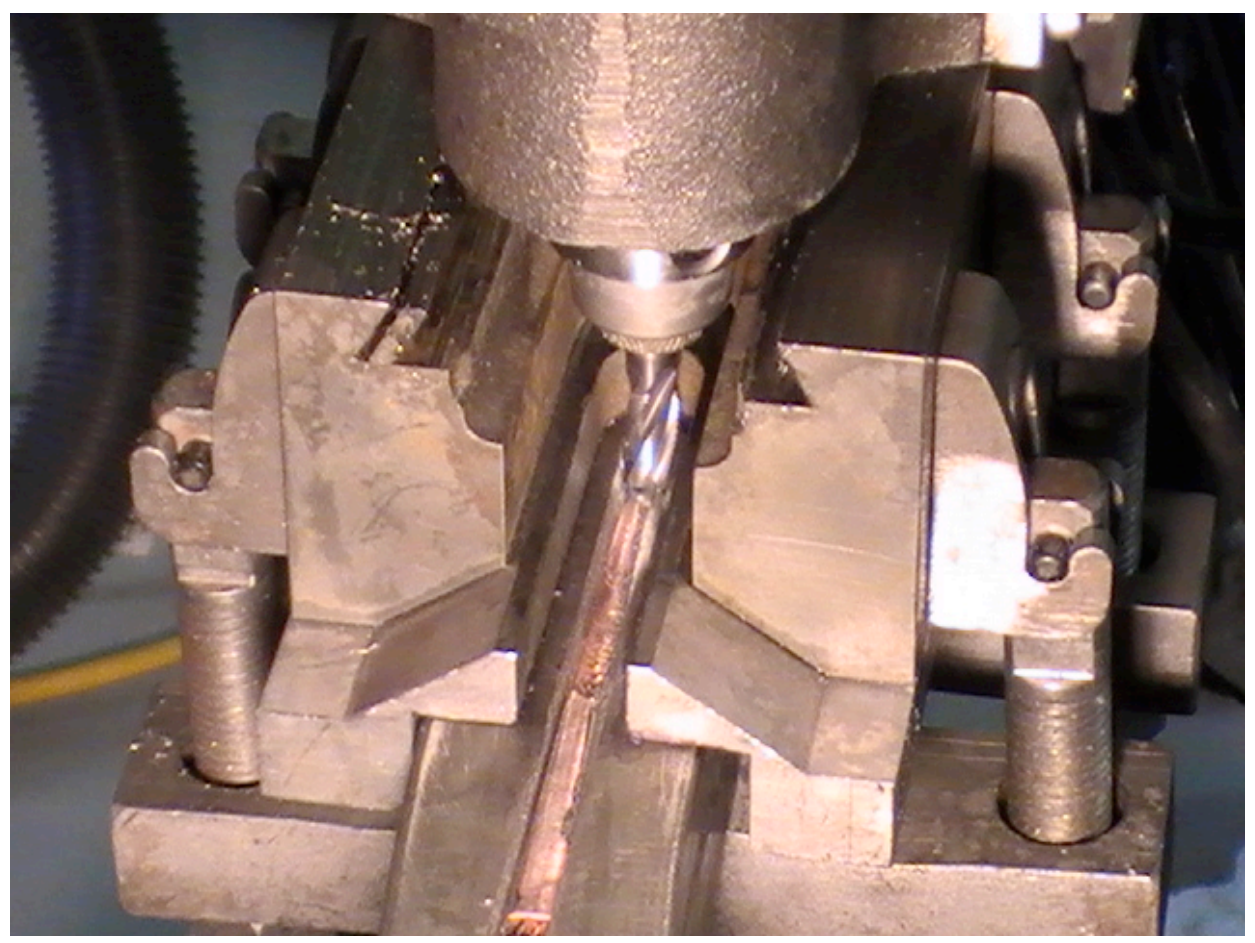

Fig. 18. Longitudinal machining by a portable mill/cutter.

\subsubsection{Compaction Tool for Lap Joint}

Custom Crimp CC30 - a 155 ton compaction machine as shown in Fig. 19 -will be used to perform the compaction of the copper part of the electric terminal around the cable in accordance with the drawing specification, drawing 1010101-OR-0410, to achieve the required $20 \%$ void fraction in the conductor. This type of compaction tool was used by the JADA during the CSMC project. Test results will be used to achieve the required diameters and surface quality.

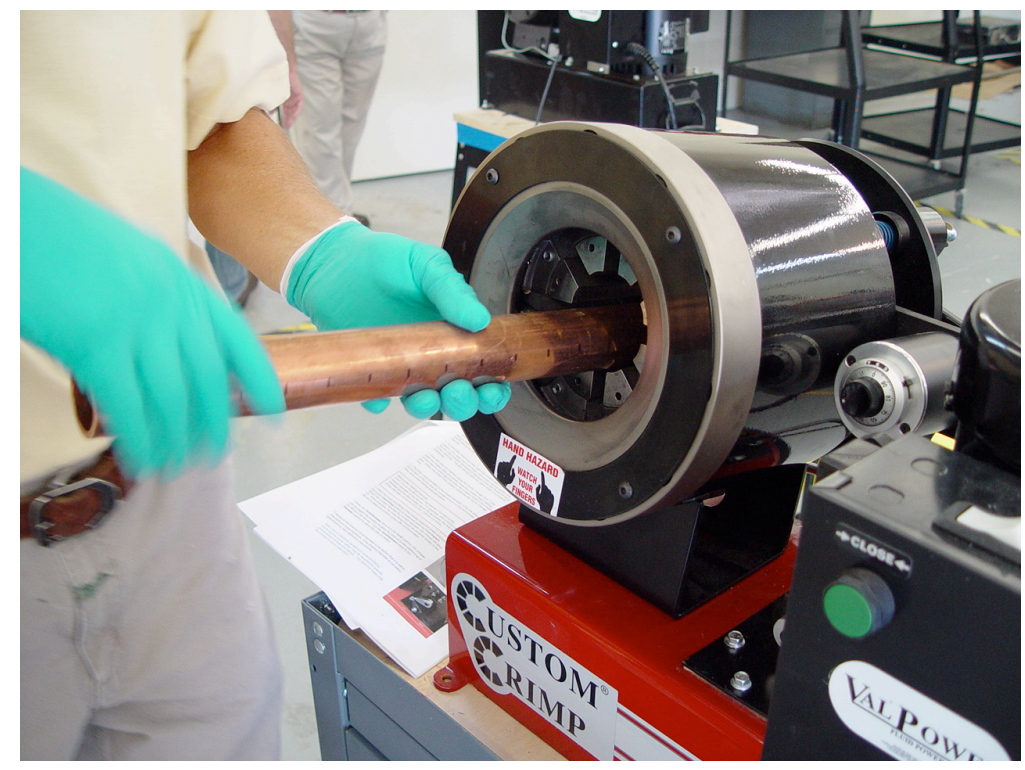

Fig. 19. Custom Crimp CC30-a 155-ton compaction machine. 


\subsubsection{Heat Treatment Furnace}

$\mathrm{The} \mathrm{Nb}_{3} \mathrm{Sn}$ superconductor is created in the heat treatment process. To carry out the heat treatment, a furnace is required.

The schematic of the furnace setup is shown in Fig. 20. The furnace needs to house the whole module, depending on the trade-off study of cost and schedule impact by Supplier.

The following are the requirements for the furnace.

- The furnace shall allow maintaining a vacuum down to $10 \mathrm{mPa}$ at all temperatures up to $700^{\circ} \mathrm{C}$.

- There should be a provision in the furnace to supply a purge gas (argon or helium) through the cable space; flow shall be controlled from the outside the furnace.

- There should be a provision to monitor the oxygen levels in the gas flow with a sensitivity of better than $0.1 \mathrm{ppm}$ and water vapor levels in the purge gas with a sensitivity of better than $0.1 \mathrm{ppm}$ and a level of organics better than $0.1 \mathrm{ppm}$.

- Furnace shall control the temperature within $\pm 5^{\circ} \mathrm{C}$ at more than $400^{\circ} \mathrm{C}$ at the flat top.

- Uniformity of temperature in space occupied during ramping temperature: $\pm 20^{\circ} \mathrm{C}$.

- The furnace shall be able to ramp the temperature up and down at a rate up to $60 \mathrm{~K} / \mathrm{hr}$.

- All pipe connections should either be welded or use CAJON VCR-type connectors. If diffusion pumps are used, cold traps for oil on the suction side are required.

- More than 18 temperature-measuring points evenly spread over the heat-treated object are required, covering all extreme points, which would guarantee that all of the conductor volume went through the desired temperature schedule.

- Control system for ambient and purging gas conditions shall include as a minimum flow meters, vacuum gauges, thermometers, oxygen monitors, water vapor monitors, a helium leak detector, and a mass spectrometer gas analyzer.

- Auxiliary equipment required: vacuum pumps, inert gas supply.

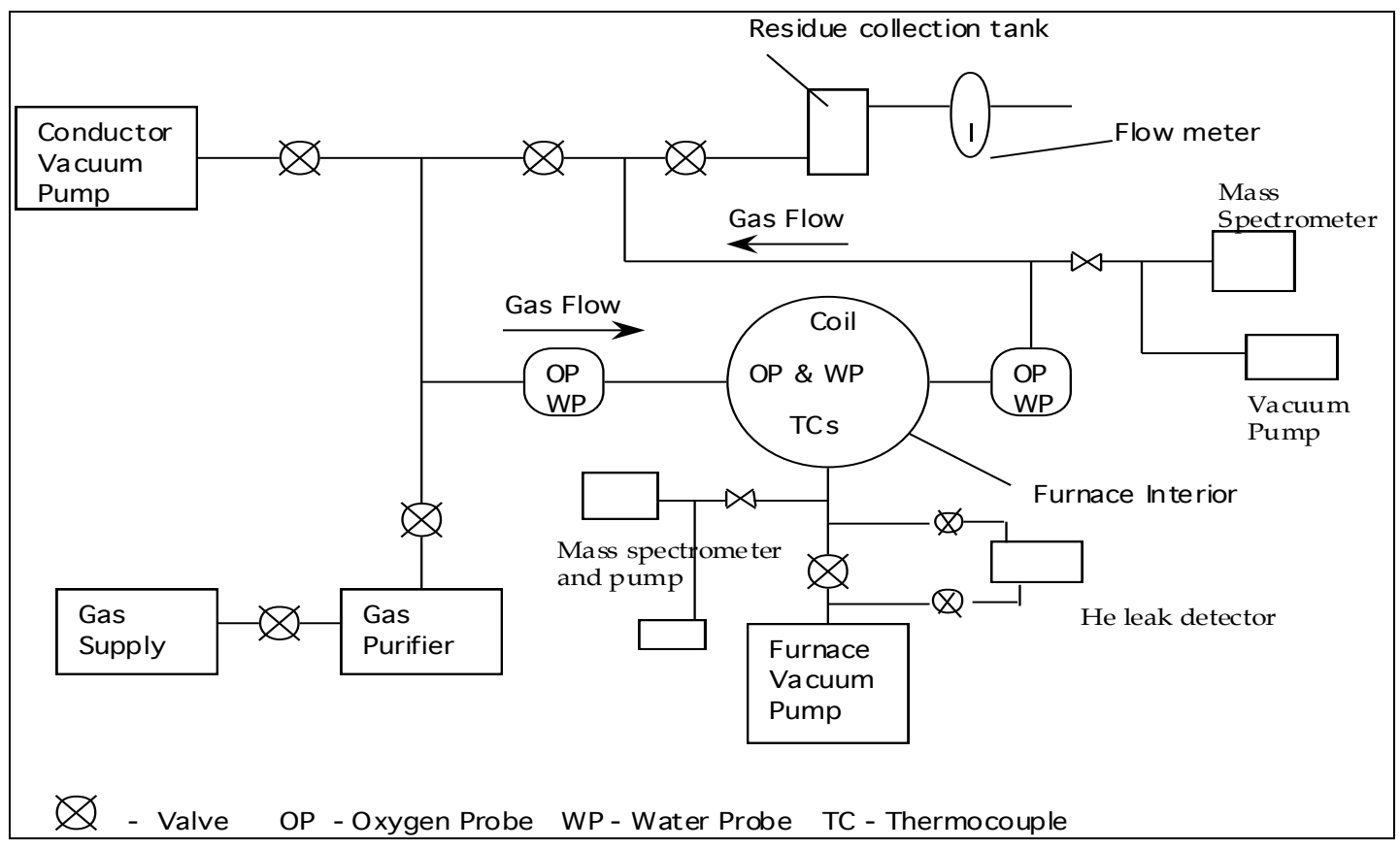

Fig. 20. Schematic of the heat treatment furnace and auxiliary equipment 


\subsubsection{Coil Insulation Station}

The coil will be sent to a vendor who will insulate and assemble the coil after heat treatment/reaction. This station needs to be built in order to provide an access in between the stretched turns.

\subsubsection{Coil Assembly Station}

After turn insulation application, the coil is assembled, the module terminals are made, and ground insulation is applied. The VPI mold will then be built around the CSI in preparation for the VPI process. This station needs to allow these operations.

\subsubsection{VPI Mold, Vacuum, Heating, and Resin Transfer Equipment}

A sheet metal mold shall be installed around the CSI module to allow the VPI. The mold shall be reinforced to withstand the hydrostatic pressure of the resin with acceptably low deflections. It shall withstand an overpressure of 0.5 bar and a vacuum down to $0.01 \mathrm{~Pa}$ and shall be leak tight at a sensitivity better than $10^{-7} \mathrm{~Pa}^{*} \mathrm{~m}^{3} / \mathrm{s}$ from room temperature to $200^{\circ} \mathrm{C}$ at a specified range of pressures.

If we use additional pressure to collapse the bubbles in the epoxy, the inner surface of the mold will require a support against the gravity of the epoxy and the positive pressure. This support to the walls will come from the inside by a bucking post made of mild steel. The gap between the bucking post and the mold will be filled by a compacted substance (such as sand or glass beads).

The equipment for resin outgassing, mixing, and transfer to the mold shall be present. The heating system shall allow the temperature in the mold and the components to be measured and controlled. The VPI tool shall have the instrumentation to monitor and control amount of resin volume transferred to the mold and level of epoxy in the mold, temperature distribution in the mold, and vacuum.

The CSMC program demonstrated that both approaches-batch resin transfer and the continuous resin transfer molded processes - could be made to work successfully. The CSMC documentation about VPI tooling and process is available upon request.

The schematic of the VPI vacuum system and photos of the mixing and controls station and resin supply used for the U.S. CSMC module impregnation are shown in Figs. 21-23. Similar system will be designed and developed. 


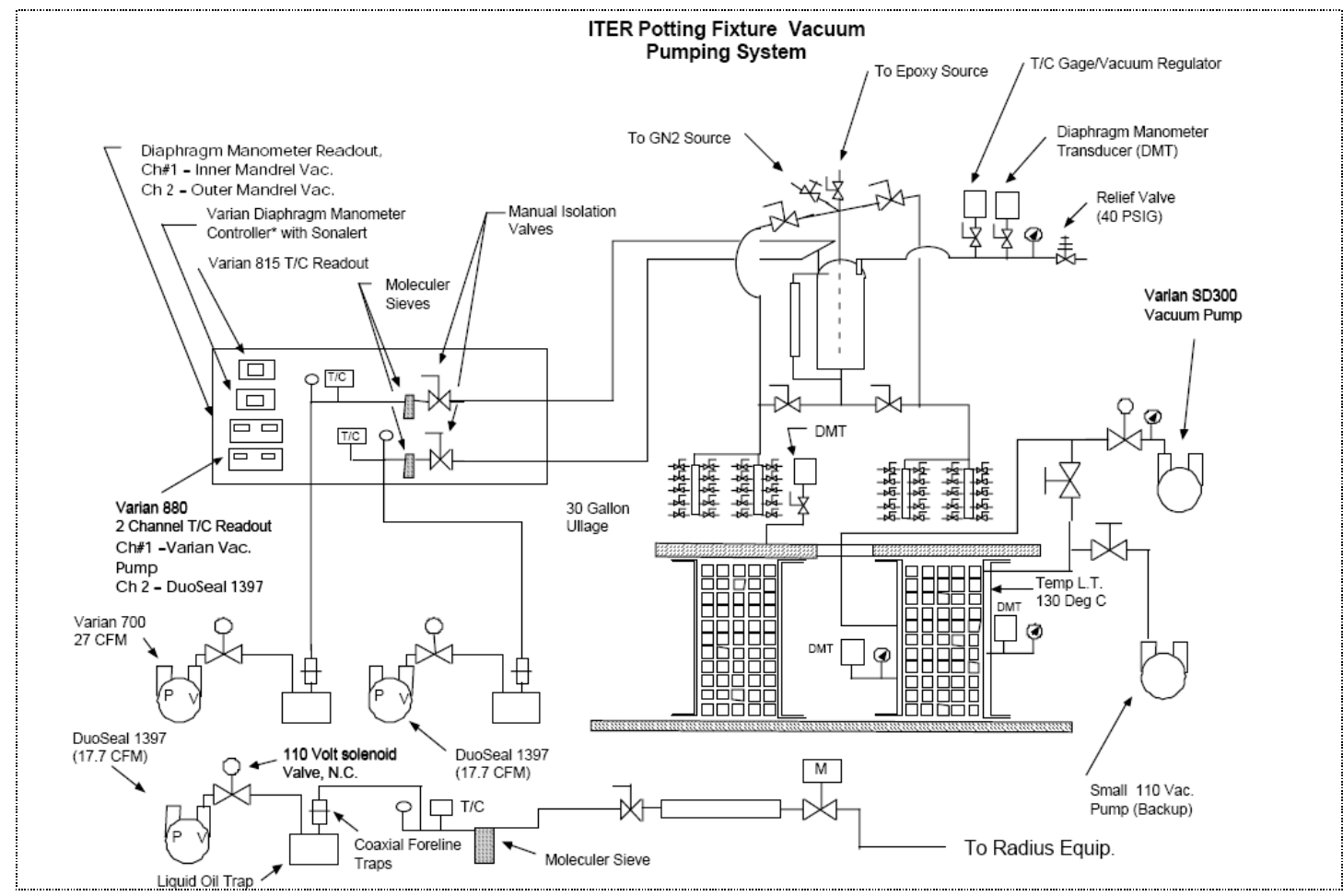

Fig. 21. VPI vacuum system schematic.

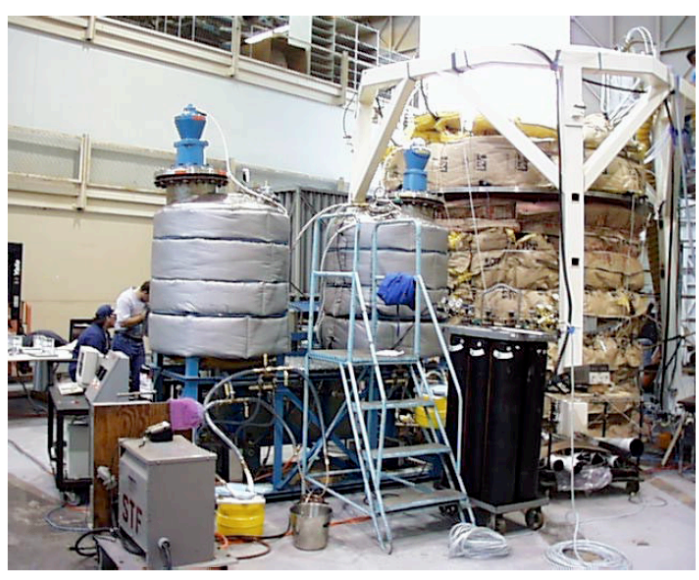

(a) Mixing System With Two Tanks

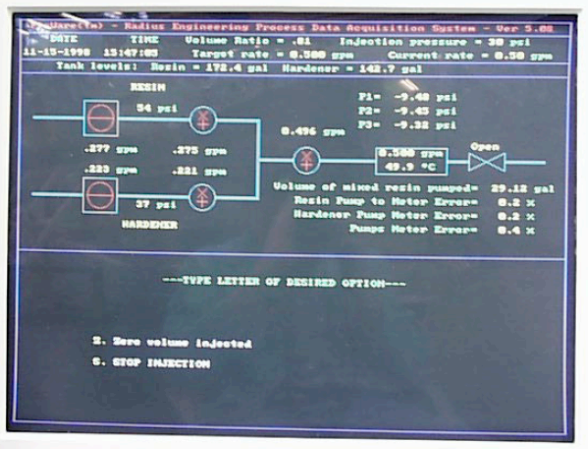

(b) Mixing System Control Screen

Fig. 22. VPI resin mixing tool and control system. 


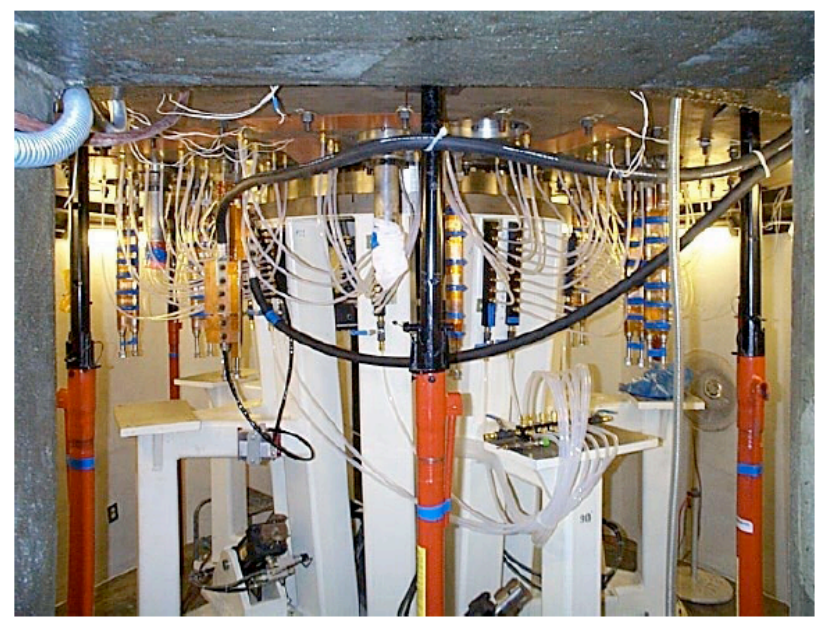

(a) VPI Supply Tubing Under Magnet

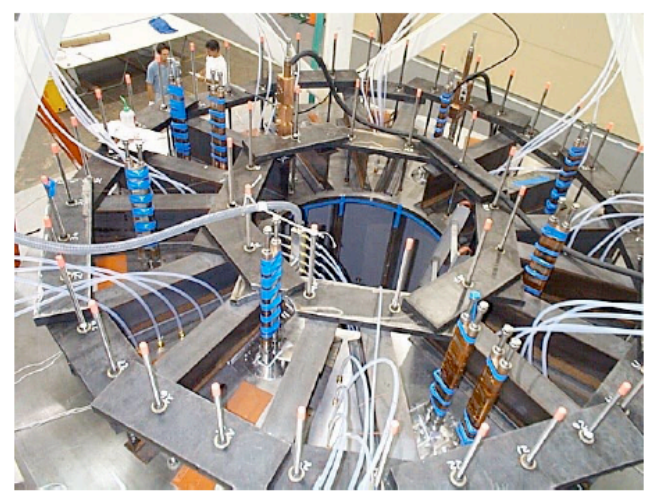

(b) VPI Resin Exit Tubing on Top of Magnet

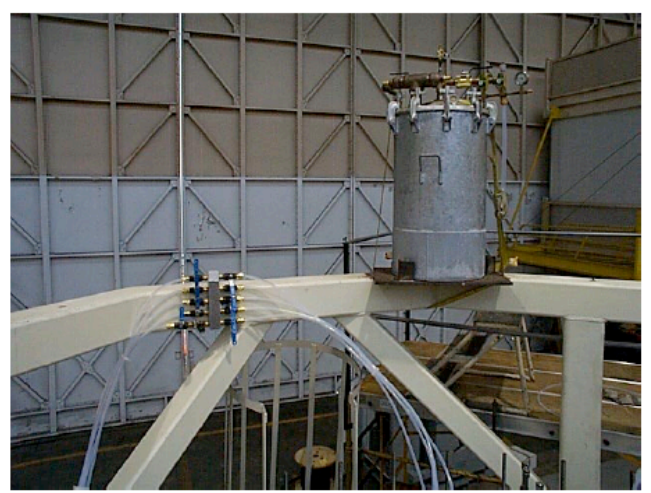

(c) VPI Vacuum Tank Above Magnet

Fig. 23. VPI resin supply and exit plumbing.

\subsubsection{CSI Assembly Station}

Final stack up, assembly, and preloading of the CSI will take place in the United States at a Supplier site. After developing the Manufacturing and QA tests plan, the Supplier will design, procure, and deliver all special tools required for these operations and will specify the generic equipment and personnel requirements. These tools include but are not limited to preloading equipment, special instrumentation for preloading, etc. The basic facility and lifting equipment will be available on Supplier site. Supplier will also provide the qualified personnel for the assembly and installation.

\subsection{SPECIAL PROCESSES REQUIREMENTS}

Some critical processes developed in the ITER R\&D effort are given as process specifications since they were proven to work adequately and there is no intention to require the Supplier to redevelop and verify these critical processes for economic and scheduling reasons, although some minor modifications to improve the proposed specifications are acceptable. The Supplier will prepare detailed manufacturing procedures based on these preliminary specifications in this section. The specifications will be approved by the Company, and updated specifications shall be submitted to USIPO by the Supplier. 
These critical processes are winding, lap joint fabrication, heat treatment, and VPI processes.

\subsubsection{Winding, Forming of Leads and Inspections}

Winding operation shall verify the settings of the winder for achieving the desired radius of curvature in the coil and formation of the leads by using separate lead forming tools. The following inspection and tests are required (Table 11).

Table 11. Inspections and tests during coil winding

\begin{tabular}{lll}
\hline Operation & \multicolumn{1}{c}{ Inspections and tests } & \multicolumn{1}{c}{ Acceptance criteria } \\
\hline Winding & Cleanliness of conductor from the pay-off spool & $\begin{array}{l}\text { No surface defects, no dirt or oil on the CICC } \\
\text { surface. }\end{array}$ \\
Winding & $\begin{array}{l}\text { Surface roughness } \\
\text { Cimensional check during winding, insertion of shims }\end{array}$ & $\begin{array}{l}\text { Compliance with the specs, even coverage } \\
\text { Compliance with drawings }\end{array}$ \\
Winding & $\begin{array}{l}\text { as required } \\
\text { Lead bending }\end{array}$ & Compliance with drawings \\
\hline
\end{tabular}

\subsubsection{Lap Joint Fabrication}

Lap joint fabrication procedures are described as follows.

\subsubsection{Termination fabrication}

The joint layout is based on a shaking-hand-type lap joint configuration, as shown in drawing IM73173000101.pdf. A concept of the joint was developed in the CS Model Coil project ${ }^{16}$.

Approximately a $0.5 \mathrm{~m}$ length of the conduit is removed from the end of the conductor as a precursor to conductor termination, exposing the cable. The overall cable wrap is removed from the conductor along the length of the termination, while the individual subcable wraps are removed only at the outer surface of the cable. The original cable structure is preserved by using stainless steel band clamps at every $\sim 5 \mathrm{~cm}$ spacing along the length of the cable. Chrome removal from the surfaces of the cable strands is accomplished by the procedure available from the report ${ }^{14}$.

A terminal sleeve consisting of a one-piece copper tube (CDA102), a stainless steel (SS316L) base piece, and a stainless steel (SS316L) end cap is prepared by fluxless, hydrogen atmosphere furnace brazing the components together using a gold/nickel brazing alloy (BAU-4 per ASME SFA5.8, solidus/liquidus$\left.950^{\circ} \mathrm{C}\right)$. The terminal assembly drawing is shown in Fig. 24.

The brazing is done in a vacuum furnace with hydrogen reduction gas flow at

- $\quad 857 \mathrm{C}-885^{\circ} \mathrm{C}$ for $15-25$ minutes

- $\quad 994 \mathrm{C}-1010^{\circ} \mathrm{C}$ for 10 minutes

- Vacuum cooled to below $870^{\circ} \mathrm{C}$

- Nitrogen cooled to below $65^{\circ} \mathrm{C}$

- helium leak checked at a rate below $10^{-8}$ Torr* $1 / \mathrm{sec}$ 


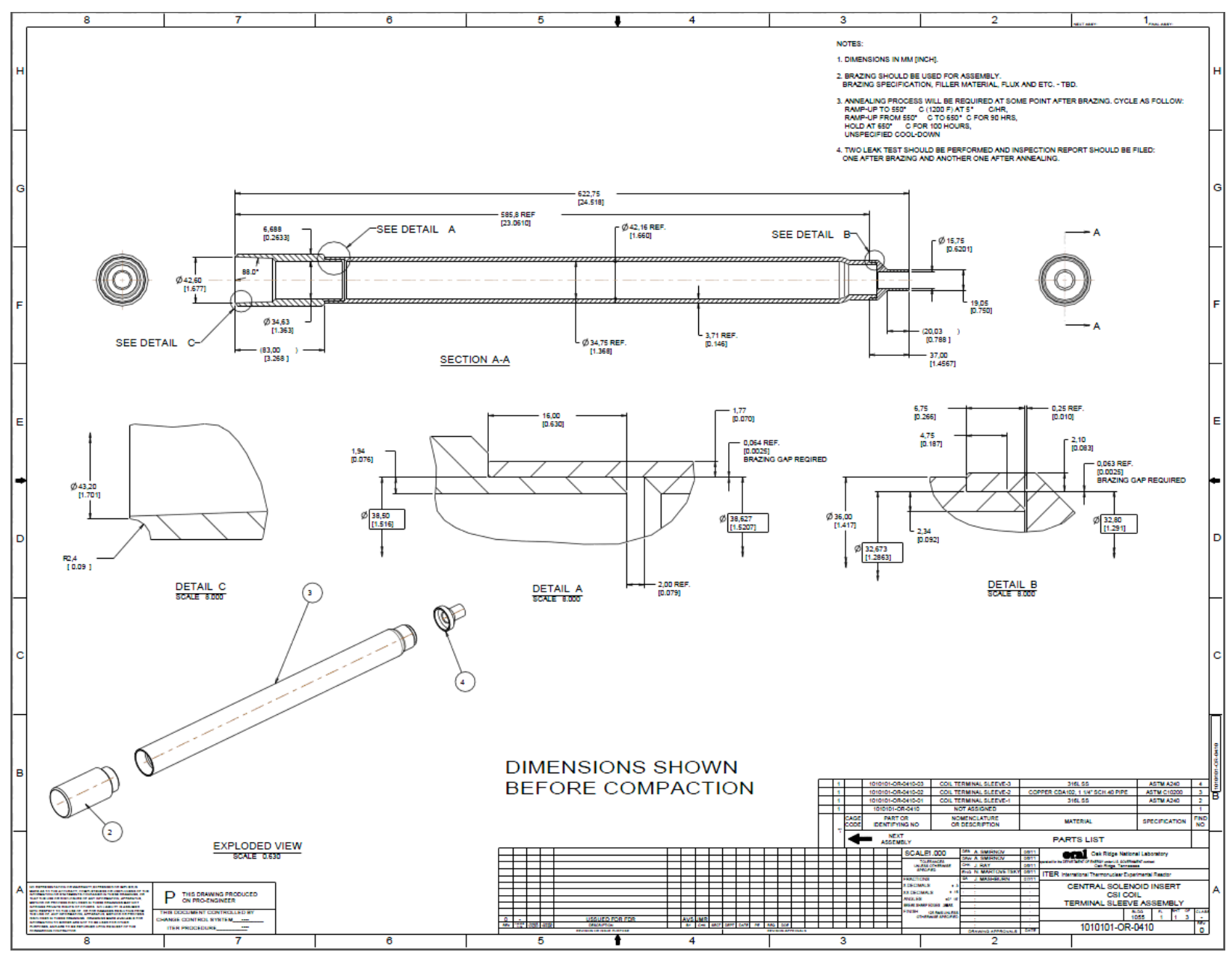

Fig. 24. Copper-stainless steel CSI electric terminal assembly drawing.

The terminals received after brazing are shown in Fig. 25.

The stainless steel end pieces are provided to allow the ends of the termination to be welded to the conduit at one end and to stainless steel tubing for helium connections at the other.

The brazed terminal sleeve assembly shell be thermally shocked three times to liquid nitrogen temperatures, proof tested to $30 \mathrm{~atm}$, and vacuum leak tested at sensitivity of $10-8 \mathrm{~Pa}^{*} \mathrm{~m}^{3}$. Each brazed joint then shall be inspected with ultrasound and X-rays to ensure there are no cavities in the lap joint region. Prior to installation on the terminal cable, the inner wall of the copper tube is mechanically scrubbed with abrasive Scotchbrite ${ }^{\circledR}$, color coded blue or green, and then cleaned with water-soluble flux, distilled water, and alcohol.

The copper-stainless steel assembly is mounted over the cable and round conduit for compaction. Figure 26 shows the terminal before compaction. 


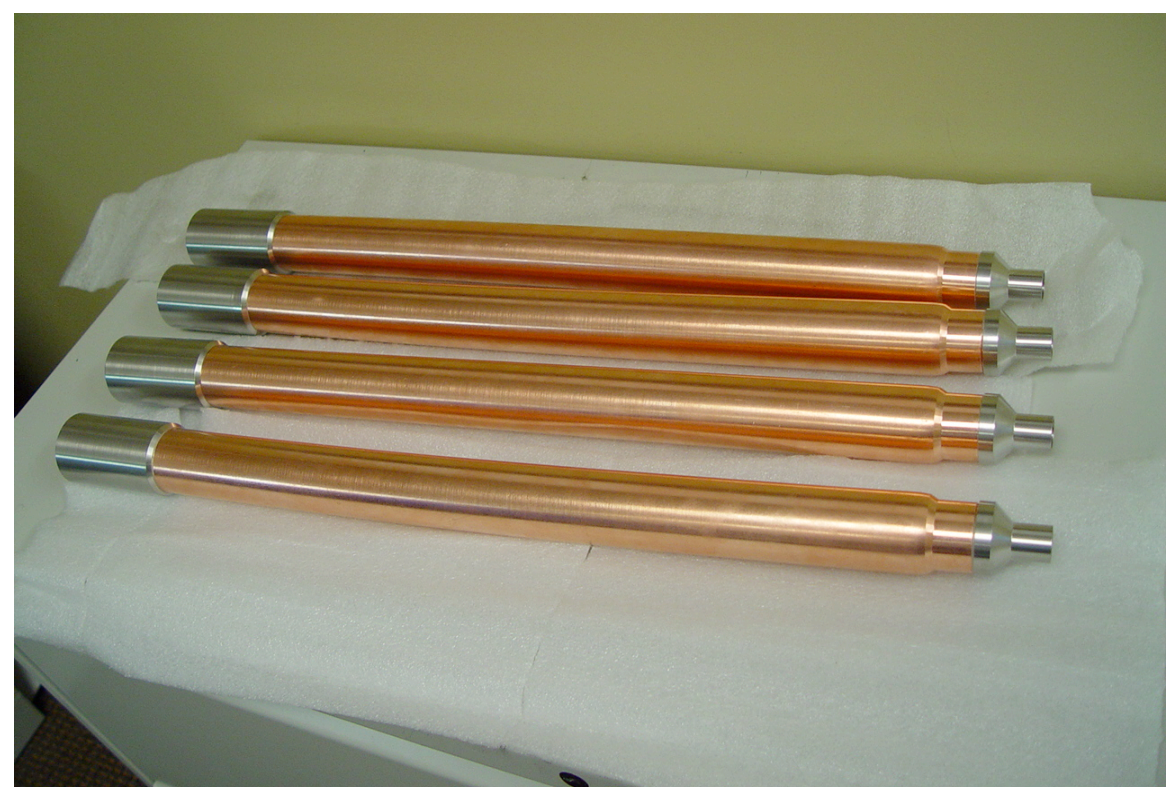

Fig. 25. CSI electric terminals received after brazing.

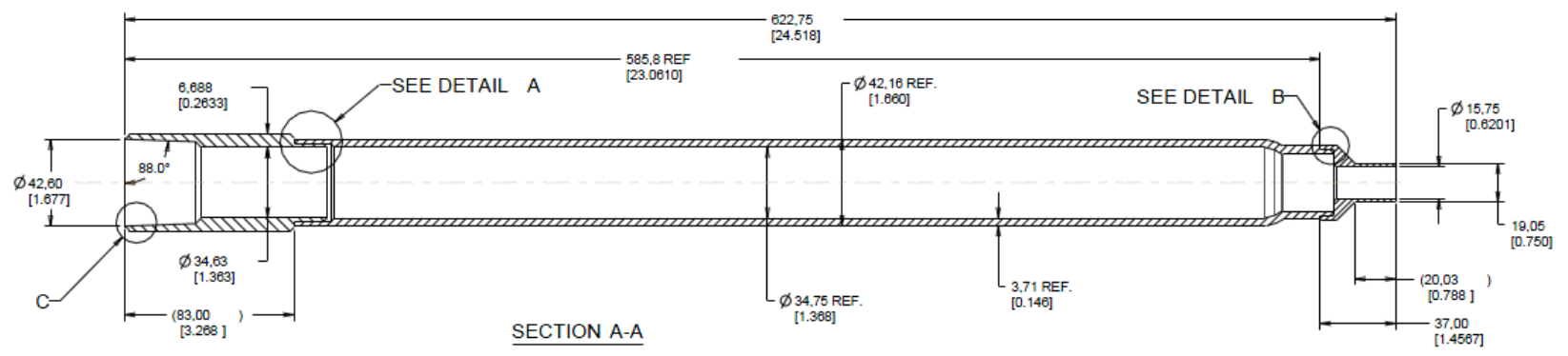

Fig. 26. Pre-compacted CSI terminal.

The copper tube will be compacted down to the cable diameter of $29.2 \mathrm{~mm}$ along its length using a singlestroke pointing machine to achieve approximately $20 \%$ void fraction in the cable space. Compaction test results are shown in Fig. 27. During compaction, the copper-stainless steel sleeve will slide on the conduit. The exact sliding distance for the CSI feeder termination actual dimensions will be established during qualification process. Test results will be used to achieve the required diameters and surface quality. The calculated dimensions after compaction are shown in Fig. 28.

The Stainless Steel transition piece is then TIG welded to the round conduit.

A detailed fabrication procedure and QA acceptance requirements developed in the CSMC program are available on request. 


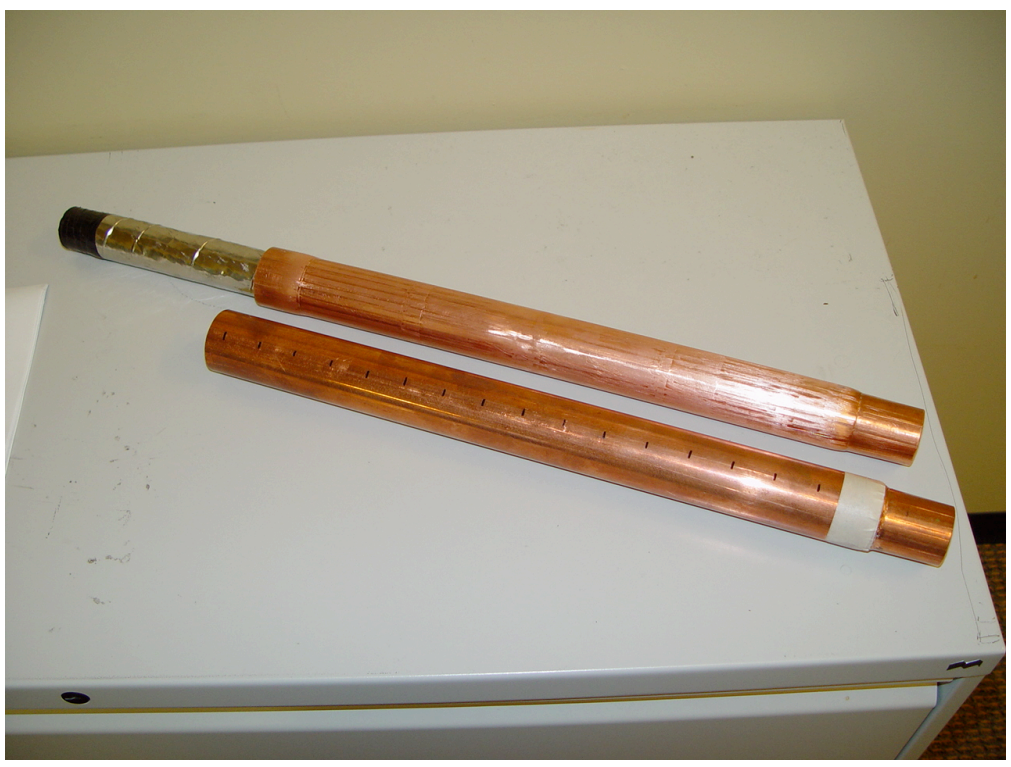

Fig. 27. Compaction test results. Tubes before and after compaction.

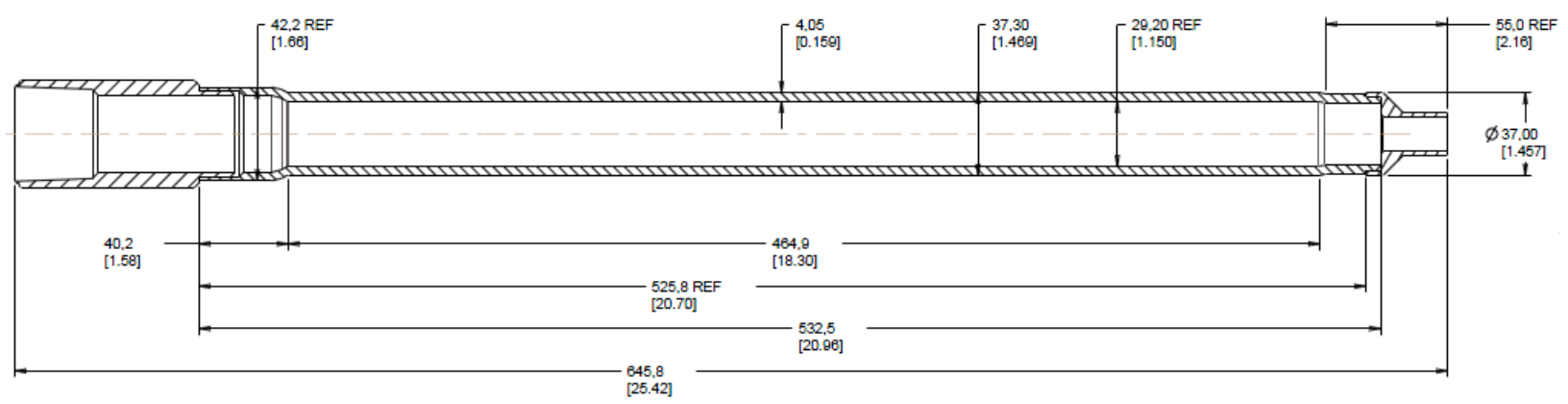

Fig. 28. The CSI terminal after compaction.

\subsubsection{Assembly of the termination joint}

Connection of the CSI module to the feeder bus bar terminal is done through the copper saddle block and bolted clamps, similar to the terminal joints developed in the CSMC program. A 3-D model generated picture of the termination joint is shown in Figs. 29 and 30. A silver coating on the interface area is necessary by using this type of the joint, both on the copper sleeves and on the copper saddle spacer. 


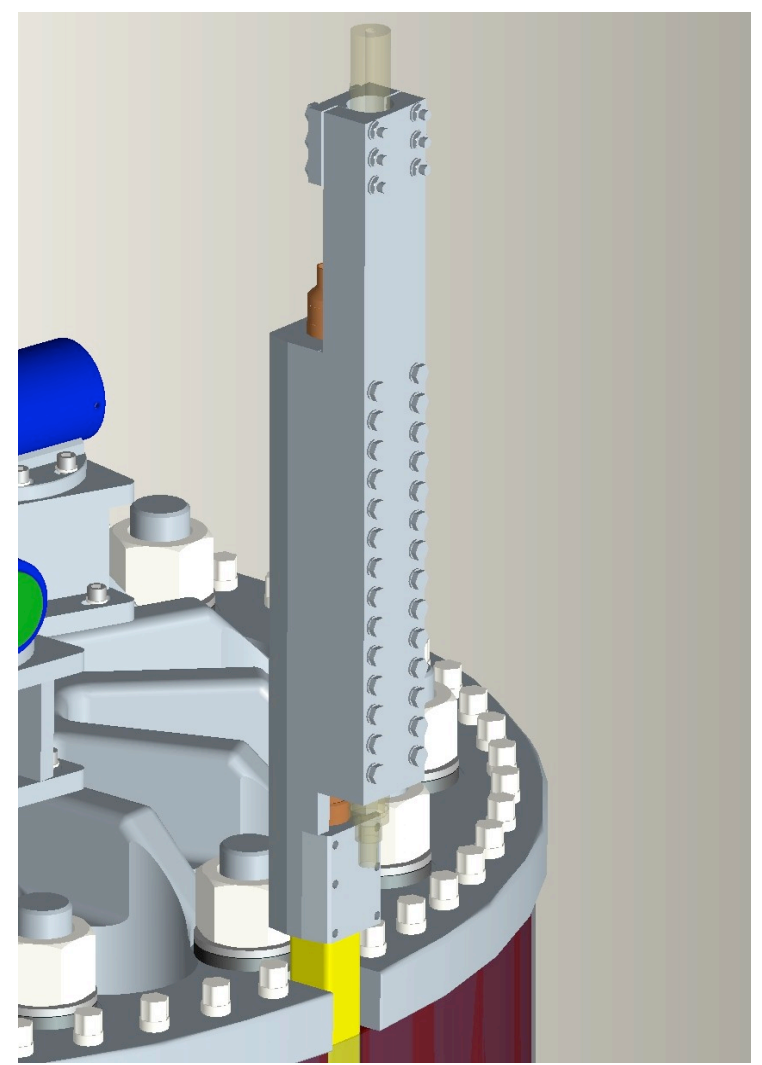

Fig. 29. The terminal: bolted clamp.

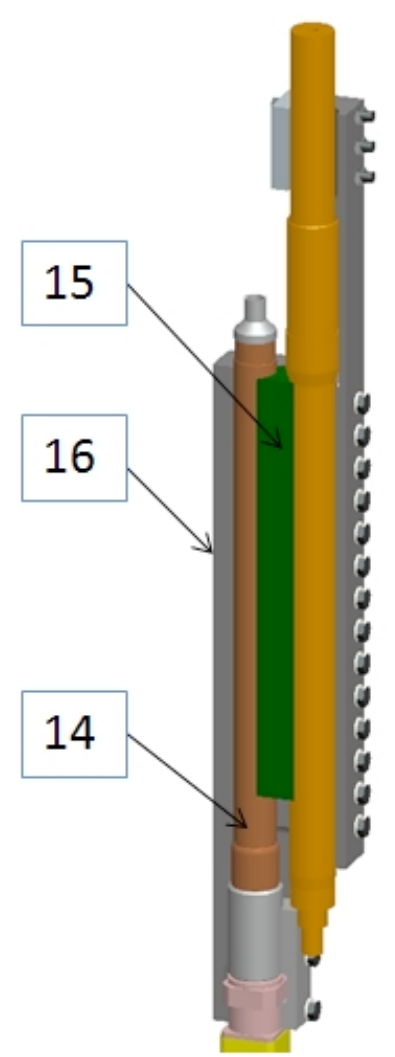

Fig. 30. Saddle block shown between the terminals.

The contact between the sleeve and the clamp blocks is provided by indium wires. The minimum length of the overlap is $0.35 \mathrm{~m}$. The diameter of the indium wires is $1.5 \mathrm{~mm}$, and the distance between the wire centers is $5-7 \mathrm{~mm}$. They are held with $5 \mathrm{~mm}$ wide Scotch sticky tape. No more than three sticky tapes shall be used over the length of the joint — at the ends and in the middle. An example of the indium wires attachment is shown in Fig. 31. The average compression between the terminations is $25 \mathrm{MPa}$ for the copper sleeve, defined as a clamping force divided by the interface area. Pressure is applied with the clamps by the bolts with calibrated and controlled torque wrenches. The creep time of the indium wire is relatively long. The bolts shall be checked for 2 weeks daily and re-tightened to the desired torque as required. If more than $5 \%$ of the torque is lost during the second week, one more week of monitoring the creep is required. After creep is stopped, the insulation of the joint could be installed. 


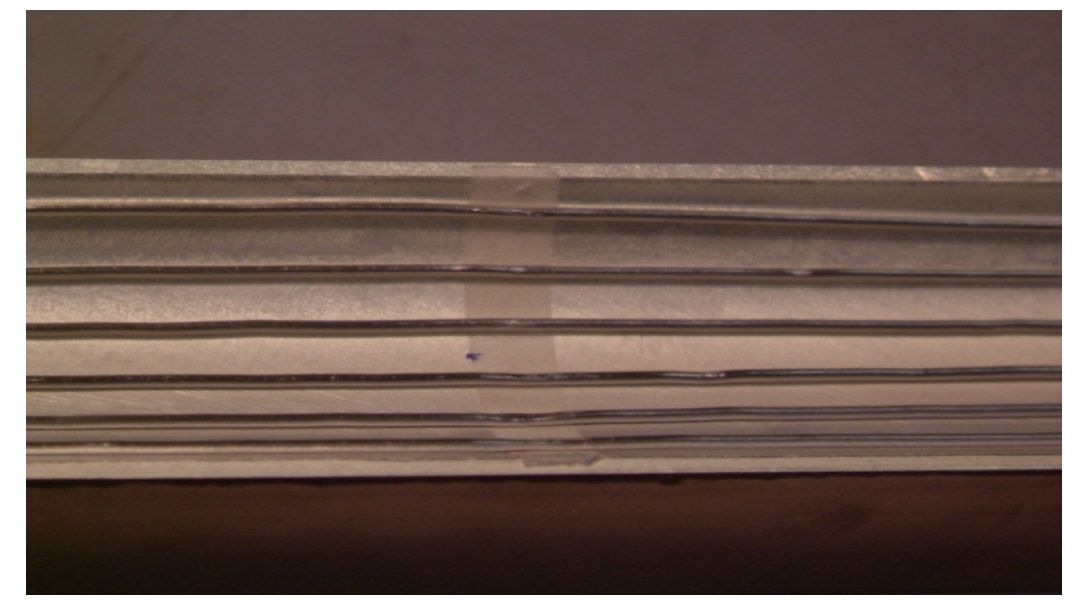

Fig. 31. Indium wires with a diameter of $1.5 \mathrm{~mm}$ are attached to the silver-plated termination before insertion of the copper transition block.

\subsubsection{Lap joint qualification}

The lap joint qualification requires the following.

- Successful demonstration of the lap joint termination fabrication process needs to show that good sintering is achieved between the strand and the sleeve by destructive evaluation.

- Before the terminals are welded, the fabrication of a lap joint termination (see a 3-D model in Fig. 32) must be successfully demonstrated. A full-size lap joint sample will be made, fill welded, and tested (similar to one shown in Fig. 33). It will have one lap like the terminal joint.

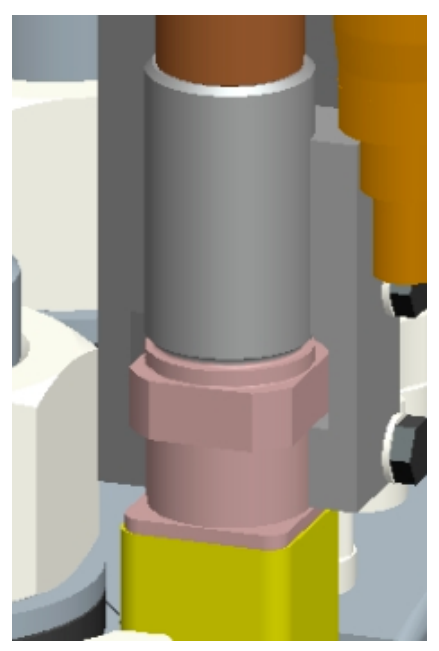

Fig. 32. 3-D model of the lap joint.

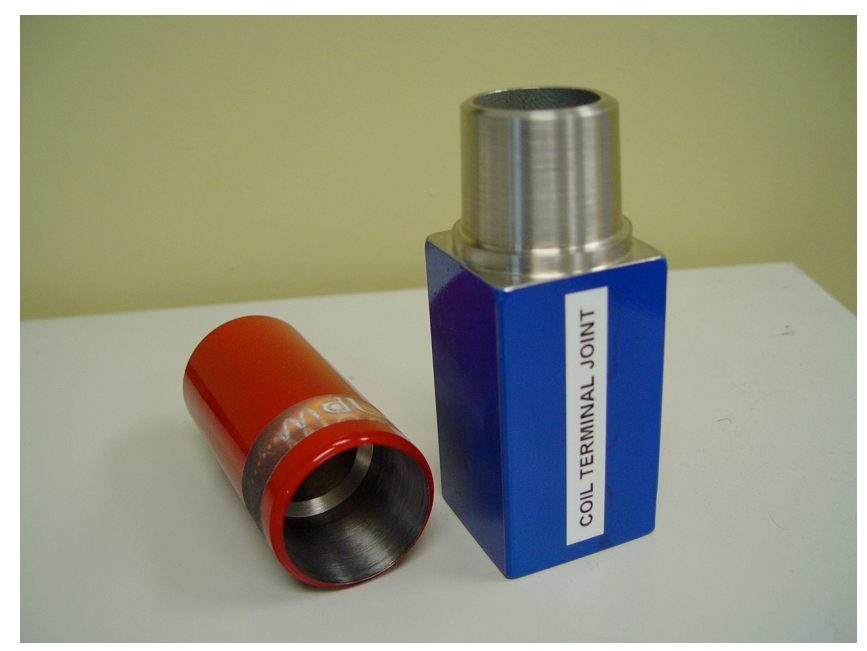

Fig. 33. Full-size lap joint sample.

- In addition, at least one proof sample of a weld joint will be fabricated for proof tensile testing and for tensile testing at room temperature for weld qualification. After CSI terminal welding, the weld will be examined visually, helium leak tested, and then checked with a dye penetration test.

The following tests and inspections are required during manufacturing on the lap joint. 


\subsubsection{Requirements, tests, and inspections}

Test welds shall achieve full penetration in visual, X-ray, and microscopic examinations, including destructive tests with de-sectioning several (3-4 minimum) cross sections of the conduit. The weld requirements are given in Sect. 3.5.11.

Test welds of the cover with calibrated defects shall be inspected to define and qualify the NDE inspection procedures and their sensitivity. Dye penetrant, X-ray, and ultrasonic inspections may be used. After completion of the weld, the samples shall be examined visually, leak tested, and then checked with a dye penetration test. Leak testing shall be carried out under conditions specified in the Appendix A. The helium pressure inside the sample shall be $\mathrm{P} \geq 3 \mathrm{MPa}$. There shall be no leak indication at a level of sensitivity of $1 \times 10^{-8} \mathrm{~Pa}^{*} \mathrm{~m}^{3} / \mathrm{s}$.

After the leak test, the samples shall be subjected to several (at least five) cooldown cycles to $77 \mathrm{~K}$ and the leak test shall be repeated. After these tests, three samples shall be cut out of these conductors with welded covers for fatigue tests at $77 \mathrm{~K}$. The fatigue tests at $77 \mathrm{~K}$ shall be carried out in accordance with the ASTM standard E739-91(1998). ${ }^{13}$ The tests shall demonstrate that the fatigue strength of the conduit with the welded inlet is sufficient to last the lifetime of the CSI with a sufficient margin.

\subsubsection{CSI tests and inspection during electric terminal fabrication}

Tests and inspections conducted during electric terminals fabrication are listed in Table 12.

Table 12. Tests and inspections during terminal fabrication

\begin{tabular}{lll}
\hline \multicolumn{1}{c}{ Operation } & \multicolumn{1}{c}{ Inspections and tests } & Acceptance criteria \\
\hline Module terminations & $\begin{array}{c}\text { Material incoming inspection } \\
\text { QA records of prefabricated } \\
\text { components }\end{array}$ & $\begin{array}{c}\text { Compliance with drawings and specs } \\
\text { Geometry inspection of termination } \\
\text { and cable preparation }\end{array}$ \\
Module terminations & $\begin{array}{l}\text { Dimensional compliance to the drawings. } \\
\text { Removal of cable wraps and chrome-coating } \\
\text { before insertion where applicable } \\
\text { Compliance with the specs, drawings }\end{array}$ \\
Module termination & $\begin{array}{c}\text { Compression in the sleeve, } \\
\text { geometry after compression } \\
\text { profiles, conduit }\end{array}$ & No leak at sensitivity $10^{-8} \mathrm{~Pa}^{*} \mathrm{~m}^{3} / \mathrm{s}$ \\
\hline
\end{tabular}

\subsubsection{Heat Treatment}

Reaction heat treatment will be performed on the coil at a time that supports the schedule and optimizes the cost-effectiveness. The heat treatment process shall be tightly controlled, monitored, and recorded. Several witness strand samples (six minimum for $\mathrm{I}_{\mathrm{c}} / \mathrm{T}_{\mathrm{cs}}$ measurements and three for hysteresis loss) using the same strand used CICC will be placed around the coil during the run. Measures shall be taken to ensure good thermal contact of the strand samples with the conductors. The heat treatment system shall also be equipped with safety equipment for fault conditions or emergency cases such as over-temperature or loss of electric power.

Preparation and characterization of the witness samples ( $\mathrm{J}_{\mathrm{c}}$ and hysteresis loss, subscale samples) after heat treatment are performed by the Company. 
Process requirements. High-purity argon or helium are required as the purge gas flow in the cable with less than 1 ppm $\mathrm{O}_{2}$ and less than 1 ppm of $\mathrm{H}_{2} \mathrm{O}$ content.

Both vacuum or inert-gas-filled furnaces were demonstrated to work successfully in the CSMC; therefore, both types of furnaces are acceptable.

Partial pressure measurements should be made directly using a mass spectrometer with a calibrated leak valve at least one location in the outlet purge gas from the inside of the conductor and in the outlet from the oven itself. Flow meters, vacuum gauges, thermometers, and oxygen and water vapor monitors must be properly calibrated for the range of operation. If the purge gas flow rate is too high for the monitors, they must be placed in a bypass loop with a separate flow meter.

The purge gas entering the conductor must have acceptably low oxygen or water vapor levels $(<1 \mathrm{ppm}$ at $100 \mathrm{kPa}$ for JK2LB).

All lines must be purged. The conductor should be purged with a steady flow of the inert gas for at least $3 \mathrm{hr}$.

The inert-gas-filled furnace must be evacuated to about $100 \mathrm{~Pa}$ and backfilled with purge gas for $3 \mathrm{hr}$. This cycle is repeated two times. The furnace is then filled with the inert gas and maintained at slight overpressure. The same process is repeated for the inside of the conductor volume, and then the purge gas flow is established.

The vacuum furnace must be evacuated to $510^{-4} \mathrm{mbar}$.

Helium leak test on conductor winding should be carried out before raising the temperature for heat treatment.

Heat treatment is performed in accordance with the schedule given in Table 13 (subject to change after the strand vendor final recommendations). Temperature of the coil (minimum six temperature sensors, two on the terminations and four evenly distributed over the CSI conductor length shall be monitored continuously with a sampling time of 5 min or less.

The level of impurity in incoming and outgoing gas must be monitored.

The turns of the coil should be clamped in place with the preventive temporary spacers in between to ensure precise geometry of the winding during that procedure. During heat treatment, the coil is positioned vertically.

Table 13. Heat treatment schedule (subject to small changes)

\begin{tabular}{|c|c|c|}
\hline $\begin{array}{c}\text { Temperature flat top } \\
\text { destination }\end{array}$ & $\begin{array}{l}\text { Ramp rate } \\
\left({ }^{\circ} \mathrm{C} / \mathrm{hr}\right)\end{array}$ & $\begin{array}{c}\text { Flat top duration } \\
\text { (hr) }\end{array}$ \\
\hline 560 & 5 & 0 \\
\hline 650 & 1 & 0 \\
\hline Hold at 650 & 0 & 100 \\
\hline Room temperature & Unspecified cool-down & 0 \\
\hline
\end{tabular}




\subsubsection{Emergency Actions Requirements for Heat Treatment}

An emergency shutdown procedure must be followed when there is a major fault in the heat treatment equipment. In the event of a loss of vacuum, the power is shut down and furnace is flooded with dry pure argon $(105 \mathrm{kPa})$. A nonconformance report is prepared and submitted to the Company along with a suggested corrective actions plan. After receiving approval, the plan is implemented. The nonconformance report shall be submitted to the Company within 3 days after the incident.

\subsubsection{Coil Insulation}

After heat treatment, the temporary spacers between turns shall be removed and the coil will be sent to a vendor who will insulate and assemble the coil after heat treatment in accordance with Sect. 3.1.2.4and drawings listed in Sect. 2. The surface will be cleaned and inspected prior to acceptance tests. Some sensors and holders for future sensors will be placed and the coil insulation will be completed as it is described in this section.

\subsubsection{Turn insulation application}

The spacers are removed, the conductor is cleaned and degreased, turn insulation is applied, and the turns are transferred from the heat treatment tool to the module assembly station. The required inspections are listed in Table 14.

Table 14. Turn insulation inspection

\begin{tabular}{clc}
\hline Operation & \multicolumn{1}{c}{ Inspections and tests } & \multicolumn{1}{c}{ Acceptance criteria } \\
\hline Turn insulation & Visual inspection & $\begin{array}{c}\text { Turn insulation is defect free; thickness } \\
\text { and lay is compliant with the drawings }\end{array}$ \\
Turn position & $\begin{array}{l}\text { Turn location measurements every } 90 \text { degrees and } \\
\text { minimum in three positions of the transition (beginning, } \\
\text { middle, end) }\end{array}$ & $\begin{array}{l}\text { Turn position is within tolerance, no } \\
\text { gaps }\end{array}$ \\
$\begin{array}{l}\text { Teasure positions of the terminals for butt joint, terminal } \\
\text { positioning }\end{array}$ & $\begin{array}{l}\text { joint } \\
\text { Compliance with the drawings }\end{array}$ \\
\hline
\end{tabular}

\subsubsection{Insulation Installation Inspection}

After lap joints and acceptance tests are completed, insulation needs to be installed on uninsulated areas, which includes areas around the joint, the outlet near the joint, module terminations and the inlets. The Supplier completes insulation in these areas, ensuring that insulation in the field does not create weak spots in the insulation system. The required inspections and tests are listed in Table 15.

Table 15. Ground insulation application qualification

\begin{tabular}{ccc}
\hline Operation & Inspections and tests & Acceptance criteria \\
\hline Install ground insulation & Insulation thickness, geometry & Compliance with the drawings \\
\hline
\end{tabular}

\subsubsection{VPI Process}

ITER CSMC program verified good properties of the following resin system, which will be used for the ITER CSI impregnation (Table 16). 
Table 16. Properties of the resin for VPI

\begin{tabular}{lcl}
\hline Component & $\begin{array}{c}\text { Parts by } \\
\text { weight }\end{array}$ & $\begin{array}{c}\text { Commercial trade } \\
\text { designation }\end{array}$ \\
\hline DGEBF & 100 & Ciba Geigy GY282 \\
MTHPA & 82 & Ciba Geigy HY918 \\
Accelerator (hardener/cure agent) & 0.25 & Ciba Geigy DY073 \\
\hline
\end{tabular}

This system has low viscosity, long pot life, reasonable gel and curing temperature, and good properties compatible with cryogenic temperatures and high stresses. The amount of epoxy transferred during the CSMC fabrication was about $1300 \mathrm{~L}$. The CSI module will have approximately 501 of epoxy resin to be transferred into the VPI mold. The detailed specifications of the CSMC fabrication for both inner and outer modules are available upon request. The mold must be leak tested and pressure proof tested to a maximum pressure of 2 bars prior to the resin components mixing. The resin, hardener, and accelerator are to be outgassed for $20 \mathrm{~min}$ or until no air bubbles seen at pressure 1 Torr, whichever is longer.

The epoxy system will be mixed as a batch or as a resin-transfer-mold (RTM) process depending on the chosen technology and available equipment. The mold shall be preheated to $50 \pm 5^{\circ} \mathrm{C}$ for resin transfer, and the mold is filled full at a rate of $0.5-1 \mathrm{~L} / \mathrm{min}$ until resin is observed at all exit ports. Then the exit valves are closed, the pressure in the mold is raised to 2 bars, and the exit valves are cracked to allow the resin to flow into the pressure pot. The exit valve is closed, and the pressure from the pot is vented. The pressure cycles is repeated until no bubbles seen in the exit lines. After eliminating the bubbles, the mold temperature is brought to the glass transformation temperature, $\mathrm{T}_{\mathrm{g}}=90 \pm 5^{\circ} \mathrm{C}$, at a rate of $2^{\circ} \mathrm{C} / \mathrm{hr}$. The mold is for $16 \mathrm{hr}$ for resin gelation. The temperature of the mold is increased to $128 \pm 7^{\circ} \mathrm{C}$ at $4 \mathrm{C} / \mathrm{hr}$ and held for $16 \mathrm{hr}$. Then pressure is then relieved and the coil is cooled to the ambient temperature.

The Supplier shall develop a detailed procedure, in accordance with the requirements, and include it in the Manufacturing and QA plan for review and approval. The procedure shall include but not be limited to the following:

- List of equipment

- Schematic of the pumping, resin mixing, and injection

- Position of the valves at leak checking, proof pressure test, resin flow and mixing testing, injecting, milking

- Instrumentation and acceptance criteria

- Heating and cooling schematic with calculations showing feasibility of temperature control and heat insulation

- Actions in emergency situations, redundancy, and contingency (loss of power, leak, temperature overshooting, etc.)

\subsubsection{VPI Mold Qualification}

The VPI mold is installed and leak tested up to pressures of $0.3 \mathrm{MPa}$ (Table 17). The heating system shall be tested and shown that the rate of heating is acceptable. 
Table 17. VPI mold qualification

\begin{tabular}{lll}
\hline \multicolumn{1}{c}{ Operation } & Inspections and tests & \multicolumn{1}{c}{ Acceptance criteria } \\
\hline VPI mold assembly & Dimensions & Compliance with the drawings \\
VPI mold assembly & Electrical isolation & No shorts between the turns and conductor to the mold \\
VPI mold assembly & Proof pressure test & No leaks at $0.3 \mathrm{MPa}$ \\
VPI mold assembly & Heating system test & Simulate the curing cycle per Sect. 3.5 .7 \\
\hline
\end{tabular}

\subsubsection{VPI Process Qualification}

The VPI process shall be qualified on in accordance with the specifications given in Table 21. The required tests and inspections are shown in Table 18.

Table 18. Inspections and tests during VPI

\begin{tabular}{lll}
\hline \multicolumn{1}{c}{ Operation } & Inspections and tests & Acceptance criteria \\
\hline VPI preparation & $\begin{array}{c}\text { Resin Transfer } \\
\text { equipment }\end{array}$ & $\begin{array}{c}\text { Compliance with specs (flow rate, mixing ratio, outgassing, leak } \\
\text { tightness, etc.) }\end{array}$ \\
$\begin{array}{l}\text { Resin transfer and } \\
\text { curing }\end{array}$ & Process parameters & Compliance with specs \\
\hline
\end{tabular}

\subsubsection{Qualification of Insulation-High Potential and Turn insulation Tests}

After VPI, the CSI shall be high voltage tested in accordance with the requirements given in Sect. 3.2.1.4.

Voltage tap ends shall be isolated from the mold. High potential source with the current limiter is used to apply $500 \mathrm{~V}$ between the mold and terminations of the CSI before the coil is extracted from the mold. Set a current limit at 100 micro Amps.

Acceptance criteria for this test is: no breakdown (leakage current less than 50 micro Amperes for $1 \mathrm{~min}$ hold).

A recommended turn insulation test procedure is given in Appendix A.1.

\subsubsection{Weld Requirements}

Welding design and requirements are described as follows.

\subsubsection{Weld design}

The design of the weld around the cable whether it is a longitudinal seam weld or butt weld or circumferential weld joining two lengths of the conduit together is a full penetration weld.

The weld joints in the CSI of the termination sleeve to the conduit, falls into the category of the full penetration butt weld with a backing strip.

The weld joint shall be welded so that there are no cracks, crevices, or incomplete fusion remaining. 


\subsubsection{Weld procedure specification (WPS)}

The vendor shall provide the WPS for production of the conduit welds. The vendor shall follow the requirements provided in the ASME BPVC, Sect. IX. Items such as holding fixtures, welding equipment, weld time, number of passes, welding sequence, filler metal, shielding gas, and cleaning procedures shall be included. Specific welding parameters, such as gas flow, current and voltage settings, preheat spray, and pulsed spray settings shall also be included, if applicable. The WPS shall be available for review and approval by the Company prior to construction. The WPS shall also be available for reference and review by the Company's technical representatives and inspectors at the fabrication site.

\subsubsection{Distortion and Dimensions Control}

Weld procedures and fixtures shall be selected to control distortion within dimensional limits specified on the drawings. All final weld inspections before heat treatment shall take place after any weld finish prep, straightening, or realignment of welded CICC. After the heat treatment, no straightening or realignment on the conductor is allowed due to the high sensitivity of the superconductor to the strain. All nonconformances shall be reported in writing, and any corrective action requires approval by the Company technical representative in writing. The Supplier shall also submit all nonconformances to USIPO CSI team with a plan of mitigation actions.

\subsubsection{Procedures qualification}

All procedures required to comply with the Japanese High-Pressure Gas Safety Law (JHPGSL) ${ }^{9}$ for design, fabrication, inspection, and documentation of the CSI except for conductor fabrication. They must comply with the requirements detailed in Application and Inspection of Imported High-Pressure Gas Equipment [the High-Pressure Gas Safety Institute of Japan (KHK)]. ${ }^{10}$

Vendor shall provide a Procedure Qualification Record (PQR) for each WPS. A PQR is a record of the welding data used to qualify a welding process by welding a test coupon, and record results of the tested specimens in accordance with ASME BPVC, Sect. IX. ${ }^{2}$ A PQR shall show that the welds meet requirements stated in Sect. 3.5.11. The PQRs shall be available for review and reference by Company technical representatives and inspectors at the fabrication site. Welding operations may require a Company assigned QA Inspector in presence, therefore prior to qualification welds and production welds the Supplier shall inform the Company about scheduled activities a week in advance.

\subsubsection{Welder performance qualification (WPQ)}

The applicable codes for welding and testing the pressure-retaining parts of the CSI must meet the Japanese industrial welding and inspection standards. All welding shall be performed by qualified welders with certifications in according with the applicable standards in the ASME Pressure Vessel Code, Sect. IX. ${ }^{2}$ Certification shall indicate that the welder or welding operator has demonstrated the ability to make sound welds of the same type and position, for the same process and materials, using the same equipment as specifically required for construction. During fabrication, questionable quality of workmanship in process may be challenged by the design agent or Certified Weld Inspector, who may request requalification of a particular welder. Vendor shall be responsible for requalifying a welder or welding operator whose performance does not meet the applicable standards in the specification. 


\subsubsection{Welder certification requirement}

A WPQ is required for each welder or welding operator covering the required welding processes. A Certified Welding Inspector shall approve all WPQ's in accordance with SNT-TC-1A 15 WPQ records shall be available at any time after commencement of welding process for reference and review by the Company technical representative during fabrication of the CSI.

\subsubsection{Filler metal}

Electrodes and filler wire for conduit welds shall conform to ASME BPVC, Sect. IX ${ }^{2}$ or specific recommendations from the Company for cases not covered by the ASME BPVC. A Certified Material Test Report on the chemical analysis from the filler metal vendor shall be delivered to the Company if applicable. If more than one lot or heat number is involved in the filler metal order or shipment, a separate report shall be provided for each heat or lot supplied. The filler metal specification and the supplier will be given to the Supplier by USIPO CSI team.

Prior to welding during fabrication, the Company shall approve the facility, equipment, and qualification of the welders, as well as a test procedure for the coupon specimens and inspection methods. Material used for the conductor jacket is stainless steel JK2LB. It will be welded with 316L SS terminal parts and tension links. The chemical properties of JK2LB are shown in Table 19. The Company will provide the filler material and a weld schedule, based on the known weld test results of work performed in Japan.

Table 19. Chemical composition of JK2LB (wt \%)

\begin{tabular}{ccccccccccc}
\hline $\begin{array}{c}\text { Chemical } \\
\text { composition }\end{array}$ & $\mathbf{C}$ & $\mathbf{S i}$ & $\mathbf{M n}$ & $\mathbf{P}$ & $\mathbf{S}$ & $\mathbf{N i}$ & $\mathbf{C r}$ & Mo & $\mathbf{N}$ & $\mathbf{B}$ \\
\hline Specification & $\leq 0.03$ & $\leq 0.50$ & $20.5 \sim 22.5$ & $\leq 0.015$ & $\leq 0.015$ & $8.0 \sim 10.0$ & $12.0 \sim 14.0$ & $0.50 \sim 1.50$ & $0.17 \sim 0.23$ & $0.001 \sim 0.004$ \\
\hline
\end{tabular}

\subsubsection{Weld finish}

The vendor shall provide a process to remove excess weld material, if any, from the conduit or other parts of the CSI so as to ensure a finished conductor or other parts within final dimensions and tolerances.

\subsubsection{Weld identification}

The vendor shall maintain records identifying the welder or welding operator associated with each weld on the conduit. Each welder or welding operator shall be signed a unique symbol or identification number that cannot be transferred.

\subsubsection{Weld specimens}

The vendor shall demonstrate one of each type of weld process, for each combination of filler wire size to be used in the construction of the CSI to ensure they meet the following requirements.

Requirements on the conduit material mechanical properties in the weld at room temperature after heat treatment:

Ultimate tensile strength: $\quad 515 \mathrm{MPa}$

Yield strength: $\quad 205 \mathrm{MPa}$

Charpy test: 24 J 


\subsubsection{Tensile test}

The largest obtainable tension test specimen as specified in Test Methods and Definitions ASTM A $370^{11}$ shall be used at room temperature with the butt weld at the center of the sample. Three tension test specimens shall be prepared. Yield strength $(0.2 \%$ offset $)$, tensile strength, elongation, Young's modulus, and breaking point shall be reported with a stress (load) — strain chart and a stress (load) - stroke (time) chart in addition to reporting items specified in ASTM E8M. ${ }^{12}$

\subsubsection{Charpy test}

Charpy tests are required for the welds samples simulating closeout welds on the conduit around butt joints. Impact test specimens shall be Charpy V-notch Type A, as shown in Fig. 11 of Test Methods and Definitions ASTM A370. ${ }^{11}$ The length of Charpy V-notch test specimens shall be equal to the width of a jacket and the thickness shall be $5 \mathrm{~mm}$. One set of three Charpy V-notch specimens shall be taken from each tensile specimen location. The notch axis of the specimens shall be the longitudinal direction of the jacket and shall be located at a center of the minimum thickness part.

The test shall be performed at $77 \mathrm{~K}$ in accordance with ASTM A370. ${ }^{11}$ The Charpy absorbed energy and lateral expansion of specimens shall be measured and reported. The average Charpy absorbed energy of three specimens shall meet a minimum value of $27 \mathrm{~J}$, and one specimen only in one set shall meet a minimum value of $24 \mathrm{~J}$.

\subsubsection{Material Identification}

Positive identification and the tracking of the CICC through the fabrication process and subsequent testing are required.

\subsubsection{Workmanship}

The Supplier and subcontractors shall perform their work to meet the given specifications in accordance with workmanship standards. In the event of discrepancy between this specification and a detail specification or drawing, the detail specification shall prevail. The product shall not have sharp edges and be free of chips, greases, and other foreign matter. Treated surfaces shall be uniform and free from scratches, cracks, or voids.

\subsubsection{Safety}

The Prime Contractor shall observe all federal and local environmental and safety regulations and shall be in compliance with all Environmental Protection Agency (EPA) regulations as they apply to all materials and material-handling methods used in any aspect of the manufacture and assembly of the CSI and its components. The workplace practices having to do with the manufacture of the aforementioned items shall conform to all guidelines established by Occupational Safety and Health Administration (OSHA).

\subsubsection{Human Performance/Human Engineering}

The Supplier shall perform an assessment of manufacturing tasks, identify critical operations that require concentrated human engineering attention due to the sensitivity of the operation or criticality of the task, and develop measures to minimize the possibility or effect of human error. The critical operations include but not limited to winding, bending, all welding and brazing operations over the cable, joints, heat treatment, and VPI. This assessment shall be included in the QA Plan. 


\subsection{DOCUMENTATION}

The CSI team (the Company) developed the documentation for the CSI listed in Sect. 2 of this document.

This documentation shall be submitted by the Supplier in the time of the contract issue unless otherwise specified in the SOW document. After the start of the qualification trials, the documentation shall be updated as frequently as significant changes are introduced and qualified. Review of the documentation is required at least once every month, and every new revision shall be submitted to USIPO. The detailed list of the data required from the Supplier is described in the SOW.

After completion of the manufacturing and assembly of the CSI, the CSI team will submit a final report on the ITER CSI manufacture, which will describe the manufacturing processes, manuals, procedures and essential test results during the project.

\subsection{MAINTENANCE}

The CSI is designed to be maintenance and repairs free for the entire time of the test. Access to the CSI is very difficult and requires many weeks of the down time. Therefore, design, fabrication, and QA shall be adequate to ensure such performance. The CSI team shall prepare a Repair Plan for a failure of the CSI module, which includes replacement the failed module and reinstallation of the CSI assembly.

\subsection{PERSONNEL AND TRAINING}

The Supplier shall make available the number and skill levels of personnel who manufacture and assemble the CSI, which meets the requirements of this document and the CSI SOW. It is the Supplier's responsibility to determine the number and types of fabrication crew personnel and their training requirements to meet the requirements of this specification. 



\section{QUALITY ASSURANCE PROVISIONS}

This section specifies requirements for formal checks, inspections, and tests of the CSI and the performance, design characteristics, and operation of its components. The test requirements and procedures are based on the performance requirements and process specification requirements given in Sect. 3 of this document. The list of tests and inspections and procedures shall be verified and revised in accordance with results of the qualification program given in Sect. 3 with preliminary tests and minimal inspection requirements. All results of the inspection and tests shall be recorded and submitted to the Company in the approved format.

Some of the critical test procedures (high potential, flow rate test, leak test and pressure proof test) are specified in Appendix A of this document. The rest of the inspections and checks procedures to verify that the components and the assembly meet the requirements shall be developed by the Supplier in the QA Plan part called Master Test Plan, submitted to USIPO in the Final Design Report and approved by USIPO as specified in the CSI SOW Document.

\subsection{GENERAL}

Verification of the ultimate performance of the CSI is not possible until the actual test. After discovery of a problem, the repairability is very limited. Therefore receipt inspections and tests, in-process inspections, and tests and acceptance inspections shall ensure a product that shall meet the performance requirements. The qualification of all manufacturing steps and pre-production development shall establish a reliable QA to accomplish this goal. Specific quality clauses are included in the SOW for each subcontract.

\subsubsection{Quality Standards}

All work shall be done under US ITER-approved QA programs. Additional quality requirements are given in SOW 'quality clauses' for each subcontract.

\subsubsection{Process Controls}

\subsubsection{Manufacturing plan}

This is in addition to the Manufacturing Inspection Plan, required by the SOW. The CSI team has developed a Fabrication Plan that gives a guidance on how the CSI can be built. A selected Supplier shall develop a detailed Fabrication Plan, which will describe the Supplier's step-by-step approach for manufacturing the different components of the ITER CSI. The Supplier's Fabrication Plan shall address all aspects of assembly and component manufacture (within prescribed SOW) including a description of equipment to be used, production line equipment layout and configuration, production and delivery schedules, a description of any designated operators' past experience with this or related production lines, a description of how QA procedures will be integrated with the manufacturing process, and all other relevant considerations. The Fabrication Plan requires ITER approval.

Note that after production has started, any changes to the approved Fabrication Plan must be approved by the Company in writing. The Company shall receive updated documents as specified in the CSI SOW. 


\subsubsection{Inspection of materials}

All incoming ITER furnished materials (if applicable) are to be inspected by the Supplier. Any material that is damaged or that appears to be unusable shall be identified and segregated from conforming material. Such material shall remain out of use until the Company has been notified and given a written recommendation on the disposition of the nonconforming material.

All incoming non-ITER-provided materials shall also be visually inspected by the vendor. All such materials found to deviate from specification requirements and unable to be brought into a state of full and complete conformance by rework shall be rejected.

\subsubsection{QA audits (internal)}

The Supplier shall provide a plan for auditing the implementation of the QA Program. Copies of all internal audits shall be furnished to the Company.

\subsubsection{QA audits (external)}

The Company shall reserve the right to conduct an unannounced audit of the vendor's QA program and manufacturing processes at any time during the project. Such an audit might include, but not be limited to, the following:

- Welder or welding operator Qualification Records

- Machine Operator Qualification Records

- Q/A Inspector Qualifications

- Material Certifications

- State and Local Permits (where required)

- Drawing Files

- QA Test Records

- Shop Travelers

- Equipment Maintenance and Calibration Records

- Inspection of Vendor's Manufacturing Facilities

- Witnessing Manufacturing Operations and Testing

\subsubsection{Responsibility for Tests}

The Supplier is responsible for all inspections and tests during manufacturing and assembly of the CSI, including those tests or inspections conducted by any subcontractor or other party. The Supplier is responsible for procedures, carrying out the tests, and generating the test reports where test results are compared with the allowable parameters and nonconformance or nonconformance are identified.

The Company and its representatives reserve the right to witness all and any of the tests, and the Supplier shall give sufficient advance notice about scheduled tests and inspections requested by the Company in order to make it possible to witness the test or inspection.

\subsubsection{Test Methods}

All testing and inspection shall be carried out in accordance with commonly recognized and accepted government and industry standards. Such standards are either identified in this specification or the Supplier is asked to propose a recognized standard that must then be approved by the Company in writing before the vendor can apply the standard. 


\subsubsection{Calibration of Test Equipment}

Calibration of all test equipment must be traceable to the National Bureau of Standards (National Institute of Standards and Technology) standards and must follow manufacturers' guidelines for frequency of recalibration.

\subsection{QUALITY CONFORMANCE INSPECTIONS AND TESTS}

During production of the CSI, the minimum requirements for inspections and tests are as follows.

\subsubsection{Conductor Receiving Inspection}

Conductors shall be delivered on spools designed and fabricated by the JADA in agreement with ITER and the conductor supplier. The coil will be $4 \mathrm{~m}$ in diameter as a coreless spool. It will be packaged in a wooden box. Conductor parameters shall be within specifications given in Sect. 3.1.4.1.

The Supplier shall check the QA documentation and perform a flow test on the conductor per Appendix A.2. The measured pressure drop shall be compared to the flow test results at the conductor supplier site. In the case of more than $15 \%$ deviation from the nominal flow rate at a tabulated pressure drop, a nonconformance report shall be issued and corrective action proposed, subject to Company's approval.

Verification of the conductor length on the spool, both total conduit length and the length filled with the cable, is required. The Supplier shall develop a way to verify the conductor length, preferably without respooling. For example, the conductor spool design can have provisions to measure the conductor length by a known number of turns and the radius of every layer. The length of the empty conduit could be verified by a feed wire fed until it stops from both ends of the CICC.

\subsubsection{ITER Furnished Auxiliary Components Receiving Inspection}

The furnished items in Sect. 3.1.4 shall be inspected by the Supplier, according to the requirements given therein. Test and inspections certificates and calibration data shall be reviewed.

\subsubsection{Coil Winding}

Minimum required inspections and tests during coil winding are given in Table 11.

\subsubsection{Tests and Inspections during CSI Electric Terminal Fabrication}

Minimum required tests and inspections are given in Sect. 3.5.2.5, Table 12.

\subsubsection{Reaction Heat Treatment Tests and Inspections}

Minimum required tests and inspections are given in Sect. 3.5.3.

\subsubsection{Turn Insulation Application Tests and Inspections}

Minimum required tests and inspections are given in Sect. 3.5.3.

\subsubsection{Lap Joints Fabrication}

Minimum required tests and inspections are given in Sect. 3.5.2. 


\subsubsection{Insulation Installation}

After lap joints and acceptance tests are completed, the insulation needs to be installed on the areas around joints per fabrication drawings. Minimum required tests and inspections for these operations are given in Sect 3.5.6.

\subsubsection{VPI Mold Installation}

The minimum requirements for the VPI mold installation around the CSI are given in Sect. 3.5.8.

\subsubsection{VPI Process QA}

The VPI process shall be qualified on the CSI in accordance with the specifications given in Sect. 3.5.9. The minimum required inspections and tests are given in Table 18.

\subsubsection{CSI Acceptance Tests}

The minimum requirements for acceptance tests of the CSI are given in the Table 20.

Table 20. Acceptance criteria for the CSI after the VPI

\begin{tabular}{|c|c|}
\hline Inspections and tests & Acceptance criteria \\
\hline Dimensions & $\begin{array}{l}\text { Compliance with the drawings and } \\
\text { specifications }\end{array}$ \\
\hline Visual inspection of the insulation surface & No cracks, voids, other defects \\
\hline Proof pressure test & $\begin{array}{l}\text { No pressure drop when isolated from the } \\
\text { pressure source at } 2 \mathrm{MPa} \text { (correction for } \\
\text { temperature variation) }\end{array}$ \\
\hline Leak test & No leak at sensitivity of $10^{-7} \mathrm{~Pa}^{*} \mathrm{~m}^{3} / \mathrm{s}$ \\
\hline $\begin{array}{l}\text { Winding pack inductance measurement at low } \\
\text { frequency (less than } 100 \mathrm{~Hz} \text { ) }\end{array}$ & Within specs \\
\hline Winding pack electrical resistance measurement & $>1 \mathrm{MOhm}$ at $100 \mathrm{~V}$ \\
\hline Flow test & $\begin{array}{l}\text { All hydraulic paths flow within } \pm 15 \% \\
\text { nominal }\end{array}$ \\
\hline High-voltage tests & Pass requirements in Appendix A.1 \\
\hline Instrumentation tests & Compliance with the test procedure \\
\hline
\end{tabular}

\subsubsection{Instrumentation Installation}

The minimum requirements for the Instrumentation installation in the CSI module are given in Sect. 3.1.4.2. The voltage taps shall pass the continuity check, the sensors checks shall comply with the sensor specifications.

\subsubsection{Test During Assembly and Final Acceptance Tests}

Table 21 gives the final inspections checks during and after the CSI assembly. 
Table 21. Inspections and tests during the CSI assembly

\begin{tabular}{|c|c|c|}
\hline Operation & Inspections and tests & Acceptance criteria \\
\hline $\begin{array}{l}\text { Support Structure } \\
\text { assembly }\end{array}$ & Geometry, fit between the components & Compliance drawings \\
\hline CSI installation & Geometry, fit between the components & Compliance with specs and drawings \\
\hline $\begin{array}{l}\text { Installation of the, bus } \\
\text { bars }\end{array}$ & $\begin{array}{l}\text { Geometry, } \\
\text { WPS }\end{array}$ & $\begin{array}{l}\text { Compliance with drawings and } \\
\text { specifications }\end{array}$ \\
\hline Preloading & Load, geometry & Compliance with specs \\
\hline $\begin{array}{l}\text { Plumbing installation, } \\
\text { clamps }\end{array}$ & $\begin{array}{l}\text { Leak check, pressure proof test, dye penetrate } \\
\text { inspections on welds }\end{array}$ & No leaks and defects \\
\hline $\begin{array}{l}\text { Instrumentation } \\
\text { installation }\end{array}$ & Functionality test & Compliance with specs \\
\hline Final acceptance & Low-voltage test & Compliance with specs \\
\hline Final acceptance & Dimensional survey & Compliance with the drawings \\
\hline Final Acceptance & Pressure proof test and leak test & Compliance with specs, no leaks \\
\hline Final Acceptance & Flow test & $\begin{array}{l}\text { No significant change since CSI } \\
\text { delivery }\end{array}$ \\
\hline Final acceptance & Resistance and inductance measurements & $\begin{array}{l}\text { No change from the values measured at } \\
\text { acceptance tests }\end{array}$ \\
\hline
\end{tabular}

\subsection{MODIFICATIONS TO EXISTING SPECIFICATIONS}

Supplier is free to propose modifications to existing specifications at any time during this project execution or to Fabrication Specifications based on this document. Modifications must be proposed in writing and shall include a detailed description of how the proposed modification(s) will impact process and product performance, reliability, cost, and delivery.

All variances must be approved in writing by the USIPO before they can be implemented.

\subsection{DOCUMENTATION AND REPORTING}

\subsubsection{Certificate of Compliance}

The vendor shall provide a written statement certifying compliance with the requirements of the purchase order and this specification with each shipment of the CSI components. The Supplier shall supply a report containing the certifications required for the conductors and the quality control reports with the acceptance test results.

\subsubsection{Nonconformance Reports}

Nonconformance in workmanship, dimensional tolerances, procedures, records, or qualifications must be reported to USIPO in accordance with the procedure given in ITER QA Manual. The Supplier shall determine the severity of the nonconformance and estimate its impact on program cost and schedule. The Supplier shall submit a nonconformance report to USIPO and, if necessary, consult USIPO for a corrective action approval. The Supplier shall provide a detailed procedure to be followed to ensure proper resolution of a nonconformance. 



\section{PREPARATION FOR DELIVERY}

\subsection{PACKAGING}

Packaging of the CSI shall be done to satisfy requirements given in Sect. 3.2.6. The Supplier shall propose the packaging method and present it for review in the Manufacturing Plan. In case of modifications, the Supplier shall present the packaging method for review and approval to the Company at least 3 months before the scheduled shipping date.

\subsubsection{Marking for Shipment}

Marking requirements for shipment shall be in accordance with MIL-STD-129 or other recognized and appropriate national standard. In any instance where reference to MIL-STD-129 is not applicable, appropriate identification of the product, on both on packages and shipping containers, shall be provided, including all marking necessary for delivery and for storage, if applicable; all markings required by regulations, statues, and common carriers; and all markings necessary for safety and safe delivery.

\subsubsection{Shipment}

Shipment shall be free on board (FOB) delivered, by common carrier. The method and frequency of shipment shall be consistent with Company-approved delivery schedules. 



\section{REFERENCES}

1. Central Solenoid Insert Development Specifications, US ITER 11102-PD0017-R00, Rev. 0, September 2010.

2. 2007 ASME Boiler \& Pressure Vessel Code, 2009b Addenda, July 1, 2009; IX, Qualification Standard for Welding and Brazing Procedures, Welders, Brazers, and Welding and Brazing Operators.

3. ASTM D3755-97, Standard Test Method for Dielectric Breakdown Voltage and Dielectric Strength of Solid Electrical Insulating Materials Under Direct-Voltage Stress, March 2004.

4. A. Smirnov and Y. Nunoya, compilers, Interface Control Document, Rev. 1, 2010.

5. N. Martovetsky, CSI Test Plan, Rev. 0, May 12, 2011.

6. A. Khodak, Analysis of CS Insert Coil, May 2011, PPPL.

7. N. Martovetsky and A. Smirnov, CS and CSI Winding Trials, US ITER 11100-TD0017-R00, April 2011.

8. N. Martovetsky and A. Smirnov, CSI Coil Fabrication Plan, US ITER 11101-PN0006-R00, May 2011.

9. Japanese High Pressure Gas Safety Law [JHPGSL] (English translation title: Designated Equipment Inspection Regulations).

10. Application and Inspection of Imported High-Pressure Gas Equipment, the High-Pressure Gas Safety Institute of Japan [KHK].

11. ASTM A370, Standard Test Methods and Definitions for Mechanical Testing of Steel Products.

12. ASTM E8M, Standard Test Methods for Tension Testing of Metallic Materials.

13. ASTM standard E739-91(1998), Standard Practice for Statistical Analysis of Linear or Linearized Stress-Life (S-N) and Strain-Life (e-N) Fatigue Data.

14. R. D. Benson, MDL Report/Procedure, Title: ITER - Chromium Removal from Stranded Copper Wire, 5/13/09.

15. Recommended Practice No. SNT-TC-1A: Personnel Qualification and Certification in Nondestructive Testing (2006)

16. A. Smirnov and N. Martovetsky, CSI Terminals Manufacturing and Inspection Report, US ITER 11100-TD0016-R00, May 2011. 



\section{APPENDIX A}

\section{A.1 TURN INSULATION TEST}

This test is performed on the CSI after the VPI and after the VPI mold is removed. The voltage taps in the CSI module are used to record the voltages across the coils. A DC power supply is attached to the terminations of the CSI. Ten amperes current DC is applied and voltage taps signals are read by a microvoltmeter. The voltage drops are recorded and compared to the length of the conductor between the voltage taps. The turn insulation is considered satisfactory if there is no large discrepancy between the voltages and corresponding lengths of the conductor between the voltage taps.

\section{A.2 FLOW TEST}

This document describes the flow testing specification for the CSI, specific test conditions, and acceptance levels. The flow test is carried out to demonstrate that there is no flow obstruction in conductors and joints and that the impedance scatter between the parallel flow paths is small, which gives uniform flow distribution in operation. The flow diagram of the CSI is shown in Fig. A.1.

Test conditions and records during flow testing are shown in Table A.1. The acceptance criterion is impedance within $10 \%$ of the value measured at the receiving inspection and following tests.

Table A.1. Conditions and records during flow testing

\begin{tabular}{|c|c|c|c|c|}
\hline & Items & Value & Unit & Note \\
\hline \multicolumn{5}{|c|}{ Condition, acceptance values } \\
\hline 1 & Gas & Nitrogen & & \\
\hline 2 & Inlet pressure & 0.2 and 0.5 & $\mathrm{MPa}$ & \\
\hline 3 & Outlet pressure & Atmosphere (0.1) & $\mathrm{MPa}$ & \\
\hline 4 & Hold time & 60 & $\mathrm{~S}$ & \\
\hline 5 & Acceptance criterion & $< \pm 10 \%$ & & Deviation from previous test \\
\hline \multicolumn{5}{|c|}{ Recorded items } \\
\hline 1 & Mass flow & & $\mathrm{g} / \mathrm{s}$ & \\
\hline 2 & Supply pressure & & $\mathrm{MPa}$ & \\
\hline 3 & Atmosphere pressure & & $\mathrm{MPa}$ & \\
\hline 4 & Temperature & & ${ }^{\circ} \mathrm{C}$ & \\
\hline
\end{tabular}




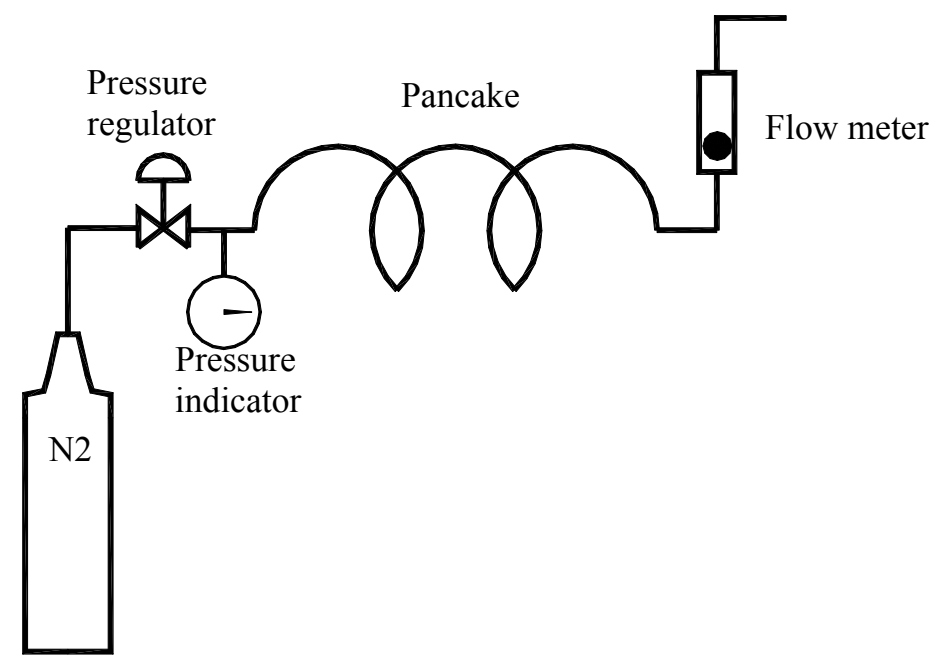

Fig. A.1. Schematic of flow test.

\section{A.3 LEAK TESTING SPECIFICATION}

This document describes the leak and proof pressure testing specification for the ITER CSI coil and components and gives specific tests condition and acceptance level.

\section{A.3.1 Vacuum Tank Method}

If a test object could be placed in a vacuum vessel, it could be pressurized in the evacuated vessel. Such an arrangement has the highest sensitivity of the leak detection.

The leak test procedure is as follows. First, the sensitivity of the leak detector is tested. The test object is evacuated and isolated by isolating valves. The calibrated standard leak, shown in Fig. A.2, is then opened to a connected source of helium outside the vacuum vessel. The time delay between the opening the calibrated leak and the signal from the leak detector is recorded. After calibration is verified, the calibrated leak valve is shut off and the test object is pressurized to the specified pressure (nominally 2.2 $\mathrm{MPa}$ unless otherwise specified). At this pressure the object is held for $10 \mathrm{~min}$ or a double delay time of the calibration test, whichever is longer. If there is no indication of a leak, the test is passed and the test results shall be recorded. Table A. 2 gives the test conditions of the leak test by the vacuum tank method. Figure A. 3 shows the test schematic.

Table A.2. Method of helium leak test by vacuum test

\begin{tabular}{lllll}
\hline & \multicolumn{1}{c}{ Items } & \multicolumn{1}{c}{ Value } & \multicolumn{1}{c}{ Unit } & \multicolumn{1}{c}{ Note } \\
\hline 1 & Standard leak calibration & 0.3 to $3 \times 10^{-8}$ & $\mathrm{~Pa}-\mathrm{m}^{3} / \mathrm{s}$ & Range of acceptance level \\
2 & Test pressure & $>2.2$ & $\mathrm{MPa}$ & $1.1 \times \mathrm{P}_{\mathrm{op}}$ \\
3 & Helium content inside conductor or tube & $>99$ & $\%$ & \\
3 & Hold time & $>10$ & $\mathrm{Minute}$ & \\
4 & Acceptance level of leak test & No indication & $\mathrm{Pa}-\mathrm{m}^{3} / \mathrm{s}$ & \\
& & of leak & & \\
\hline
\end{tabular}

Note: $>$ : more than, $<$ : less than 


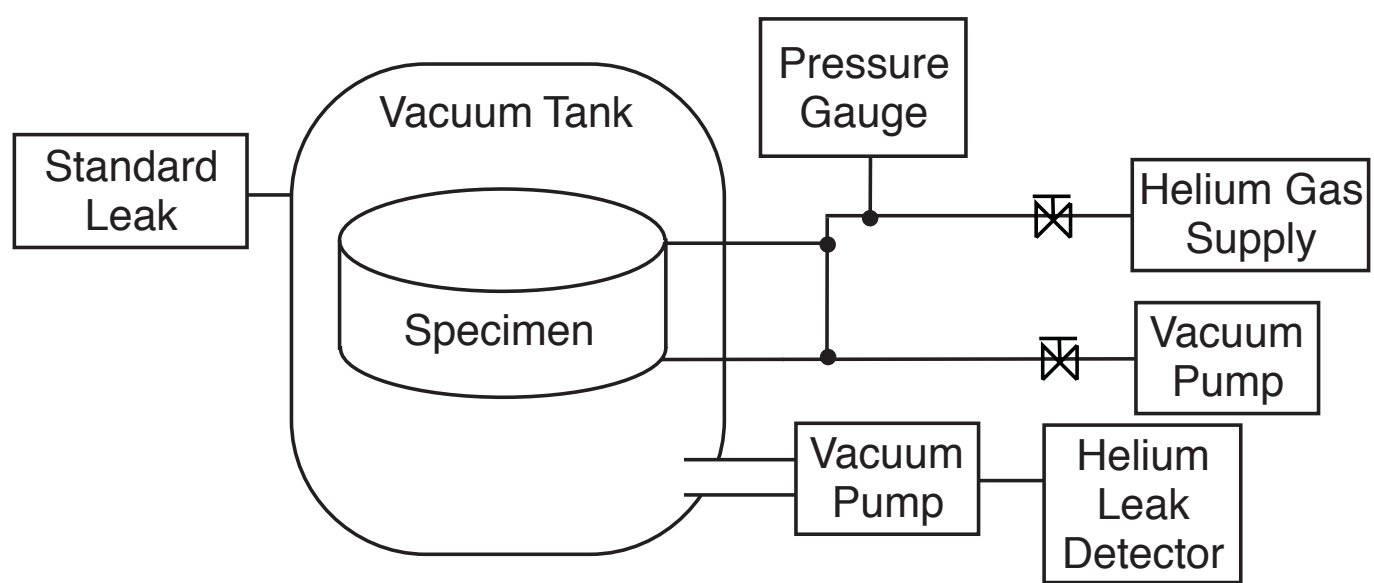

Fig. A.2. Test circuit for helium leak test by vacuum tank method.

\section{A.3.2 Vacuum Bag Method}

When the vacuum tank method cannot be used or is not practical, the vacuum bag sniffing method is applied. The sniffing method can be designed to have a high sensitivity. ${ }^{\text {A.1 }}$ The specimen to be tested is enclosed in two plastic bags with pure nitrogen gas in the interspaces between the bags. The sniffing equipment is shown in Fig. A.3.

The procedure of the leak testing also requires a calibration of equipment by using a calibrated leak as shown in Fig. A.3 and after that performing the leak test itself at the test pressure in the tested object. It is expected that most of the elements of the CSI will use the vacuum bag method for leak tests.

Table A.3 indicates the test conditions of leak test by the sniff method.

Table A.3. Method of helium leak test by sniff test

\begin{tabular}{lll}
\hline \multicolumn{1}{c}{ Items } & \multicolumn{1}{c}{ Value } & \multicolumn{1}{c}{ Unit } \\
\hline Standard leak & 0.3 to $3 \times 10^{-7}$ & $\mathrm{~Pa}-\mathrm{m}^{3} / \mathrm{s}$ \\
Test pressure & $>2.2$ & $\mathrm{MPa}$ \\
Helium content inside specimen & $>99$ & $\%$ \\
Hold time & $>60$ & $\mathrm{Minute}$ \\
Acceptance level of leak test & No indication of leak & $\mathrm{Pa}^{3} / \mathrm{s}$ \\
\hline
\end{tabular}

Note: $>$ : more than, $<$ : less than

\section{A.3.2.1 Record and reporting}

- All equipment shall be listed and data recorded as shown in Table A.4.

- Standard leak and pressure gauge shall be used within their date of validity.

- The equipment shall be systematically checked against the standard leak.

- Results of leak rate and other information shall be recorded in test report, as shown in the Table A.4.

- All record and data shall be submitted within 2 weeks after each testing in electronic format. 


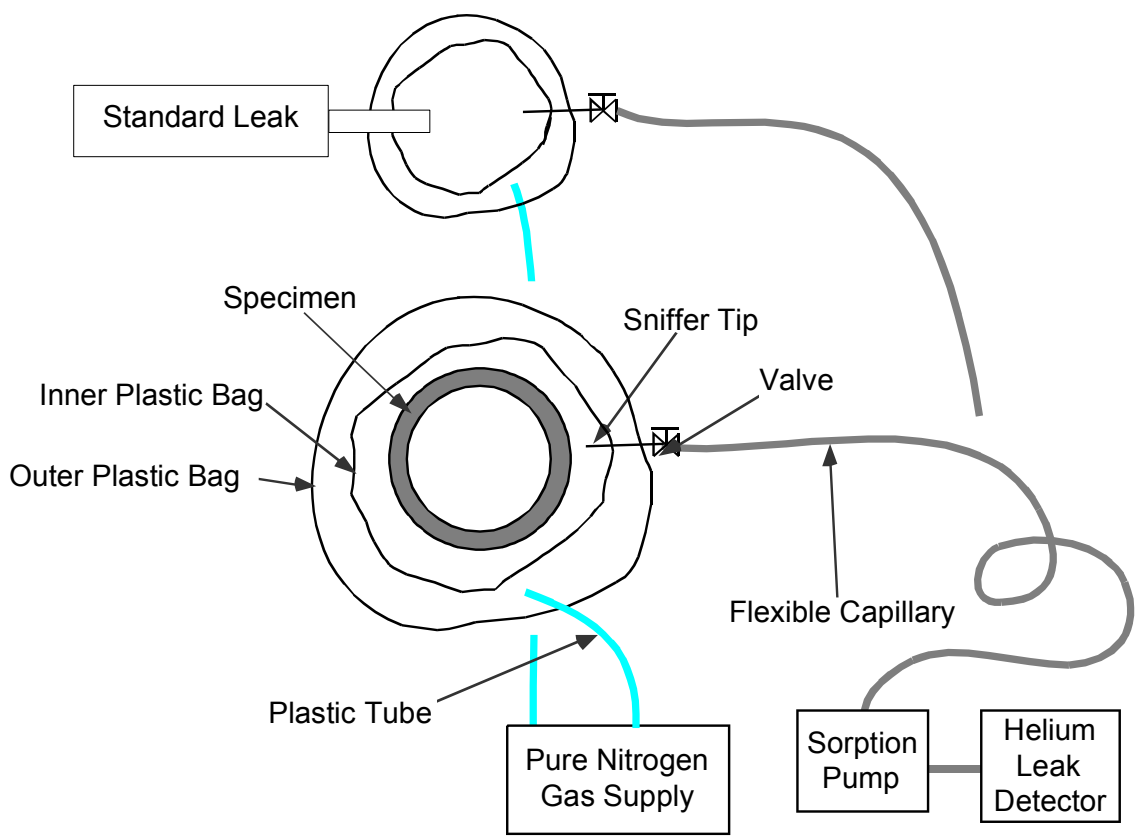

Fig. A.3. Vacuum bag and tool for helium leak test. Sniffer Tip is moved to the bag with a standard leak for calibration and then to the bagged object for measurements of the leak rate.

Table A.4. Minimum data requirement for leak test report

\begin{tabular}{lll}
\hline \multicolumn{1}{c}{ Equipment list } & \multicolumn{1}{c}{ Recording item } & \multicolumn{1}{c}{ Note } \\
\hline Standard leak & Manufacturer/type, valid date & Shall be within allowable \\
Pressure gauge & $\begin{array}{l}\text { Manufacturer/type, calibration date } \\
\text { Vacuum gauge }\end{array}$ & Shall be within allowable \\
Leak detector & Manufacturer/type \\
Leak rate verification & & \\
Temperature at beginning testing & & \\
Date/time & & \\
Tester & & \\
Test schematic diagram & & Record in scanning of chart or \\
Calibration procedure description and & & electrical data \\
observed results & & Record in scanning of chart or \\
Leak rate test procedure and observed & & electrical data \\
result & & \\
\hline
\end{tabular}

\section{A.4 PROOF PRESSURE TEST}

The proof pressure test of CSI modules shall be carried out in the conditions shown in Table A.5. The pressure is supplied from a high-pressure source (normally gas cylinder with pressure regulator). The object is pressurized to the desired pressure and then source of pressure is isolated from the pressure source. The pressure inside the object is monitored for $10 \mathrm{~min}$ with a high-resolution pressure indicator or transducer (1\% accuracy is required). No abnormal expansion or deformation in the CSI coil shall be observed during the proof pressure test, and no detectable pressure drop will occur when the source of pressure (gas bottle) is isolated from the CSI. The proof pressure test shall be carried out before the specimen is installed in the tank or the bag for the leak test. 
Table A.5. Conditions of proof pressure test

\begin{tabular}{llccc}
\hline & \multicolumn{1}{c}{ Items } & Value & Unit & Note \\
\hline 1 & Test pressure & $>3.0$ & $\mathrm{MPa}$ & $1.5 \times \mathrm{P}_{\mathrm{op}}$ \\
2 & Hold time & $>10$ & Minute & \\
3 & Acceptance criteria & No abnormal expansion or deformation, no detectable leak \\
\hline \multicolumn{4}{l}{ Note: $>$ : more than, $<$ less than } &
\end{tabular}

\section{A.5 REQUIREMENTS FOR THE AUSTENITIC STAINLESS STEELS CASTING}

\section{A.5.1 Scope}

This specification covers requirements for the semi-finished product for fabrication of the flanges for the support structure.

\section{A.5.2 General Requirements}

General requirements for the casting are given in ASTM A743M, which outlines manufacturing requirements, testing and retesting methods and procedures, permissible variations, marking and, certification. If the requirements of this specification are in conflict with the requirements of ASTM A743M, the requirements of this specification shall prevail.

\section{A.5.3 Referenced Documents}

\section{A.5.3.1 ASME codes}

Section III, NB-2542

Section III, ND-2546

Section V, Article 5

Section V, Article 6

Section V, Article 9
Liquid Penetrant Examination

Ultrasonic Examination

Ultrasonic Examination Methods for Materials and Fabrication

Liquid Penetrant Examination

Visual Examination

\section{A.5.3.2 ASTM standards}

A 240

A262

A 370

A609/A609M

A $743 \mathrm{M}$

A 700

E $8 \mathrm{M}$

E 23

E 45
Specification for Heat-resisting Chromium and Chromium-Nickel Stainless Steel Plate, Sheet, and Strip for Pressure Vessels

Standard Practices for Detecting Susceptibility to Intergranular Attack in Austenitic Stainless Steel

Test Methods and Definitions for Mechanical Testing of Steel Products

91(2007) Standard Practice for Castings, Carbon, Low-Alloy, and Martensitic Stainless Steel, Ultrasonic Examination

Specification for castings, $\mathrm{Fe}-\mathrm{Cr}$, Fe-Cr-Ni, and nickel-base corrosion-resistant for general application.

Standard Practices for Packing, Making, and Loading Methods for Steel Products for Domestic Shipment

Standard Test Methods for Tension Testing of Metallic Materials [Metric]

Standard Test Methods for Notched Bar Impact Testing of Metallic Materials

Standard Test Methods for Determining the Inclusion Content of Steel 
E 112 Test Methods for Determining Average Grain Size

E 165 Test Method for Liquid Penetrant Examination

E $813 \quad$ Standard Test Method for JIC, A Measure of Fracture Toughness

E 1450

Standard Test Method for Tension Testing of Structural Alloys in Liquid helium

E 1820

Standard Test Method for Measurement of Fracture Toughness

\section{A.5.3.3 JIS standards}

G 5121:1999 Stainless steel casting for general applications.

Z 2277:2000 Tensile Testing Method for Metallic Materials in Liquid Helium

Z 2284:1998 Method of Elastic-plastic Fracture Toughness JIC Testing for Metallic Materials in Liquid Helium

\section{A.5.4 Manufacturing}

Prior to flange fabrication, the Supplier shall submit to USIPO for review and approval a Manufacturing Plan, which shall include detailed manufacturing procedures and a QA Plan, including all tests, procedures, and acceptance criteria.

\section{A.5.4.1 Chemical composition}

The material shall be the austenitic stainless steels AISI 316L or 304L. The steel producer shall perform the analysis of every heat in accordance with ASTM A 743M. The chemical composition shall comply with Table A.6.

The Supplier shall make the product analysis according to ASTM A 743M Sect. 7 to verify the identity of the material. The chemical composition of the product shall also conform to the Table A.6 composition.

Table A.6. Chemical compositions of austenitic stainless steels (wt \%)

\begin{tabular}{|c|c|c|c|c|c|c|c|c|c|c|}
\hline Material & C & $\mathbf{S i}$ & Mn & $\mathbf{P}$ & $\mathbf{S}$ & $\mathrm{Cr}$ & $\mathrm{Ni}$ & Mo & Co & $\mathbf{N}$ \\
\hline SST316L & 0.03 max. & $1.00 \max$. & $1.4-2.0$ & $0.04 \max$. & 0.03 max. & $16.5-18.0$ & $10.0-14.0$ & $2.0-3.0$ & 0.05 max. & 0.10 \\
\hline SST304L & $0.03 \max$ & $0.75 \max$ & $1.4-2.0$ & $0.045 \max$ & $0.03 \max$ & $18.0-20.0$ & $8.0-12.0$ & & & 0.10 \\
\hline
\end{tabular}

\section{A.5.4.2 Finish of the rolled plates}

The finish of non-machined surfaces shall be in accordance with 10.1.2 of ASTM A 743M (No. 1 Finish).

\section{A.5.5 Mechanical Properties}

\section{A.5.5.1 General requirements}

The material shall conform to the requirements for mechanical properties given in Table A.7. The Supplier shall submit a detailed Test Plan for the casted flanges as a part of the QA Plan document.

Table A.7. Mechanical requirements at RT in accordance with ASME A240

\begin{tabular}{lcccccc}
\hline Material & Temp. & $\begin{array}{c}\text { Yield strength } \\
\text { min. }\end{array}$ & $\begin{array}{c}\text { Tensile } \\
\text { strength min. }\end{array}$ & $\begin{array}{c}\text { Elongation } \\
\text { min. }\end{array}$ & HB & HRB \\
\cline { 4 - 6 }
\end{tabular}




\begin{tabular}{llcccccc} 
& & $(\mathbf{M P a})$ & $\mathbf{( M P a )}$ & $\mathbf{( \% )}$ & max. & max. & max. \\
\hline ST316L & RT & 170 & 485 & 40 & 217 & 95 & 220 \\
ST304L & RT & 170 & 485 & 40 & 201 & 92 & 220 \\
\hline
\end{tabular}

HB: Brinell, HRB: Rockwell B, HV: Vickers

\section{A.5.5.2 Tension test and hardness test at room temperature}

One hardness test shall be performed.

\section{A.5.6 Additional Requirements}

\section{A.5.6.1 Grain size}

The grain size of the plates shall be ascertained according to the Test Methods ASTM E 112. A.2 $^{\text {. }}$

\section{A.5.6.2 Phase composition}

The material shall be homogenous to the maximum extent possible and be essentially fully austenitic. The material shall be free of $\alpha$-ferrite and $\beta$-phase.

\section{A.5.6.3 Inclusions}

When examined in accordance with ASTM E45, Method A, ${ }^{\mathrm{A} .3}$ the inclusion content shall not exceed Field Number 3 for inclusion types A, B, C, and D. The worst area of the specimen shall be selected to determine the rating.

\section{A.5.6.4 Intergranular corrosion}

The material shall be free of precipitated carbides that form a continuous network. The material shall be tested per ASTM A262, Practice A. Photomicrographs shall be compared to Fig. 1 of ASTM A262. Material, which does not conform to Fig. 1, shall be tested per ASTM A262, Practice E. Practice E shall be used as a basis for rejection of the material in accordance with the ASTM A262 specification. ${ }^{\text {A. } 4}$

\section{A.5.7 Non-destructive Examination}

The manufacturer shall perform the nondestructive examination (NDE) of each flange in accordance with the requirements given in the following subsections. The manufacturer shall also submit a detailed NDE procedure description as a part of QA Plan document.

\section{A.5.7.1 Visual examination}

All external surfaces and accessible internal surfaces of each flange in the finished condition shall be visually examined in accordance with ASME Sect. V, Article 9. ${ }^{\text {A. }}$ Injurious imperfections such as sand flaws and segregations are not acceptable. The results shall be reported with a sketch showing the locations, size, and distribution of the acceptable imperfections, and photographs if any. 


\section{A.5.7.2 Liquid penetrant examination}

All external surfaces and accessible internal surfaces of each flange in the finished condition shall be examined by a liquid penetrant method. The procedure for liquid penetrant examination shall be in accordance with ASME Sect. V, Article $6 .{ }^{\text {A.6 }}$ Acceptance criteria shall be in accordance with ASME Sect. III, ND-2546.3. ${ }^{\text {A.7 }}$ The results of the liquid penetrant examination shall be reported with a sketch showing the locations, size, and distribution of the acceptable indications, and their photographs.

\section{A.5.7.3 Ultrasonic examination}

Each flange in the finished condition shall be examined by ultrasonic in accordance with ASME Sect. III, NB-2531. A.8 The procedure for ultrasonic examination shall be in accordance with ASME Sect. V, Article 5. ${ }^{\text {A.9 }}$ Acceptance criteria shall be in accordance with ASME Sect. III, NB-2532.1. ${ }^{\text {A.9 }}$ Results of the ultrasonic examination shall be reported with a sketch showing the locations, size, and distribution of the acceptable indications, and their photographs.

\section{A.5.7.4 Repair welding}

Repair welding of flange is not permitted.

\section{A.5.8 Marking}

Each flange shall be legibly identified by the following markings. The markings shall be done by impression stamping, engraving, etching, or other acceptable means as specified in the ASTM A 743M specification. ${ }^{\text {A.11 }}$

1. Manufacturer's name or symbol

2. Manufacturer's identification heat number

3. Grade of material (AISI 316L/AISI 304L)

4. Contract Identification

\section{A.6 APPENDIX A REFERENCES}

A.1. Y. Murakami et al., "A new helium sniffing device for locating very fine leaks," J. Vac. Sci. Technology A, 2, 4, 1589-1592 (1984).

A.2. Standard Test Methods for Determining Average Grain Size, ASTM E112.

A.3. Standard Test Methods for Determining the Inclusion Content of Steel, ASTM E45.

A.4. Standard Practices for Detecting Susceptibility to Intergranular Attack in Austenitic Stainless Steel, A262.

A.5. Visual Examination, ASME Sect. V, Article 9.

A.6. Liquid Penetrant Examination, ASME Sect. V, Article 6.

A.7. Ultrasonic Examination, ASME Sect. II, ND-2546. 
A.8. 2010 ASME Boiler and Pressure Vessel Code, Sect. III: Rules for Construction of Nuclear Power Plant Components, Division 1, Subsection NB: Class 1 Components.

A.9. Ultrasonic Examination Methods for Materials and Fabrication, ASME Sect. V, Article 5.

A.10. Specification for castings, $\mathrm{Fe}-\mathrm{Cr}, \mathrm{Fe}-\mathrm{Cr}-\mathrm{Ni}$, and nickel-base corrosion-resistant for general application, ASTM A 743M.

A.11. Standard Practices for Packing, making and Loading Methods for Steel Products for Domestic shipment, ASTM A 700.

A.12. Standard Specification for Aluminum and Aluminum-Alloy Bar, Rod, and Wire, ASTM B211. 